\title{
Die steierische Reimchronik und die Königsaaler Chronik.
}

\author{
Eine quellenkritische Untersuchung \\ ron
}

\section{Miloš Vystyd ${ }^{1}$ ).}

In der Einleitung zur Neuausgabe der österreichischen oder steierischen Reimchronik ${ }^{2}$ ) hat der verdienstvolle Herausgeber eine ganze Reihe von neuen Beobachtungen gebracht, welche unsere Kenntnis und die Forschung wesentlich und vielfältig förderten. Einzelnes bleibt jedoch Vermutung, einzelnes läßt sich nicht halten. So nach unserer Meinung die Ansicht, daß der steierische Chronist auch die Königsaaler Chronik und zwar das erste Buch derselben benützt hat ${ }^{3}$ ). (Einleitung $59,86)$.

1) Diese Arbeit ist aus den quellenkritischen Übungen hervorgegangen, welche im Wintersemester 1910/11 am Institute für österr. Geschichtsforschung unter der Leitung ron Prof. A. Dopsch abgehalten wurden.

2) J. Seemüller, Ottokars osterreichische Reimchronik, M. G. H. Dentsche Chroniken, V., 1890-3. Ich führe sie mit Rchr. oder St. Rchr. abgekürzt an; ebenso $0 .=$ Ottokar, $\mathrm{S} .=$ Seemüller.

s) S. hat die Loserth sche Ausgabe der Königsaaler Chronik = Kgs. Chr. (Königsaal, Zisterzienser-Kloster südlich von Prag, lateinisch Aula Regia, böhmisch Zbraslav) zur Hand gehabt, Fontes rerum austriacarum = F. R. A., 1. Abt., 8. Bd., 1875. Seit dem Jahre 1875 sind zwei neue Ausgaben erschienen : die erste rührt von Em l er her, in Fontes rerum bohemicarum =F. R. B., 4, 1884 Prag; sie bietet bessere Lesarten und ist durch einen unvergleichlich reicheren Apparat vervollständigt. Die zweite erschien in čechischer Utbersetzung: Kronika Zbraslavská, übersetzt von J. V. Novák. Prag 1905, hrg. vom Historischen Vereine in Prag als zweiter Band der Samminng 
Die Zeit der Abfassung der Rchr. ist von Lorenz (Geschichtsquellen $\left.1^{3}, 249\right)$ in die Jahre 1278-1309 gesetzt worden. Seemïller hat sich der Meinung Jacobi's angeschlossen (Einl. 75) und die Kintstehungszeit bis in das zweite Jahrzehnt des 14. Jdts. verschoben. Er tat dies auf Grund von stofflichen Stichproben, bei welchen er die Zeitgrenzen der Abfassung bestimmte. So ergab sich (angenommen, daß das Werk in der durch $\mathrm{S}$. gegebenen Reihenfolge der Teile verfaßt wurde), ,daß die ersten 20.000 Verse vor dem Jahre 1308, die übrigen 70.000 Verse zwischen 1308 und 1318 verfaßt wurden". (Einl. 83.)

Da aber die Beweisführung auf Grund des Inhaltes leicht irreführen kann, so hat sich der Herausgeber noch eine andere Stütze verschafft. Er hat festgestellt, daß O. die Kgs. Chr. gekannt hat. Sie ist in drei Büchern ïberliefert. Das erste Buch ist nach Loserth um 1316 oder 1317 vollständig vorgelegen (Archiv f. österreichische Geschichte 51, 480). Dem ersten Buche folgen das zweite und das dritte Buch, welches mit dem J. 1338 abschließt - wahrscheinlich mit dem Tode des Verfassers im. J. 1339 (Novotný, Einl. 32). S. hat nur zwischen dem ersten Buche der Kgs. Chr. und der Rchr. Übereinstimmungen gefunden; er nahm an, daß 0. nur dieses erste Buch benützte, welches, wie er meint, kurz nachdem es abgefaßt war — noch vor Vollendung des ganzen Werkes. - den Zeitgenossen bekannt wurde; deshalb setzte er die Schlußredaktion der St. Chr. erst nach 1316 an.

Loserth's Ergebnisse über die Abfassungszeit der Kgs. Chr. wurden von Emler (F. R. B., 4, Einleitung), Bachmann (Mitteilungen des. Vereines f. Gesch. d. Deutschen in Böhmen 36, Seite 28, Über Entstehung und Inhalt des ersten Buches der Kgs. Chr.) und neuestens. von Novotny (Einl.) einer Nachprüfung unterzogen ${ }^{1}$ ); sein Resultat wurde bestätigt und präzisiert in dem Sinne, daß ,das erste Buch der Kgs. Chr. in seiner heutigen Fassung nicht vor April 1317 vollendet sein könne“ (Novotný, Einl. 40). Man müßte folglich den von S. angegebenen terminus a quo nach April 1317 setzen.

,Sbírka kronik a letopisů českých v překladech«. Diese Ausgabe hat V. Nov otn ý mit einer Einleitung und Anmerkungen versehen, welche die bisherigen kritischen: Ergebnisse zusammenfassen. (Ich zitiere bloß Novotný.) Am Schlusse des Buches. hat derselbe ein Verzeichnis von Korrekturen und Nachträgen zur Emlerschen Ausgabe, ferner H. Kollmann die Varianten der vatikanischen Hdsft. des II. Buches. der Kgs. Chr. hinzugefugt. Fur den Forscher ist die letzte Ausgabe unentbehrlich. - Ich zitiere die Seiten der Loserthschen Ausgabe in F. R. A.: sie ist den nicht böhmischen Lesern am besten zugänglich, und $\mathrm{S}$. hat sich auch derselben bedient: ihre Lesarten korrigiere ich jedoch nach Emler.

1) Andere einschlägige Literatur siehe bei Norotny Einl. 8, Anm. 1. 
Gegen die Annahme Seemüllers, die sich sonst fast einer allgemeinen Anerkennung erfreute, hat der Herausgeber der Kgs. Chr. Widerspruch erhoben ${ }^{1}$ ). Loserth leugnet nicht, daß zwischen beiden Darstellungen Ähnlichkeiten obwalten, aber er hält die Benützung der Kgs. Chr. durch 0 . für ausgeschlossen ${ }^{2}$ ). Hingegen wirft er die Frage auf, ohne auf sie näher einzugehen, ob nicht das umgekehrte Verhältnis stattfand, ob nicht vielleicht Peter von Zittan, der ein Freund von Vers und Reim war, die Rchr. gekannt und benützt hat? Wenn die Annahme von Lorenz (die Rchr. sei vor 1309 abgeschlossen worden), wieder zu Ehren gebracht wäre, dann würde es allerdings nicht ausgeschlossen sein, daß Peter von Zittau, der im Jahre 1314 an die Arbeit gegangen ist (Novotny, Einl. 59), die Rchr. gekannt hat. Aber dieser Vermutung Loserth's steht gleich vom Anfang eine Schwierigkeit im Wege: S. hat die Ähnlichkeit der Darstellungen auch in den Anfangsteilen der Kgs. Chr. konstatiert, welche von dem Vorgänger Peters in der Abtwürde, Otto (von Thüringen) herrührt ${ }^{3}$ ) und zwischen 1305-1314, folglich gleichzeitig mit der Rehr. entstanden ist4). Es würde dann ein einziger Ausweg offen bleiben, nämlich, daß die Verwandtschaft der ersten 51 Kap. des ersten Buches der Kgs. Chr. mit der Rchr. erst durch die späteren Abänderungen Peters im Werke Ottos entstanden sei ${ }^{5}$ ).

Die kritische Forschung verfügt noch über eine dritte mögliche Lösung6), nämlich, daß die Übereinstimmungen durch Verwendung einer gemeinsamen Vorlage seitens der beiden Autoren entstanden sind.

1) Historische Zeitschrift, 74, $282 \mathrm{ff}$. Anschließend an Loserth hat sich auch (1. RedIich gegen die Annahme S.'s ausgesprochen. M. I. Ö. G. 16, 678.

2) Loserth sagt S. 290: „Die von S. hervorgehobene Ähnlichkeit läßt sich auch für da s zweite Buch der Kgs. Chr. (Kap. 23) nachweisen. Man mülbte deshalb die Benützung der Kgs. Chr. für den Anfang der dreißiger Jahre annehmen und àie Schlußredaktion der Rchr. nach 1339 setzen, was unmöglich ist". Daraus schließt er, daß eher eine umgekehrte Annahme am Platze wäre.

3) Ottos Arbeit umfaßt den Beginn des ersten Buches der Kgs. Chr. bis zum 51. Kap. (inbegriffen). A. Ö. G. = Archiv für österreichische Geschichte 51, 463.

4) Novotný, Einl. 33 ff.

b) Über die Abänderungen Peters in der Partie seines Vorgängers siche Novotny, Einl. 43.

8) Wir werden auch die vierte Moglichkeit - die Übereinstimmungen gingen auf eine mündliche Überlieferung zurück - im Auge behalten; sie wird in der historischen Kritik immer mehr und mehr verlassen, auch in unserem Fall (nach den Forschungen Hubers und Bussons) - wenigstens für die Anfangspartien. Siehe S., Einl. 58. 
Der Überzeugung Seemüllers nach sind dem steierischen Chronisten nicht die vollständigen handschriftlichen Quellen vorgelegen, sondern nur Exzerpte, Auszüge aus solchen (Einl. 63ff.), die er nicht einmal selbst gesammelt hat: sie sind von seinen Gönnern für ihn gesammelt worden (Einl. 74). Die Notizen, manchmal sehr dürftiger Natur, habe 0. auf dreierlei Art verwendet: nur selten komme eine Übersetzung vor, wie es der Fall bei den Salzburger Annalen (Einl, 63 ff.) ist; gewöhnlich reiße er einige knappe Sätze, Redessendungen, Begebenheiten heraus, die er mit anderen Nachrichten oder Literaturschilderungen verbinde (Einl. 60), oder er entlehne die Grundgedauken seiner Vorlagen, um nach ihnen im breiten Umfange den Gang der Ereignisse zu regeln (Einl. 87). Folglich sei seine Vorlage (nicht gerade leicht) erkennbar , bei der allgemeinen Verwandtschaft des Zusammenhanges hier und dort durch Wiedergabe eines einzelnes Satzes, oft nur eines einzelnen Wortes " 1 ) (Einl. 63ff.).

Was die Kgs. Chr. betrifft, ist S. derselben Ansicht (Einl. 65); aber sie wurde nicht gleichmäßig zu allen Teilen der Rchr. herangezogen: „In dem ersten Teile, der beiläufig bis zu Vers 58.000 reicht, hat die Kgs. Chr. auf „die Darstellung der im engeren Sinne böhmischen Verhältnisse eingewirkt". Einzelne, aus der Kgs. Chr. herausgerissene Begebenheiten wurden erst nachträglich in das schon fertige Werk eingeschoben [nach April 1317] und die entsprechenden Partien abgeändert (Einl. 87). Einen weit größeren Umfang nimmt die Benützungder Kgs. Chr. von 58.000 aufwärts ein (die Königswahl zu Frankfurt. 1292); da verläßt 0 . die regelmäßige Sonderung zwischen den Angelegenheiten Österreichs und der Nachbarländer einerseits, des Reiches andererseits; böhmische, österreichische, ungarische und Reichsangelegenheiten sind in engen Zusammenhang gebracht (Einl. 51). Da hat die Arbeit Peters von Zittau unmittelbar auf die ganze umfangreiche Darstellung Einfluß genommen und der Rchr. den Grundgedanken gegeben' (Einl. 87).

Ich habe mir zur Aufgabe gestellt, die Resultate Seemüllers in dem ersten Teile der Rchr. nachzuprüfen ${ }^{2}$ ), und beginne mit dem Verse 1393, wo Sr. das erstenmal fand, daß Ottokar die Kgs. Erzählung benützte.

1) Diese Ausführungen hat Redlich als bloße Vermutungen bezeichnet. M. 1. Ö. G. 16, 678.

2) Der Gang meiner Arbeit ist durch die Fußnoten S.'s in der Rchr. bestimmt, denen ich Schritt für Schritt folge; sie bewahren die Resultate seiner quellenkritischen und vergleichenden Untersuchung auf. 


\section{Premysl Ottokar II.}

Vers 1393-1712. Seemüller sag (S. 19, Anm. 2): den Kern dieser Schilderung bot der Bericht der Kgs. Chr., Kap. 4.

O. erzählt von den Ereignissen des J. 1251 in Österreich. Der Mannsstamm der Babenberger ist erloschen, das Land in Wirren geraten; alles sehnt sich schon nach einem geordneten Regime. Die Landherren sammeln sich zu Trübensee, um die Anarchie abzuschaffen und die Ordnung wieder herzustellen. Es wurde besehlossen (vers 1393) zu Markgraf Heinrich von Meissen eine Gesandtsehaft zu schicken und einem seiner Söbne die Herrschaft anzubieten. Die Gesandten: (Heinrich) von Habsbach, Heinrich von Liechtenstein, Propst Dietmar von Klosterneuburg und ein Abt begaben sich auf den Weg von allen Herren und Prälaten beglückwünscht, denen die Unruhe im Lande schwer zu tragen war. Auf der Durchreise kamen die Boten nach Prag „nû truoc des landes krône (1459) in den ziten schône der mehtic kunic Wenzlâ." Er hatte einen Sohn Ottokar, welcher Markgraf in Mähren war. Für ihn ließen sich die Gesandten gewinnen (ausführliche Schilderung des 16., 17. und 18. Kap.) und kehren heim mit dem Auftrage die Erwählung Ottokars durchzusetzen. Ottokar wird auch teilweise anerkannt (vers 1712; das folgende soll der Cont. Sancrucensis und Cont. Garstensis entnommen sein. Seite 23, Anm 1) $)$.
D i e Kgs. Chr., Kap. 4. (Seite 42). Die Aufschrift; "Quomodo Ottokarus, rex Bohemie, dominam Margaretham duxerit et quomodo Austriam et Styriam et Karinthiam cum aliis terris obtinuerit."

Die Erzählung fängt an mit Margaretha; im weiteren setzt Peter kurz fort:

"Mortuo igitur Friderico, fratre suo [der Margaretha] duce, nobiles Austrie convenerunt et qualiter sibi suisque posteris providerent, salubriter cogitare ceperunt. Intervenientibus autem hinc inde diversis tractatibus regem Ottakarum vocaverunt ipsumque, ne succumbere viderentur acephali, pro duce ac domino elegerunt" etc. Darauf wird über die Heirat Ottokars mit Margaretha referiert.

1) Mit dieser Schilderung beschäftigen sich: L orenz, Die Erwerbung Österreichs durch Ottokar von Böhmen² ; 1857, Seite $12 \mathrm{ff}$. $\mathrm{Huber}$, Die steirische Rchr. und das österreichische Interregnum, M. I. Ö. G. 4, $41 \mathrm{ff}$. Besonders von ihm ist -die Rehr. streng beurteilt worden. „Von allem - sagt er - was die Rchr. in C. 11-20 erzählt, ist nichts wahr, als daß Ottokar von Mähren als Herzog von Österreich anerkannt ista. (S. 45.) Palack $y^{\prime}$, der gegen die Tendenz der Rchr. scharf polemisierte, hat ihre Angaben fast vollständig übernommen - wir werden es auch später beobrchten können. $\left(\mathbf{1}^{\mathbf{B}}, 325.\right)$ Ablehnend verhielt sich Dudík, 
Die Kgs. Chr. sagt uns viel weniger als uns der wortarme Auszug aus der Rchr. geboten hat; die ganze Kongruenz schrumpft auf einen Punkt zusammen: die Landherren convenerunt... und Ottacarum vocaverunt - eine allgemein bekannte Tatsache ${ }^{1}$ ), für welche 0 . keineswegs zu der Kgs. Chr. greifen mußte. Was dieselbe darüber hinaus mehr bringt, ist inhaltslos (salubriter cogitare coeperunt ..., intervenientibus tractatibus...., ne succumbere viderentur...) und ohne jeden Anhaltspunkt zu einer weiteren Konstruktion unverwendbar. Der Kgs. Abt weiß nichts über die Anarchie im Lande zu erzählen, nichts über den Tag zu Trübensee, über die Berufung eines Sohnes Heinrichs von Meißen, nichts über die in Prag weilende Gesandtschaft und noch weniger kennt er ihre Namen, ihr Verhalten und ihre Verhandlungen; (gerade hier konnte sich eine böhmische Quelle geltend machen!) Es ist schwerlich zu glauben, daß wir es da mit den rein erfundenen $\mathrm{Zu}-$ taten 0.'s zu tun haben, oder daß 0 . diese - anderswo gefundenen - Einzelheiten an die Erzählung der Kgs. Chr. (an den sogen. Gedankengang) angehängt hat; denn, wo er die Einzelheiten gehört oder gelesen hat, dort fand er selbstverständlich auch den "Gedankengang“" vor. Es ist meines Erachtens überhaupt kaum zulässig in solcher Weise den „Gedankengang " von der Erzählung abzutrennen, wie es S. tut.

Wir können noch einen anderen Unterschied dartun: nicht nur, daß 0. wichtige Momente mehr aufweist, auch der Gedankengang d. h. der Mittelpunkt des Berichtes - deckt sich nicht mit der Erzählung der Kgs. Chr. Die Kgs. Chr. weiß nicht, daß damals noch König Wenzel in Böhmen regierte; sie spricht vom "rex Ottacarus", der auf den Herzogsstuhl von Österreich berufen wurde. In der Rchr. ist es Wenzel, der Verhandlungen führt, der den Boten seinen Sohn aufzwingt - Ottokar, den Markgrafen von Mähren. Wenn die Erzählung Ottos (von Thüringen) der Rchr. das Substrat geliefert hätte, würde auch die unrichtige Auffassung in die Rchr. mit übergangen sein. Aus der richtigeren und unvergleichlich reicheren Schilderung 0.'s schließen wir, daß er seinen Bericht einer, wenn nicht den Begebenheiten näheren, so doch wenigstens besser unterrichteten Quelle entlehnt hat ${ }^{2}$.

Mährens Allg. Gesch. 5, 385, Anm. 4. Bachmann, G. B. 1, 546, Anm. 1 folgt konsequent den Ausführungen S.'s.

1) Vgl. die Belegstellen bei Dudík, M. A. G. 5, 385, Anm. 4. (Ich zitiere später bloB $\mathrm{Dudík.)}$

2) $\mathrm{Zu}$ demselben Resultate ist Loserth in dem gleich nachfolgenden Abschnitte der Rchr. gekommen. Es wird ïber Margaretha und ihre Vermählung mit Ottokar gesprochen. Nach der Schilderung der Kgs. Chr. müBte man glauben, daß sie eine 
Im Großen und Ganzen steht zwar die Schilderung Ottokars vereinzelt da; für den „Gedankengang " aber, welchen S. mit der Kgs. Chr. in Zusammenhang bringt, können wir mehrere Quellen nachweisen, welehe den Begebenheiten - aber auch 0. viel näher stehen als die Kgs. Erzählung:

a.) Die Annalen des Abtes Hermann von Niederaltaich ${ }^{1}$.) (M. G. H., SS., 17, 393) Sie referieren ẗber die Teilnahme Wenzels an der Erwerbung Österreichs; außerdem finden wir auch andere korrespondierende Motive.

„Postremo misericordia dei de celo prospiciente,

fatigatis et depauperatis iam nimium optimatibus terre,

dominus Premizel qui Otakker filius Wenceslai regis Boemie,

consilio patris et vocatione magnatum, civitatum Austrie (et Styirie utrumque ducatum sibi attraxit.)
Ottokar.

Vers 1393 „nû sande got der guot in ir herz und ir muot" — daß sich die Landherren entschieden einen fremden Herzog einzuladen, das Land in Besitz zu nehmen.

Vers 1356 „nû begund ouch pinen die herren umb ir herze der jâmer und der smerze, den man tegelichen sach".

Vers 1362 „ich kann iu niht bediuten, waz dem lande geschach ze leid ....

Vers 1459 "nù truoc des landes krône kunic Wenzlâ. einen sun het er da . . 1466 Merhaern der vater im liez, dâ von er marcgrâve hiez und was genant Ottacker."

verhältnismäßig junge Fran gewesen sei; ... sie solle dem Lande Österreich ein neues Fürstengeschlecht geben (Kap. 4). Hingegen weiß O. gut, wie gering die Hoffnungen waren. (Vers 1809 ff.) Vgl. Hist. Zeitschrift, 74, 287. Die Schilderung der Kgs. Chr. ist einerseits verblaßt - wie Loserth sagt -, andererseits in allgemeinen Phrasen ohne strikte Anhaltspunkte gehalten. Es scheint, daß der Verfasser mehr wußte, als er gesagt hat (... intervenientibus trictatibus etc.), und daB er sich nicht die Mühe gab, in die Einzelheiten einzugehen: nobiles Austriae convenerunt - wo? cogitare coeperunt - wie? intervenientibus tractatibus - welche Verhandlungen? Er hat seinem Gedächtnisse (seine Schilderung kann als eine Reihe von blossen Reminiszenzen einer Lektüre aufgefaßt werden) oder seiner Vorlage nur die belanglosen Worte entnommen.

1) S. meint, daß O. sie auch als Quelle verwendet hat. Einl. 59. 
b) Noch prägnanter als in den Annales Hermanns von Altaich tritt der Anteil Wenzels an der Erwerbung Österreichs in den Annales Pragenses pars I auf (Letopisy ceské od roku 1196-1278): 1251, nov. 21 Austria subdidit se regi Bohemorum Wenceslao, ad cuius possessionem habendan missus est filius regis Prziemysl, qui intravit civitatem Viennam ...1).

c) Das dritte Annalenwerk, das wir zu Rate ziehen, betont zwar weniger die Teilnahme Wenzels an der Erwerbung Österreichs, hingegen hebt es wieder die Rolle hervor, welche dabei einige österreichische Vinisterialen gespielt haben. Annales s. Rudberti Salisburgensis (M. G. H. SS., 9, 792) „Filius regis Boemie Austriam consilio et auxilio quorundam ministerialium ${ }^{2}$ ) ibidem occupavit, receptus a plerisque civitatibus in dominum et defensorem ".

d) Endlich konnte der st. Chronist seine Auffassung einer urkund. lichen Quelle entlehnen. Spiegelt sich nicht dasselbe triste Bild, welches er uns in Vers 1393 ff. vorführt, auch in der Arenga der Neustädter Urkunde vom April 1253 wieder, in welcher (Herzog) Ottokar die städtischen Freiheiten bestätigt? „Cum post obitum nobilium principum Austriae tt Styriae - heißt es in der Urkunde - propter insolentem nimis turbationem iidem principatus sic anxie vexarentur, tamquam navis fluctuans in procellis suique rectoris gubernaculo destituta, ut iam quasi dato libello repudii iustitia et pax extra easdem provincias exularent, nosque in occursum tanti discriminis, pietatis innatae moti clementia, et per nobiles ducatuum eorundem comites et barones provide invitati: honorabiles milites et cives Novae Civitatis ... nostro se dominio subjecerunt" 3 ).

Ich wage es nicht zu sagen, daß die Schilderung 0.'s einer dieser vier (oder allen zusammen) nachgebildet ist. Dazu müßten wir den gesamten Inhalt aller Quellen sowie auch das große Plus bei 0 . in Erwägung ziehen und in den Stoff selbst eingehen; aber sie zeigen, daß die Rchr. ihnen viel näher steht als der Kgs. Chr.

Rchr. Kapitel 66. (S. 102). 0. führt uns in das Jahr [1264]. Der Krieg zwischen König Ottokar und Bela erscheint mit der Niederlage des letzteren (bei Marchegg 1260) beendet, man sucht den Frieden her-

1) F. R. B., 2, 289 (gleichzeitige Aufzeichnung eines Prager Kanonikus).

2) Es darf uns nicht befremden, daß bei Or. die Herren von der Gesandtschaft als Landherren auftreten. Die Erklärung suche bei Lorenz: Die Erwerbung Öst. d. Ottokar v. B., Seite 16 und 17, 4nm. 69.

3) Erben, Reg. Boh. 1, 612, Nr. 1326 (1253, Apr. 29, Neustat; ex origin. Neustadt); ich zitiere künftighin bloB Erben (oder Emler) R. B.

Mitteilungen XXXIIII. 
zustellen. Die Verhandlungen schließen mit der Heirat von Ottokars Nichte Kunigunde (der Tochter des Markgrafen Otto III. von Brandenburg und K. Ottokars Schwester Beatrix) und dem Sohne K. Belas IV. Die Hochzeit wurde mit großem Aufwand und Pompe gefeiert ${ }^{1}$ ). Über das 66. Kapitel dieser ausführlichen Schilderung sagt der Herausgeber Folgendes: „Ich glaube, da $\beta$ der ganze in Tätigkeit gesetzte Größenund Zahlenapparat nichts anderes als eine Nachahmung jener ausführlichen Beschreibung des Aufwandes und Prunkes bei Wenzels II. Krönungsfeier ist, die wir in der Kgs. Chr. 1, Kap. 63 (S. 154) lesen. Ottokar hat das Kapitel der Kgs. Chr. jedenfalls gekannt, denn er benützt es für die Darstellung der Krönung Wenzels 69033 ff." (Einl. 69). S. folgend gehen auch wir zum zweiten Teil des Werkes (Vers 69033) in das Jahr 1297 über; wir müssen die logische Kette seiner ganzen Beweisführung untersuchen, um dann zum Ausgangspunkte zurückzukehren.

\section{Wenzels Krönunga2).}

0. Vers 69003 (Seite 913).

0 . gibt der Krönung Wenzels II. eine politische Fürbung, indem er sie mit der Aktion gegen Adolf von Nassau in Zusammenhang bringt. (69458. Vgl. S. Seite 919, Anm. 2).

Die Schilderung schließt an die Erzählung vom Tode Abt Heinrichs von Admont (69003) an. Vgl. S. Seite 913 , Anm. 4.

69033 Übergangsphrase.
Peter von Zittau, Kap. 61 (Seite 147).

In der Kgs. Chr. stehen die Kap. 61 ff. inmitten der rein lokalen Begebenheiten (Kap. 58, 59, 60-64, 66) als eine glänzende Episode in Leben Wenzels II. - und für sich selbst.

In dem 59. Kap. erzählt Peter von der Begünstigung der Geistlichen durch Wenzel, in dem 60. Kap. von der Vorliebe desselben für den Zisterzienserorden.

Kap. 61 trägt den Titel: De solempnitate coronationis. Wenzel beschließt sich krönen zu lassen; allgemeine $\mathrm{Zu}$ stimmung. Bitte an den Papst um den päpstlichen Segen; wohlwollende Antwort. Bitte an den Erzbischof Gebhard von Mainz, die Krönung zu vollziehen. Über ihn ist aber dus

1) Zwischen dem Kriege und der Hochzeit sind in der Wirklichkeit vier Jahre verstrichen; im J. 1260 wurde die Heirat als eine der Friedensbedingungen aufgestellt. $O$, rieht beide Begebenheiten zusammen.

2) Vgl. B u s s o n: Beiträge zur Kritik der St. Rchr. III. Sitz. Ber. Wiener Akad. 117, 14, Seite 30. - Palacký $2^{\circ}, 135$ und Dud\}k 7, 199 folgen treu in der Schilderung der Kgs. und der Rchr. die eine Quelle durch die andere ergänzend. 
69043 ${ }^{1}$.) Anschaffungen von Edelsteinen und kostbaren Stoffen für das Krönungskleid ${ }^{2}$ ) (typisch).

69075 Aufzählung dər Gäste.

69121 Datum.

69124 Entbindung der Königin ${ }^{3}$.)

69136 Krönung: Ort und Verlauf.

69182 Am selben Tag ist Herzog Albrecht mit neuen Gästen und großem Gefolge angekommen.

69205 "mit aller der hêrschaft sach man den kunic in den gesideln ezzen".

69210 Beschreibung der Krone Wenzels, des vorangetragenen Schwertes, des Schildes und des Krönungsornates $(-69304)$. Nach 69304 soll eine Lücke folgen, die in der Handschrift nicht bezeichnet ist. Die ausgefallene Stelle enthielt - nach S. den Schluß des Festessens, das Wenzel gab; es gieng der Festlichkeit, die am anderen Tage Herzog Albrecht veranstaltete, voran (S. 917 Anm. 1) $)$.

69306 Schliderung des Festes, das Albrecht gab:

69322 Vorräte an Fischen und Wildbret.
Interdikt verhängt worden. Auf die abermalige Bitte suspendiert der Papst das Interdikt, so daß Gebhard die Krönung vornehmen kann.

Einladung der Güste zur Feier (typisch).

Kap. 62: de die consecrationis. Die Anschaffungen zu den Festlichkeiten aus den fremden Ländern (kurz und allgemein gehalten).

Aufzählung der Gäste.

Datum und Ort der Krönung.

Die Tollziehung der Krönung.

Kap. 63. „De precioso apparatu ad coronacionem regiam adaptato" (S.153).

Das Fest wurde auf dem linken Moldauufer gegeben; Beschreibung des Königzeltes.

Die Ansammlung des Volkes in Prag. (Der Zahlenapparat, um den Volkszufiuß anschaulich zu machen.)

Vorräte Wenzels an Wein.

1) S. bemerkt Seite 913, Anm. 5: Erinnert an die Kgs. Chr. S. 150.

2) Nach 69073 nimmt S. eine gröBere Lücke an; in der Hds. ist sie nicht bezeichnet. Die Annahme ist durchaus nicht notwendig,

s) S. sagt Seite 915, Anm. 3: Einzelheiten übereinstimmend mit der Kgs. Chr.

4) S. nimmt in der Rchr. viele Lücken an, besonders dort, wo er eine Unterbrechung des logischen Gedankenganges wahrzunehmen glaubt und schätzt sie auf mehrere Tausend Verse (Einl. 52); sie sollen durch die Überlieferung verursacht worden sein. Es ist aber auch moglich, daf 0 . bei der Bearbeitung des Stoffes nicht logisch verfuhr und einzelne Lutcken gelassen hat. Man könnte vielleicht zum Zwecke der Kontrolle diejenigen Autoren zu Rate ziehen, welche im 14. und 15. Jahrhundert $O$. als Vorlage benützten. (Victring, Die Chronik . von den 95 Herrschaften u. a.) 
69327 Die Schwertleute (0. nennt) Volksbelustigungen (allgemein gedabei einige Namen !)

69339 Die Buhurt.

69346 Die Fortsetzung des Mahles.

69383 Albrechts Freigebigkeit.

69422 Albrecht huldigt dem gehalten).

Die Beschenkung der Gäste seitens. des Königs (allgemein gehalten).

Kap. 64. Die Gründung der neuen Marienkirche in Königsaal (am Pfingstmontag).

krönten König auf der Burg; Wenzel läßt ihn dabei lange knien.

69458 Beratung der Fürstlichkeiten. Klagen gegen Adolf. Die Kandidatur Albrechts.

69570 Der Abschied. O. geht gleich darauf zu den österreichischen und sàlzburgischen Angelegenheiten über.

Kap. 65. Tod Guttas, der Gemahlir Wenzels.

Kap. 66. Die neue Münze in Böhmen.

Ich kaun hier leider nicht einen umfassenderen und vollständigeren Auszug von beiden Erzählungen nebeneinander setzen; trotz dieses Mangels wird, wie ich hoffe, aus der kurzen Übersicht ersichtlich, daß unsere beiden Berichterstatter selbständig und unabhängig von einander vorgehen. In der Kgs. Chr. bildet. König Wenzel den Mittelpunkt der Erzählung. 0. läßt wieder dịe Person Herzog Albrechts stark hervortreten. Die Auffassungen sind heterogen, der Zusammenhang und die Struktur ebenfalls. Auch im stofflichen Inhalte gehen beide vollständig auseinander. Sie berühren sich nur in fünf Punkten (vgl. weiter), das übrige stimmt nicht überein: verschiedene Begebenheiten werden zur Sprache gebracht. Das fällt besonders bei Vers 69306 und der Kgs. Chr. Kap. 64 auf. 0. erzählt von dem Feste, welches Albrecht am 3. Juni (am Tage nach der Krönung) veranstaltete1). Er erwähnt nichts von dem (falls in der Hds. keine Lücke ist), was. die Kgs. Chr. bringt: „Completo igitur memoriali die et festo celeberrimo cononacionis regie statim inmediate die sequenti altera, id est Juni 3, cum universa curia et turba principum, nobilium et omnium aliorum, qui ad diem festum convenerant, rex venit in Aulam Regiam valde mane orto iam sole, ubi statim novum. monasterium fundare nititur; . . . nullus a u tem, ut puto, qui corona-

1) Vers 69307 , meniclich des jach, ez hiete der von Ôsterich begangen als volliclich hûsêr mit den gesten - als man des vordern tages tet. 
cioni interfuit, huic fundacioni defuit....* Des österreichischen Festes wird in der Kgs. Chr. mit keinem Worte gedacht. Schon dieses Moment (obwohl man beide Erzählungen zeitlich in Einklang bringen könnte, indem das Fest, das Albrecht gab, auf Pfingstmontag Nachmittag verlegt wird) scheint mir auf die Ursprünglichkeit und sachliche Unabhängigkeit beider Berichte zu deuten.

\section{Die Berührungspunkte des Inhaltes.}

1. Aufzählung der Gäste.

O. Vers 69075 (Seite 914).

Peter, Kap. 62 (Seite 150).

0 . führt von den geistlichen Personen allein den Erzbischof von Mainz an (69119) und nur deshalb, weil er die Krönung vollzog. Ihm schickt er eine Fülle von Namen (fast 20) der weltlichen Fürstlichkeiten voran (69075), die ihm „alle sint erkannt." [Die Geistlichen nicht?] Busson (S. B. W. A. 117, 14, Seite 32) und S. polnische Fürsten. (Die Herzoge von in den Anmerkungen (Seite 914) Oppeln und Glogau; mit 0. allein haben gezeigt, daß einige von denen, übereinstimmend. Vers 69078). welche die Kgl. Chr. nicht anführt, durch andere Quellen belegt sind.

\section{Das Krönungsdatum.}

0. Vers 69121. ;ûf den schoenen phingstae" (2. Juni 1297).

Was bedeuten die Worte: und an qu dem naehsten tage fruo....dâ wart gelesen und gedônt ete. War der Autor anwesend?

Dieses Datum muß aber nicht von der Kgs. Chr, übernommen sein; es ist allen Quellen geläufig ${ }^{1}$ ).

1) Cronica s. Petri Erfordensis moderna, M. G. H. SS. 30, 431, in die sancto penthecostes«. (S. war der Meinung, daß O. auch diese Chronik benutzt habe: dagegen hat sich der neue Herausgeber der Chronik - Holder-Egger - entschieden ausgesprochen. „Sed oportet adiciam - sagt er ibidem Seite 354 - me nullo modo adduci posse, ut credam hanc Cronicam ab Ottocaro in magno suo Chronico rhytmico Austriaco adhibitam esse, quod A. Busson et post eum J. Seemüller censuerunt. ..... Neben Loserth und Redlich auch einer der Ungläubigen.) Hermanni Altahensis continuatio, M. G. H. SS. 24, 55 ,in festo pentecostes" ; Cont. Vindobonensis, M. G. H. SS. 9,719 , in pentecosten u. a. z. B. Sitrir de Balnhusin, M. G. H. SS. 25, 713; von den böhmischen Qüellen Annales Aulae Regiae, F.,R. B. 4, 343). 
3. Die Ortsbezeichnung.

0. Vers 69138 ,in den munster| Peter, Kap. 62, S. 152 „in ecclesia wit, dâ sant Wenzla in lit.." kathedrali iuxta altare summum beati Viti martyris."

0 . bezeichnet den Krönungsort vollkommen verschieden und doch richtig.' Diese Inkongruenz ist nicht unwichtig. Ich glaube, wenn 0 . die Kgs. Schilderung benutzt hätte, würde er sich kaum die Mühe gegeben haben, den Krönungsort anders anzuführen, umsoweniger - da er die Bezeichnung, welche er anwendet, in keiner anderen (uns heute bekannten) erzählenden Quelle finden konnte; die ïbrigen Quellen erwähnen keinen Ort, oder drücken sich ganz allgemein aus: ,in Prag *1). Die Ortsbezeichnung 0.'s ist vollständig vereinzelt; aber noch mehr: sie ist keineswegs eine Umgestaltung der bei den Kgs. Abt gebotenen; sondern sie trägt meines Erachtens die Zeichen eines fremden, in Prag anwesenden Beobachters.

Peter von Zittau brauchte nicht die Domkirche in Prag dadurch zu charakterisieren, daß sich in ihr die Reliquien des hl. Wenzel befinden; dies war $\mathrm{ihm}$ so selbstverständlich, daß er nicht einmal auf den Gedanken gekommen ist. Hingegen hat er als nötig betrachtet den Krönungsort in der Kirche selbst näher zu präzisieren: iuxta altare summum ...

Einem Fremden - sagen wir einem Zuschauer — fällt zuerst der Bau auf: in dem munster wit; auch andere Kirchen gab es in Prag; aber die waren nicht „wit". Diese Charakteristik genügt nicht; es ist nötig, die Kirche bestimmter zu bezeichnen und zwar durch den für jeden mittelalterlichen Menschen kostbaren Schatz der Reliquien. Er uennt die Kirche nach dem Hauptheiligen, der dort begraben ist und dessen Name auch in der Ferne bekannt war. Ich glaube darin den Standpunkt eines fremden Erzählers zu sehen, der Prag besuchte und die Domkirche gesehen hat - unentschieden ob es Ottokar oder sein Berichterstatter war; jedenfalls aber eine von der Kgs. Chr. ganz verschiedene Auffassung').

1) Cron. s. Petri erfordensis moderna, M. G. H. SS. 30, 431 , in Praga coronatus ; Cont. Vindob., SS. 9, 719 ... „Praga civitas*; Sifrid de Balnhusin SS. 25, 713 „Prage ${ }^{\circ}$. Der letzte folgt der Chronik 8. Petri Erfordensis, aber enthält doch eigene Nachrichten.

2) Wenn wir weiter gehen wollten, wäre noch zu untersuchen, ob die $\mathrm{Be}$ asichnung einer (unbekannten) schriftlichen Quelle entnommen ist, oder (die Möglichkeit ist auch nicht ausgeschlossen), ob sio auf 0 . selbst zurtickgeht. . Der Erzähler - mochte es 0 . oder sein Berichtenstatter sein - muB aber nicht gerade bci der Krönung Wenzels in Prag anwesend sein; er konnte bei einer anderen Ge- 


\section{Die Krönungszeremonie.}

0. Vers $69121 \mathrm{ff}$.

Das Datum der Krönung wurde im voraus anf den Pfingstsonntag fest-
Die Kgs. Chr., Kap. 62, S. 152.

Die Salbung und die Krönung Wenzels und seiner Gemahlin nahm

legenheit Prag kennen gelernt haben. Ich glaube jedoch, daß die übrige Erzählung einige Haltpunkte bietet, welche auf die Anwesenheit des Erzählers in Prag während der Krönung 1297 schließen lassen. - Mir scheint auch, der vielverketzerte 0 . ist es, der uns positive Nachrichten bringt und den Verlauf der Festlichkeiten wiederzugeben sucht; hingegen schrumpfen die posititiven Nachrichten Peters (Kap. 62 und 63) auf einige wenige Daten zusammen. Es ist bei ihm viel Schönreunerei, die ihren geistigen Fonds in der Bibel hat. (Kap. 63. Das ganze Lob über Prag ist aus Bibelzitaten zusammengesetzt. Vgl. Novotný, 130 Anm. 3); oder er bewegt sich in allgemeinen (typischen) Schilderungen, die keinen großen Wert beanspruchen dürfen (Kap. 63). Über den Verlauf der Festlichkeiten wird nichts berichtet. Außerdem vermute ich, daß der Bericht Peters nicht selbständig ist - gegen die Annahmen von Bachmann (Mitt. Ver. Gesch. der Deutschen in Bőhmen 36, 17) und Novotný (Einl. 15, 48), welche glauben, daß Peter bei dem Feste anwesend war und seine Eindrïcke aufgezeichnet hat; diese Aufzeichnungen sollen dann in seine Chronik übergegangen sein. (Novotný sagt sogar — ohne jede Veränderung. Einl. S. 48).

Die Wiener Continuation erzählt (M. G. H. SS. 9, 719-720) zum J. 1297:

"rex Bohemorum Wenzeslaus in pentecosten cum inestimabili solle m pnitate ac inennarabili hominum multitudine ... per manus archiepiscoporum et episcoporum coron a regali gloriose in regem Boemorum soll e m pniter coronatus est.

Simili modo et .... nobilis regina, Rudolphi quondam Romanorum regis filia et soror ducis Austrie Alberti ... in reginam Bohemie corona ... coronota est ab eisdem archiepiscopis reverentissimis et episcopis devotissimis ...

. inenarabilis multitudo, ut pote Praga civitas tantam multitudinem hominum capere nequibat, sed in campis cum curribus suis et tentoriis cogebanturmanere:

Sed heu ac proh dolor. Paulo postversa est in luctum cithara eius, in vocem flencium organa eius.
Peter, Kap. 62 (S. 152 ff.).

„indie sanctissimo pentecostes ... a reverendo domino Gerhardo ... et aliis pluribus episcopis et prelatis solempnibus solempnissime ... princeps dominus Wenceslaus secundus una-

cum sua coniuge, illustri domina Guta, domini Rudolphi regis Romanorum quondam filia, est decentissime corona sceptroque regio ... insignitus.

Kap. 63. congregatus erat populus innumerabilis ... Ad presenciam tam inestimabilis multitudinis magnitudo civitatss pragensis minoratur, platearum latitudo angustatur, omnis locus amplus constringitur; ... forinsecus autem fixis ubique tentoriis campi (Pragae) replentur.

Kap. 65. gaudia mundana pereunt quasi sompnia vana... Sic igitur versa est in luctum cithara nostra et organum nostrum in vocem flencium, quia tam jocundas 
gesetzt. Die Königin ist aber „dritt- $\mid$ der Erzbischof von Mainz vor. (Was halb" $[21 / 2]$ Wochen vorher entbunden. folgt, ist eine inhaltslose Schilderung Da aber schon alles zum Feste vor- der Volksfreude. Über den Verlauf bereitet war, wollte man nicht warten. der Krönung wird nichts berichtet.) Am Krönungstage wurde sie in die Kirche hin und zurückgeführt.

69145. "Daz kom ir übel hernâch." [Verweis, daß 0. später darauf zurückkommt.]

69153. "Des tages er [Wenzel] mit niemen wolde hân ze schaffen wan [nur] aleine mit den phaffen."

Dann folgt eine Art von Sentenzen, die an Wenzel adressiert sind. (Für die Abfassungszeit der Rchr. oder der Vorlage — nicht unwichtig.)

5. Der Tod der Königin.

0. 69820 (S. 924).

Peter, Kap. 65 (Seite 158).

O. hat 69143 angedeutet, daß er Er sagt, daß sie „am 17. Tag der auf den Tod der Königin zurück- Krönung d. h. am 18. Juni" verkommen werde. Nachdem er die schieden ist und daß ihre Krankheit Schilderung der Festlichkeiten zu Ende in der Entbindung ${ }^{1}$.) den Ursprung

Nam 14. die coronationis sue ex hac luce migravit ad dominum ...

De cuius inorte tota Boemia . . . stupefacta et turbata. (Gloriosa matrona deo et hominibus dilecta et devota uxor eius....)

post partum infra dies sue purificationis in lecto suo ... coronata est. festivitates inclite domine Gute regine, septima decima die a coronatione sua, hoc est quarto decimo kal. Julii mors obfuscavit.

Proch dolor, exuta nexu carnis bona Guta... laude fuit digna, generosa, 'pudica, benigna -

Cum antem eadem domina regina Guta invalescente morbo, quem in infantuli partu tum noviter precedente contraxerat etc.

Ich bin weit entfernt zu behaupten, daß Peter bei der Schilderung des Krönungsfestes diese oder eine andere nahestehende Quelle benützt hat. Man müßte den Vergleich die beiden Quellen hindurch führen und auch alle übrigen Erzählungen in Erwägung ziehen. (Schon Bachmann war bemüht zi beweisen, daB der Vorgänger Peters, Otto, die Wiener Kontinuntion benützt hat; Nov otn ý leugnet das und meint, eher eine unbekannte, hente verlorene Quelle, Einl. 38. Der Umstand fällt doch auf, wenn zwei Verfasser gleiche Momente hervorheben und sich auch ähnlicher Gedanken und stilistischer Wendungen bedienen - zwei Verfasser, deren Interessenkreis und Wirkungsort ganz verschieden war).

1) 0 . führt den Tod der Königin weniger auf die Entbindung zurück - eher duranf, daß man sic in dem. Kindbett gestort und zur Kronug hingefthrt habe. Dirses Wagnis mußte sie mit dem Leben büßen 69145. 
geführt und über die Verschwörung hatte: Guta, invalescente morbo, quem gegen Adolf von Nassau berichtet hat, in infantuli partu tunc noviter [ 0 . setzt er über die Fehde Osterreichs hat ein bestimmtes Datum angeführt!] und Salzburgs fort. Als der Abt precedente contraxerat etc. $\Lambda$ ls VollEngelbert [von Admont] nach Wien strecker ihres letzten Willen hat sie wegen Unterhandlungen kommt, findet den Abt Konrad von Königsaal beer den Herzog in trübseliger Stim- stimmt.

mung; er erhielt die traurige Nachricht, daß seine Schwester »an dem drizehenten tac" der Krönung „dâvơn starp". (69831).

Das Resultat. Die beiden Quellen divergieren sowohl in der Siruktur und in dem Zusammenhange des Erzählten, als auch in dem Inhalte. Sie berüluren sich nur in fünf Punkten; aber nicht einmal liier - - wo sie doch eine and dieselbe Begebenheit zur Sprache bringen - stimmen sie ïberein. Sie gehen parallel nebeneinander (Krönungsort), manchmal stehen sie auch gegeneinander (Todestag der Königin), oder es läßt sich gar nichts schließen (Krönungstag). Die ganze Ähnlichkeit'1) schrumpft auf die Nennung einiger Krönungsgäste zusammen, welche Peter und 0 . allein anführen. Die bloßen (3) Namen beweisen nichts für S. Es ist folglich nicht richtig, wenn S. sagt, daß O. „die Krönung Wenzels in der Darstellung Peters (Kap. 61 ff.) jedenfalls gekannt und für seine Schilderung der Krönung Vers 69033 ff. benützt hat* (Einl. 69); damit fällt auch die Schlußfolgerung, durch welche S. seine Annahme über die Verwandtschaft des Kap. 66 bei O. (die Hochzeit rom J. 1264) mit dem Kap. 63 bei Peter unterstützen wollte und wir kommen zur ursprünglichen Aufgabe zurïck.

Mit dem 66. Kapitel der Steierischen Reimchronik gehen wir von der Historie auf ein anderes Feld über - das Feld der höfischen Dichtung und der Romanpoesie ${ }^{2}$ ). Das bedeutet, daß wir bei dem Vergleiche zwar eine gleiche Methode - jedoch nicht einen gleichen Maßstab anwenden dürfen: wir haben es da mit schablonenmäßig wiederkehrenden Motiven zu tun, welche ein allgemeines Eigentum (loci com-

1) Ich habe nur die positiven Mitteilungen 0.'s in Erwägung gezogen. Man findet aber sonst in der Schilderung der Festlıchkeiten (und der Vorbereitungen) analoge Romanmotive (nie die gleichen!) - hierüber im folgenden.

2) Das sagt S. selbst, S. 101 Anm. 4. "Die folgende Hochzeitsschilderung enthält zumeist typische Züge, ohne daß ich ein einzelnes bestimmtes Muster nachzuweisen vermöchte". Wie stimmt der zweite Satzteil mit dem, was er in der Einleitung (S. 69) gesagt hat überein? (nämlich, daß sie eine Nachahmung der Kgs. Chr. sei!) ... Wir finden da auch keine Fußnoten, welche auf ein Vorbild hingewiesen hätten. 
munes) waren und welche in den verschiedensten Versionen in die literarischen wie auch historischen Werke Kingang gefunden haben; folglich beweist der yleiche (oder der analogische) Gedankengang für die Verwandtschaft der Quellen gar nichts, wenn er nicht von andern Umständen, hanptsächlich der stilistischen Übereinstimmung begleitet ist. Wir dürfen auch nicht vergessen - worauf 0 . Redlich aufmerksam gemacht hat - daß derartige Hoffeste in Wirklichkeit anch nach solch herkömmlichem Zeremoniell vor sich gegangen sind (M. I. O. G. 16, 680) - und daf dadurch die stets wiederkehrende Form der Schilderungen bedingt wird.

Ich werde nicht das ganze Gedankenschema der beiden Berichte wiedergeben - es hätte auch keinen Zweck. Zwei verschiedene und zeitlich abgetrennte historische Ereignisse (die Heirat vom Jahre 1264 ${ }^{1}$ ) und die Krönung vom Jahre 1297) werden da geschildert, deshalb geht auch der Inhalt des Erzählten vollkommen auseinander; - nur die typisohen Motive treffen zusammen, und mit diesen werden wir uns beschäftigen. In der Reihenfolge folge ich 0.

\section{Vers 7650 (Seite 101).}

„wie diu selb hôchzit ergie, der sol darumbe frâgen die, die dâ wâren ... doch wil ich iu sîn machen kunt, als mir dâvon ist geseit".

7666-7684. König Ottokar betraute zwei (genannte) Herren mit den Vorbereitungen zur Hochzeit. Ōsterreich - in zweiter Reihe Steiermark und Mähren sollen alles notwendige liefern.

7685-7694. Er instruierte sie - besonders über die Einrichtung der Gesidel; mit Aufwand von 20000 pfund Silber hat er die dazu nötigen Stoffe und Tücher angeschafft.

7695. "mit briefen hiez er loufen sin boten unde riten nâhen unde
Peter, Kap. 63 (Seite 153).

sopere precium erat commendare posteris tale festum, quod et commandabat ipsa raritas, nobis semel visum " 2). (In anderem Zusammenhange.)

Kap. 62 (Seite 150). Die nötigen Sachen zum Krönungsfeste hat Wenzel von den fernen Ländern besorgt.
Kap. 61 (Seite 149) Schlußverse: „Cursores multi ... ad loca longinqua.

1) Siehe Palàckj́, $2^{a}, 27$ - er hat die ganze Schilderung der Rchr. übernommen - und Dudik 6, $19 \mathrm{ff}$.

2) Während die früheren Editoren Loserth (A. Ö. G. 51, 470) und Emler (F. R. B. 4, Einl. 8) Haltpunkte dafür zu haben glaubten, daB Peter von Zittau bei der Krönung Wenzels in Prag nicht anwesend sein konnte, wird von den neueren Forschern (von Bachmanu, Mitt. des Vereines für Gesch. d. Deutschen in Böhmen $=$ M. V. G. D. in B. 36, 17 und Novotn ý Einl. 15, 48) die Anwesenheit Peters bei der Krönung behauptet; ich bin durch ihre Begründung nicht überzeugt. 
witen über al zuo den herren, swer|non obmittendo propinqua tunc disin wolde êren daz er sich der dâmit currebant, qui regia scripta ferebant, für naeme und êrlich zuo der hôch- in quibus hoc thema fuerat: ... rex zit kaeme". Auch gibt er die Zeit ... supplicat, ut adveniant". ete. und den Ort kund.

7717. Es verbreitete sich ein so großer Ruf von der Pracht der bevorstehenden Hochzeit, daß fremde Fürsten Boten schickten: „daz die solden nemen war, wie diu hôchzît ergiene".

7724 (Kap. 66). Der Ort wurde hei der Donau gewählt und über die Donau eine Brücke geschlagen, die so breit war, daß 10 Reiter nebeneinander hinüberreiten konnten.

7732 . Vorräte -

7740 an Wein, daß die Bevölkerung von zwei Ländern ihn nicht hätte austrinken können.

7747. Fünf Schober Pferdefutter und Heu wurden angehäuft, die größer waren als die Solenauer Kirche. (Vgl. S. Seite 102, Anm. 1).

7755. Bei dem Lager stand so viel Schlachtvieh, dal es nicht einmal in 4 Wochen von allen Anwesenden zn verzehren war; „diu heide und diu ouwe was vol $\ll$.

7765. „ungerechnet muost beliben, swaz koste an dem brôte lac. mir sagte sit; der sin phlac, daz er sin nie zal erfunde ... unz daz des kunigs schribaere zuo der reitung sazen ... der selben reitunge wart weizes tûsend mutte ..."

Kap. 63 (Seite 153). Die Festlichkeiten wurden auf dem linken Moldauufer »in loco campestri plano et amoeno" veranstaltet.

Kap. 63, S. 154. (Peter führt die Vorräte an, um die Zahl der Gäste anschaulich $\mathrm{zu}$ machen.)

„In novo foro fontes facti fuerant, de quibus vinum more fluminis, qui voluit, hauriebat ..."

.. "pabulum de curia regis dabatur pro equis, quorum numerus fuit 191000 " und noch mehr.

Peter beruft sich auf einen Gewührsmann: Capiat, cuius possit estimacio, quanta ibidem expensarum summatim racio et populi fuerit multitudo, quia ut honestus vir dominus. Lutoldus, plebanus de Wilhelmswerde mihi retulit, qui pro tunc pabuli notarius exstitit ${ }^{1}$ ), solis hospitibus et

1) Lutoldus plebanus de Wilhelmswerde ist urkundlich nicht belegbar. Wilhelmswerde $=$ Wildenschwert (Ústí nad Orlici, n. 8 . Böhmen), war eine villa forensis, die dem König Wenzel II. gehörte; er schenkte sie im J. 1292 dem neu gegründeten Kloster Königiaal (Emler, Reg. Boh. 4, 745 xin territorio Vsti, quod in teutonico Wilhelmsuerd vocatur, praedicta villa forensis Wilhelmsuerd $)_{\text {). Das. }}$ Kloster war seine Stiftung, sein Kloster; es ist deshalb nicht auffällig, wenn der Abt oder die Klosterleute den kőniglichen Dienst versehen. Eine Pfarre ist dort erst in der eweiten Hälfte des 14. Jhdts. und im 15. Jhdt. belegt. (Libri confirmationum I, hrg. von Tingl, S. 168 z. J. 1362; ibidem VI, hrg. von Emler, 
7781. Vorrat an shüenern und an viltpraete; des fuorte man so vil, ob al die meisen unde sperken in Ostrîch und Merhaeren hüener gewesen waeren, der genuhte waer genuoc ... Die 'Tuonouwe kûm getruoc in den scheffen der spise last".

An diese Verse wird die Schilderung des Hochzeitsfestes (Einzug Ottokars und der Braut, ihre Kleidung, Aufzug der Ungarn u. s. w.) angeknüpft. (Siehe auch Huber, M. I. Ö. G. 4, 62.) adveris pabulum de curia regis dabatur pro equis, quorum numerus fuit 191000 etc. ...

„pro ovis pullorum expensae fuerant 800 Mark Silber".

Zu dem 63. Kap. fügt Peter : noch mehrere Verse hinzu (S. 155):

a) über den Überfluß der Sachen bei dem Feste und den Volksandrang;

b) die Beschenkung der. Herren seitens des Königs;

c) dann werden summarisch verschiedene Volksbelustigungen angeführt.

Ich ziehe zum Vergleiche noch eine dritte Erzählung heran, einen gleichzeitigen Roman, um zu zeigen, in wie weit wir es mit einem typischen Schema zu tun haben. Ulrichs von Eschenbach. „Wilhelm“1) steht auch örtlich dèn beiden Chroniken — und besonders der Kgs. Chr. nahe; er soll um das Jahr 1290 am Prager Hofe entstanden $\operatorname{sein}^{2}$ ). An drei Stellen (Seite $2,36,196$ ) gibt Ulrich eine Schilderung des'Hoffestes und der Vorbereitungen wieder - man sieht daraus, wie beliebt der Stoff war - und jedesmal fast gleich. Die Schilderung verläuft in folgenden Motiven: Einladung der Gäste durch Briefe (S. 2, 36, 196); das Fest wird auf einem schönen Feld veranstaltet (S. 195 ... vor der stat ûf einem plân) - womöglich in der Nähe des fließęnden Wassers (Vers 1320); auf dem Felde werden Tribünen und Zelte aufgestellt, dazu kostbare Tücher und Teppiche verwendet (S. 37); in den Zelten wird gespeist; der Überfluß an Essen (S. 4, 44); die ,amptliute" dürfen nicht fehlen (S. 4, 38; Vers 1326: Willehalmes amptrian wârn gemeine ûf dem plân ... die marschalke und kameraere, truh-

S. 107, 212 z. J. 1403,1407 u. s.,w.). Es ist sehr wahrscheinlich, daß sie schon Ende des 13. Jhdts. existierte; wir haben keinen Grund, die Angabe Peters gu bezweifeln. Aber das, was scin Gewährsmann erzählt, ist nicht wahr, ist eine evidente Übertreibung, ein literarisches Motiv.

1) Hrg. von Wendelin Toischer, Prag 1876 in der „Bibliothek der mhd. Literatur in Bohmen.". $\mathrm{Bd} .1$.

2) ibidem. Einleituag. Vgl, auch ,Grundriß der germanjschen Philologie 2, $^{2}$ 1. 303 hrg. von Hermann Paul, Straßburg 1893. 
saezen unde spîsaere); Bèlustigungen: die. Buhurt, der Tanz, das Turnier u. s. w. (S. 5, 45); endlich wird die Beschenkung der Gäste durch den Gastgeber (S. 46) erwähnt.

Aus dem Vergleiche dieser drei Schilderungen geht hervor, daß man bei der Veranstaltung solcher Festlichkeiten nach einem herkömmlichen Schema vorgegangen *ist. Man hat ein ebenes Feld gewählt, Zelte und Tribünen aufgestellt, Teppiche und kostbare Tücher dazu verwendet, Ritterspiele und Festessen veranstaltelt; zuletzt werden die Gäste, da sie nach Hause aufbrechen, beschenkt. Wir haben keine Ursache, daran zu zweifeln, daß man bei der Hochzeit von 1264 und der Krönung von 1297 ebenso vorgegangen ist - um so weniger, da wir es für die Hochzeit v. J. 1264 auch von einer anderen Seite bestätigt erhalten. (Annales Ottocariani, F. R. B. 2, 320, welche 0. auch benützt haben soll — S. Einl. 59; Historia annorum, M. G. H. SS. 9, 649; Continuatio Praedic. Vindob. ibid. 728). Wir sehen aber auch, in wie weit solche Schilderungen, besonders in der übermäßigen Übertreibung, typisch geworden sind und daß man sehr irren würde, wenn man aus dem ähnlichen Motivenschema die Abhängigkeit der Quellen ableiten wollte. Überdies ist die Reihenfolge in der Kgs. und in der Rchr. völlig verschieden.

S. hat speziell vier Motive herausgeholt, welche 0 . Peter nachgebildet haben soll: Berufung auf die Amtsperson ${ }^{1}$ ), Erwähnung des Pferdefutters, des Weines, Hühner (Hühnereier), der „Reitung“. Meiner Meinung nach könnte man vielleicht (!) einen solchen Schluß ziehen, wenn auch für die übrigen (positiven) Teile der Erzählung die Abhängigkeit 0.'s von der Kgs. Chr. nachgewiesen wäre; wenn die Reihenfolge der Motive dieselbe wäre; wenn diese "loci communes" sachlich und stilistisch ïbereinstimmten. Es ist nicht der Fall; sie haben nichts stilistisch übereinstimmendes und sachlich sind sie nur an alogisch gebildet.

Das Ergebnis: Aus dieser Stelle darf man nicht anf eine Benützung des 1 . Buches der $\mathrm{Kg}$ s. Chr. durch 0 . schließen ${ }^{2}$ ).

1) Daß diese Berufung einen typischen Charakter hat, bezengt auch Franz von Prag. Er hat die Erzählung Peters tiber die Krönung Wenzels Wort fürWort kopiert, aber er schiebt (ganz willkürlich) noch einen Gewährsmann ein : „Nam: notarius pabuli pro certo retulit, quod pro solis hospitibus pabulum dabatur etc. ...et notarius coquine retulit, quod pro ovis pullorum expense therant marce $800^{\star}$. F. R. B. 4, 362. Kap. 11.

2) S.'s Annahme ist auch von einer anderen Seite - der logischen Auffassung - unhaltbar: Warum hat 0 . die Motive zur Schilderung des Prager KrönungsJestes niuht benitzt? Warum hat er sie - an einer anderen Stelle - verwendet und seine schon längst verfaßte Partie geändert? 
Vers $17471 \mathrm{ff}$. (Seite 231).

\section{Die St. Rehr.}

Schluß des Jahres 1278. Ottokar ist tot, König Rudolf zieht mit einem Teile seines Heeres gegen Böhmen (17311 mit den, die riche wolden werden ûf bêheimischer erden); unterwegs zieht er die entlassenen Hifstruppen wieder an sich, weil er die Nachricht über den Anmarsch der Brandenburger erhielt (17365). Er rückt bis Sedlec vor $(17426$ Zedlitz, Ostböhmen). Unweit von ihm bei Kolín (17429 Kolne) hat Markgraf Otto von Brandenburg Aufstellung genommen. Beide rüsten sich zum Kampfe. Ehe es aber dazu kommt, vermittelt Bischof Bruno [von Olmütz] zwischen beiden Frieden. Er entwirft dem Frzbischof Friedrich von Salzburg einen Friedensplan (17 462), „daz zwischen in bêden der haz wurde drat [alsbald] verriht mit hirât". Mit der Rache an Ottokar soll sich Rudolf begnügen. (17 459) ${ }^{\mathrm{E} z}$ füegte niht dem rîch, daz der hôhist amtman ${ }^{1}$ ), der dem rìch waer undertan, siner lande wurd enterbt und in kindes wis verderbt". (17 468.) - Die Bischöfe von Gurk und Seckau (17484) begeben sich darauf in das Lager Ottos, um ihn zum Frieden zu bewegen. Der Markgraf ist aber ein treuer Verbündeter (17491, 17511,17577$)$; er bält fest zu Ottokar und Wenzel ... Die Bischöfe stellen ihm jedoch vor, was Ottokar gegen das Reich verschuldet

\section{Die Kgs. Chr.}

Die Schilderung der Kgs.Chr. verläuft in folgenden Zügen (Kgs. Chr., Kap. 9, Seite 50 ff.): Der Tod des Königs Ottokar war das Signal zur Anarchie in Lande. Als es König Rudolf erfuhr, kam er mit Heeresmacht nach Böhmen (bisZcedlicz=Sedlec). Seine Absicht war, dem Schwiegersohn zu helfen und den Landesfrieden durch Einsetzung eines Vormundes zu sichern. Inzwischen kam auch Markgraf Otto von Brandenburg nach Böhmen Wenzel zu beschirmen. Rudolf lud ihn zu sich und übertrug ihm mit Zustimmung der böhmischen Herren die Verwaltung von Böhmen. Abschied. - (Weiter wird nur über Markgraf Otto berichtet).

1) Anspielung auf die böhmische Kurwürde. Dieselbe sowie das Schenkenant wurden Böhmen seit 1273-1275 abgesprochen. Erst 1289 hat Wenzel diese Würde von neuem erlangt (Redlich, Rudolf von Habsburg 717). Wenn O. von Wenzel als shôhist amtman " des Reiches spricht, zeigt er, wenn diese Stelle nicht bei einer späteren Redaktion hinzugefügt wurde, daß die Rchr. nicht vor 1289 verfaßt wurde. (Gegen die Annahme Lorenz's - siehe bei S. Einl. 75). Es ist aber auch möglich, daß die Bezeichnung einer Vorlage entlehnt ist und demnach wäre schon die Vorlage nach $1289 \mathrm{zu}$ setzen. Uther das Kurrecht und das Schenkenamt Böhmens vgl. auch Max Buchner: Über die Entatehung des „Kurfürstenspruches* M. I. Ö. G. 1911, Seite $230 \mathrm{ff}$. 
habe und daß er sich selbst - wenn er den Kampf aufnehmen wolle einer nicht geringen Gefahr aussetze. Otto sucht Rat bei den böhmisehen Herren und Prälaten (17623), „die zuo der Bêheim rât gehôrten". Die Böhmen sind des Kampfes müde und mutlos (1 17645 ), deshalb nimmt Otto das Anbot der Gesandten an. Der Friedensschlu $\mathbf{B}$ wird durch 5 genannte Vertrauensmänner vermittelt (Schluß des 169. Kap.) und zwar auf die Weise (Kap. 171): der junge Wenzel wird Gutta, die Tochter Rudolfs, heiraten; der gleichnamige Sohn Rudolfs die Tochter Ottokars, Agnes. Als Mitgift wird Gutta (17840 „die kuniginne Guote") das Land nördlich der Donau bekommen ${ }^{1}$ ). (17 844; der sumen hân ich niht gelesen - vgl. dazu Steinacker: Regesta Habsburgica 1. Abt. Nr. 608.)

Der Vergleich beider Quellen ergibt folgendes: Sie treffen nur in der einzelnen Tatsache zusammen, dal3 sie über den Anmarsch Rudolfs und Ottos nach Böhmen und über ihre Vereinbarung bei Sedlec berichten. Sie war überall bekannt; Ottokar konnte sie einem anderen Geschichtswerke oder einer Urkunde entlehnen - er konnte sie auch gehört haben. Im übrigen gehen beide Quellen auseinander: Ihr Standpunkt ist grundsätzlich verschieden. Bei 0 . bildet Rudolf den Mittelpunkt der Begebenheiten, bei dem Kgs. Abt Wenzel und Markgraf Otto. Beide Quellen weisen gegenseitig verschiedene Erzählungen auf. Besonders 0. weiß eine Fülle von neuen Einzelheiten zu erzählen, die beglaubigt sind: das ergibt der Vergleich mit den Urkunden und anderen Chroniken (Böhmer-Redlich: Reg. S. 254 ff.). Dagegen ist das wenige in der Kgs.

1) Böhmer-Redlich: Reg. 1026a. Redlich sagt „Ganz irrig bringt die Rchr. die zu 1276 gehörige Verpfändung Österreichs nördlich der Donau an Böhmen in Zusammenhang mit den jetzigen Abmachungen . Ich glaube jedoch, die Erzählung $0 . ' s$ sei nicht so unlogisch; ich werde später Gelegenheit haben zu zeigen, daß er die böhmisch-habsburgische Wechselheirat als Hauptresultat der Kriege vom J. 1276 und 1278 betrachtet; deshalb zieht er die Verhandlungen darüber und die Bedingungen zusammen und setzt dieses Ereignis in das Jahr 1278. - Er tut dies auch sonst gerne, daß er zwei zeitlich voneinander getrennte, aber sachlich zusammengehörende Begebenheiten vermengt. Vgl. den neuesten Beitrag zur Kritik der Rchr. von Novotný, „Přemysl Ottokar II. und der Adel von Steiermark in M. I. Ö. G., 1910, S. 291. 
Chr. unvollständig und auch nicht besonders richtig (vgl. Novotny,, S. 23 Anm. 7). Aber auch da, wo beide Autoren in der Schildenung eines Ereignisses zusammentreffen, gehen sie sowohl in der Auffassung, als auch in dem Stoffe auseinander, z B.:

0 . erzählt, daß Rudolf ïber Mähren gezogen sei und in welcher Weise. Der Kgs. Abt weiß nichts davon. Rudolf kommt als Feind nach Böhmen, als Rächer des Reiches, und ihm folgen alle Schrecken des Krieges: Raub, Brandstiftung, Plünderung (vgl. 17 330)1). Mit den Tode Ottokars hat die Rache nicht aufgehört; Rudolf sucht sie noch auf das Land und auf Wenzel auszudehnen. In der Kgs. Chr. erscheint er als fürsorglicher Schwiegervater Wenzels: , audiens insolentiam (des Adels) aliis pretermissis negociis cum multa milicia proficiscitur in Bohemiam, ut incommodis genero(!) suo adhuc infanti affuturis consuleret" (S. 51). In der Rchr. wird der Waffenstillstand und endlich der Friede durch einige hohe Prälaten vermittelt. Rudolf und Otto treten durchaus als Feinde auf. In der Erzählung der Kgs. Chr. herrscht die schönste Eintracht und die größte Ruhe: Rudolf kommit um Wenzel Hilfe gegen die Herren zu leisten, Otto ebenfalls. Weshalb kämpfen? - rex Romanorum hoc intelligens ladet ihn zu sich ein, und sie schaffen die Ruhe im Lande. Der Friedensschlub und die Friedensbedingungen sind grundsätzlich verschieden. Bei 0 . steht die Wechselheirat zwischen Ottokars und Rudolfs Kindern im Vordergrund; er weiß nicht - jetzt und auch später, daß dem Markgrafen Otto die Vormundschaft über Wenzel und die Verwaltung Böhmens überlassen wurde. Bei der Kgs. Chr. das Gegenteil: es verlautet nichts über die Eheverlöbnisse, ihre ganze Aufmerksamkeit konzentriert sich ausschließlich auf Otto.

Das sind wichtige Momente, welche bei jedem unvoreingenommenen Leser gegen die Beniitzung der Kgs. Chr. durch 0 . sprechen. S. hat es selbst gesehen: deshalb nahm er an, daß Ottokar seine Vorlagen nur als Notizen und Exzerpte gekannt und verwendet hat - wir müssen deshalb auch in das Detail eingehen und die kleinen Übereinstimmungen

1) Die Annales Ottocariani, F. R. B. 2, 332 berichten von der Schädigung des Klosters Vilémov durch das Heer König Rudolts. Redlich, Rudolf von Habsburg, S. 329, Anm. 2 will die Nachricht (oder ihre Tendenz) in Abrede stellen. Und doch hat auch 0 . dieselbe Nachricht - und weit ungünstiger - überliefert Vers 17346 ff. Zwölf Tage soll Rudolfs Heer bei Habry — nicht weit vom Kloster Vilémov - mit Raub gelegen sein (wunder man dâ zuo treip, phert, rinder und vich .... i. s. w.). Vgl. Palacký.6, S. 15̄1, Anm. 226. (Vilémor und Habry in dem Bez. (́áslav, Ostböhmen.) Auch das Chronicon Colmariense (M. G. H. SS. 17, 252) erzählt: Rudolphus intravit marchionatum Moraviae, terram volens totaliter devastare... 
priifen, welche $\mathrm{S}$. in den Texten beider Chroniken gefunden hat, ob sie unbedingt die Kenntnis der Kgs. Chr. seitens 0 . voraussetzen?

Vers 17468 (Seite 231, Anm. 3). Die Kgs. Chr., Kap. 9, Seite 51.

Der Leitgedanke der geistlichen Rudolfus rex ... pociores Bohemie Friedensvermittler: „ez füegte niht ad se venire mandavit; hoc utique dem rîch, daz der hôhist amtman idcirco factum creditur, ut videlieet siner lande wurd enterbt und in kin- incommodis genero suo adhuc infanti des wis verderbt". Vgl. Vers 17448 affuturis consuleret.

„ez waer ein swaere burde dem kinde ze tragen ... ob ez hin nâch dulden müeste, daz im wurden wüeste siniu erbelant".

Es ist zwar wahr: mit beiden Gedanken wird der Friedensschluß motiviert, aber die Art, in welcher es 0 . und der Kgs. Abt tun, ist nicht dieselbe. Ich glaube kaum, daß ihn 0 . aus der Kgs. übernahm - er hätte dann auch entsprechend seinen Rudolf abändern müssen. Rudolf in der Schilderung des Kgs. Abtes ist ein Freund von Wenzel; er kommt ihn zu retten und das Land vor den Schäden zu schützen: O. aber faßt die Sache ganz umgekehrt auf; er macht aus ihm den unversöhnlichen Gegner Wenzels und legt den Friedensgedanken einem andern in den Mund1). O. hätte hier (auch in dem kleinsten Exzerpte!) lesen können, daß Wenzel bereits "g en er" Rudolfs war und daß Otto als "tutor inibi institutus" die Regierung in Böhmen übernahm, und sich leicht überzeugt, daß seine Erzählung sehr lückenhaft und sehr verfehlt sei. An dieser Stelle ist die von $\mathrm{S}$. (nicht ohne Zweifel) annommene Nachbildung der Kgs. Chr. ausgeschlossen.

Vers 17514,17577 und bes. 17595 ff. (S. Seite 231, Anm. 3). Die Rchr. stellt den Markgrafen Otto dar als einen Mann, der eigens kam, um Wenzel zu schützen (17376 und wolt den ôheim rechen). Er tritt uns als ein selbstloser, aufopfernder Freund entgegen, der mutig der Rache Rudolfs die Stirne bietet. Die Kgs. Chr. (Kap. 9, S. 51) erzählt: Audita autem nece Ottakari Otto marchio ... exercitum convocavit ac inde proficiscens Wenceslao iuveni, suo consangwineo ${ }^{2}$ ), exhibititurus,

1) O. steht auch damit der Wahrheit näher. Vgl. Cont. Vin dobonensis, M. G. H. SS. 9, 710 ,Venientes ambo [Rudolf und Otto] cum exercitibus ad Coloniam, mediantibus principibus ac aliis nobilibus multis inter eos pace reformata, sub hac forma inter se convenerunt*... etc.

2) Woher hat der st. Chronist die bestimmtere Verwandtschaflskenntnis, wenn er den König Ottokar als Ottos sôheim* (auch umgekchrt) bezeichnet? Vgl. S. 233, Anm. 1. 
ut puto, presidium, venire in Bohemiam festinavit*... Der Gedanke ist hier zwar gleich; jedoch hätte 0., wenn er nur einige Zeilen weiter gelesen (Kap. 9-14) hätte, die Friedensbedingungen ganz anders stilisieren und über Otto eine andere Meinung bekommen müssen; dann wäre es unmöglich gewesen, ilın in so heldenhafter Pose darzustellen ....

S. wollte seine Annahme damit retten, daß er sagte, die Kgs. Clır. habe 0. nicht als ein Ganzes, sondern nur in Exzerpten vorgelegen ... E's drängt sich ein Bedenken methodischer Art auf. Wenn ein mittelalterlicher Erzähler aus einem oder aus mehreren Annalenw erken eine Chronik kompiliert, dann gestattet ihm deren ungebundene Struktur und lockere Erzählungsart, da ein jedes Ereignis für sich besonders steht, einzelne Nachrichten willkürlich aus dem Kontexte herauszureißen und mit anderen zusammenzusetzen. Die Kgs. Chr. (und auch die Rchr.) ist aber kein Annalistenwerk. Sie weil - auch in den Anfangskapiteln - die Begebenheiten logisch (manchmal naiv und. legendenartig) zu verbinden. Ihre Kapitel vermag man nicht in einzelne Nachrichten (oder sogar Gedankensplitter, wie S. annimmt) aufzulösen. Ich kann es mir nicht recht vorstellen, daß 0 . (oder ein auderer für ihn) einzelne Sätze (manchmal nur Satzteile) hätte abtrennen - und ohne auf den Zusammenhang und die Personenverschiedenheiten zu achten - in seine Erzählung hineinschieben sollen, eine Erzählung, welche, wie wir sahen, der Auffassung der Vorlage schroff gegenübersteht. Wenn er schon die Kgs. Chr. benützt hätte, würde er eher einzelne Kapitel, vielleicht auch kürzend, aber doch den Gedankengang bewahrend, übernommen haben.

Aber auch von einer anderen Seite erscheint uns die Annahme S.'s als nicht zwingend. Die Nachricht, daß Otto von Brandenburg nach Böhmen gekommen ist, um Wenzel gegen Rudolf Hilfe zu leisten, ist keineswegs vereinzelt. Daselbe Motiv kennt anch Dalimil $\left.{ }^{1}\right)$ und von den dentschen Quellen Ellenhard ${ }^{2}$ ) (welchen 0 . auch benützt haben soll; S. Einl. 59); darauf spielen ferner auch an: die Wiener Continuation (SS. 9, 710), Cont. Claustroneoburg. VI (SS. 9, 746) und Annales s. Rudberti Salisb. (ibid. 805) - zwar nicht so deutlich, daß man auf eine Verwandtschaft oder eine Ableitung schließen dürfte; aber sie

1) Der deutsche Dalimil erzählt (F. R. B. 3, 196) : „Rudolfus gink gein Behem nach dem strit, den er gwan und von Brandeburg der margrebe gein Behem kom mit dem hof. Er wollt mit im gestrittin habin um dez konigiz son mit nam". Das böhmische Original sagt: „Chtè za kraloviç s ním boj vzieti๔, ibid.

2) Ellenhardi Chronicon (M. G. H. SS. 17, 124) : (Ottokar) reliquerat filium unum cuius avunculi erant marchiones de Brandenburg, qui se regi opposuerunt propter filium Bohemi. 
bezeugen, daß dieselbe Auffassung (die auch heute geläufig ist und den Tatsachen entspricht) verbreitet war - und daß 0 . auch eine (uns heute unbekannte) Variante hören (resp. lesen) und benützen konnte.

Es ist auch nicht ausgeschlossen, daß 0 . eine urkundliche Quelle verwendete. Wir besitzen eine solche, die von der Motivierung 0.'s nicht weit absteht - - den Brief der Königin-Witwe Kunigunde an die Markgräfin von Brandenburg. (Emler, Reg. Boh. 2, Seite 491, Nr. 1144). Der Brief ist dem Formelbuche Peters de Hallis entnommen' und entbehrt nicht der Glaubw ürdigkeit ${ }^{1}$ ). Die Königin schreibt:

"dominus et maritus noster [Ottokar] vobis et filio vestro, domino Ottoni, marchioni de Brandenburg, nos et pueros nostros ac terras suas recommisit; quare dileccionem vestram monemus attentius et rogamus, quatinus filium vestrum inducatis, ut se de nobis et filio nostro ac terris suis celeriter intromittat, ac nos ab inimicis nostris tueatur; . . vos sola cum filio vestro nostrum asilum existitis et solamen".

Aber dieser Brief entspricht noch in höherem Maße der Auffassung 0 .'s, indem er auch die Intentionen Rudolfs mit ihm übereinstimmend beschreibt:

„audivimus - sagt die Königin -, quod dominus rex Romanorum non contentus eo, quod maritum nostrum preclarum transire tam impie de hoc seculo procuravit, verum etiam ad finale exterminium nostri filii conatus suos dicitur extendire..."

Aus diesem Sachverhalt geht hervor, daß man auf dieser Stelle auf die Benützung der Kgs. Chr. durch 0 , nicht schließen darf.

Die Chroniken, welche uns über die Ereignisse nach Přemysl Ottokars Tod belehren, lassen sich, was dieses Ereignis anbelangt, territorial gruppieren, natürlich nicht ohne Ausnahme.

I. Eine Gruppe bilden die böhmischen Quellen: Annales Ottokariani (F. R. B. 2, 332); Annales Pragenses pars II. und III. =- Vypravování o zlǵch létech po smrti krále Premysla 0t. II. (F. R. B. 2, 335 ff.); Chronicon domus Sarensis = Letopis Ž̉̆árský větší (F. R. B. 2, 542); Dalimil (F. R. B. 3, 196); die Kgs. Chr. (Seite 51 ff.) und Neplach (F. R. B. 3, 477). Sie weisen gemeinsam folgende Motive auf: der Tod des Königs, die Unruhen im Lande (König Rudolf in Böhmen), die Vormundschaft des Markgrafen Otto über Wenzel, Hungerjahre ete . .; sie haben auch eine negative Eigenschaft gemeinsam: sie erwähnen nicht die Ernenerung des Ehevertrages zwischen Ottokars und Rudolfs Kindern.

1) Vgl. J. B. Novák, K nové literatuře o Václavu II. Ceský časopis historický 12, 48: 
Eine vermittelnde Stellung zwischen der böhmischen Annalistik und der Gruppe der österreichischen Quellen nimmt die mährische ${ }^{1}$ ) Erzählung Heinrichs von Heinburg ein, welche die Ereignisse in Mähren betont (Zug Rudolfs über Mähren, seine Verfügungen über das Land; sie enthält auch Nachrichten von den Alpenländern). Mit den böhmischen Chroniken stimmt sie darin überein, daß sie die böhmischhabsburgischen Eheverträge mit Stillschweigen übergeht.

II. Die zweite Gruppe bilden die österreichischen Annalen: I)ie Continuatio Vindobonensis (SS. 9, 710); die Annales s. Rudberti Salisburgensis (SS. 9, 805); mit der Wiener Continuation stimmt die Continuatio praedicatorum Vindobonensium überein (ibid. 731). Die. Continuatio Claustroneoburgensis VI (ibid. 746) bewahrt nur den Hauptteil des Berichtes (Zug Rudolfs über Mähren, Ankunft Ottos, contractus matrimoniales). Die Historia annorum hört mit dem Tode Ottokars. auf (ibid. 654)2). Sie enthalten folgende Nachrichten: den Zug Rudolfs. über Mähren; er unterwirft das Land seiner Herrschaft. Die Ankunft. Ottos in Böhmen; er stellt sich dem König feindlich entgegen. Die Herstellung des Friedens unter folgenden Bedingungen: Rudolfs und Ottokars Kinder heiraten untereinander; Otto bekommt die Vormundschaft über Wenzel und die Verwaltung in Böhmen (auf 5 Jahre); Rudolf übernimmt Mähren auf dieselbe Zeit.

III. Während die österreichischen Annalen von dem Zuge Rudolfs über Mähren, von der Regentschaft Ottos und der Heiratsvereinbarung sprechen, heben die süddeutschen Chroniken hauptsächlich das letzte hervor. Sie fassen die Sache so auf, als wenn Wenzel unmittelbar nach dem Tode seines Vaters den Thron bestiegen und die habsburgische Prinzessin geheiratet hätte: Ellenhardi Chronicon (Straßb. Quelle, SS. 17, 124); Annales breves Wormatienses (ibid. 76); der Mönch von Fürstenfeld (Böhmer, F. R. G. 1, 10); Compendium histor. Sifridi de Balnhusin (türingische Chronik, SS. 25, 709); Burkardi de Hallis Notae historicae (schwäbische Quelle; Böhmer, F. R. G. 2, 474)3). Eine A usnahmsstellung. nehmen einige bayerische Erzählungen ein, welche sich der böhmischen (oder österreichischen) Fassung stark nähern: Die Continuatio. Hermanni Altahensis (SS. 17, 411; von da hat es Eberhardus Ratisponensis übernommen, ibid. 593); Chronicon imperatorum et pontificum.

1) vgl. F. R. B. 3, 305.

2) Sie erzählt noch - analog der Kgs. Chr. - über die Anarchie, in welche das Land Böhmen nach dem Tode Ottokars geraten ist.

s) Diese Fassung weisen auch die entfernteren Quellen auf: Johannis de Thilrode Chronicon (Genter Quelle; SS. 25, 562); Martini continuatio Brabantina (SS. 24, 263). 
bavaricum (SS. 24, 224; autor - Slavus fortasse natu — vixit in Bavaria prope fines Bohemiae). Das Chronicon bavaricum erzählt, daß Rudolf Mähren gewann und Böhmen - omnibus volentibus eam diripere dereliquit; die Continuation des Hermann von Altaich referiert über den traurigen Zustand Böhmens nach der Schlacht am Marchfelde und über die Yormundschaft Ottos.

Zuletzt erwähnen wir das Chronicon Colmariense, welches auch einen Übergang von den süddeutschen zu den österreichischen Quellen schafft; mit den letzteren gemeinsam erzählt es von dem Zug Rudolfs über Mähren (SS. 17, 252).

Die Ursachen, warum sich die Annalen und Chroniken des ausgehenden 13. Jahrhunderts gegenüber der älteren Geschichtsschreibung dem Inhalte, der Auffassung und der Verbreitung gewisser Motive nach territorial gruppieren lassen, sind bekannt. Seit dem Interregnum macht sich im Reiche immer mehr ein Prozeß bemerkbar, der zur Verselbständigung einzelner Territorien und Abschließung gegen das Reich führte. Auch die Geschichtsschreibung „macht jetzt bei den Landesgrenzen halt"; für die Chronisten ist jetzt in dem Landesfürsten und in den neuen, mächtigen und dem Reiche gegenüber fast geschlossenen Territorien ein neuer Mittelpunkt erstanden. Vom Standpunkte der Territorialgeschichte wird auch die Reichsgeschichte beurteilt. Die Verschiebung der Interessensphäre der Geschichtschreiber und der Leser (Lorenz, D. G. Q. 13 $^{\mathbf{3}}$ 2; vgl. auch Vildhant: Hb. 2, Einl.) hat verursacht, daß die Geschichtsschreibung sich territorialisierte; andererseits müssen wir auch mit der engeren Verbreitung einiger Quellen, Erzählungen und Motive rechnen: auch sie "machteu bei den Landesgrenzen halt".

Wie verhält es sich mit der Rchr.? Welche Stellung nimmt sie zwischen diesen Quellen ein? Sie weiß nicht, mit der süddeutschen Quellengruppe übereinstimmend, daß Otto auf fünf Jahre die Regentschaft in Böhmen übernahm. Die Regierung geht gleich an Wenzel, resp. Kunigunde über. Sie weiß auch nicht, was mit Mähren (und mit der Grafschaft Glatz) geschah. Die wechselseitige Eheschließung der Kinder Ottokars und Rudolfs gilt ihr als Hauptresultat des Krieges v. J. 1278. Von dieser Seite gehört sie vollständig der süddeutschen Quellengruppe an. Aber sie greift hinaus - ähnlich der Kolmarer Chronik - in die österreichische Gruppe. Sie berichtet über den Zug Rudolfs durch Mähren, über den bewaffneten Widerstand Ottos, über den Frieden - aber nichts mehr.

Verbindet sie alsodie Eigenschaften derbelden Quellengruppen, so ist der südeutsche Standpunkt doch der 
tonangebende. Diese Wahrnehmung ist, wenn sie sich auch weiter bestätigen sollte, - für 0 . oder für seine Vorlage ${ }^{1}$ - nicht unwichtig. Der Übergang von der einen zu der anderen Gruppe wird durch die Person König Rudolfs vermittelt. Die Rchr. holt aus der österreichischen Gruppe nur die Einzelheiten heraus, die Rudolf betreffen, oder welche zur Verherrlichung seiner Person und seiner Familie dienen. Man beachte die Schilderung des siegreichen Zuges nach Böhmen²), die Haltung Rudolfs gegenüber Wenzel ${ }^{3}$ ), die poetische Beschreibung des Iglaner Hochzeitsfestes (17859). Die böhmische Geschichte wird soweit herangezogen, als sie mit Rudolf und dem Hause Habsburg in Verbindung steht (wir werden dies auch später beobachten können); deshalb wird von den Friedensbedingungen nur die Wechselheirat der Kinder Rudolfs und Ottokars herausgegriffen.

Vers 17496 (Seite 232). Markgraf Otto von Brandenburg kam nach Böhmen um die Kinder Ottokars zu beschützen.

Vers $17496 . » 0$ ttacker, dô er schiet $\mid$ In dem 5. Kapitel seiner Chronik von dem lîbe, er lie bî sînen êwîbe erzühlt Kgs. Abt von der Lösung der zwô töhter unde einen knaben. noch Ehe König Ottokars mit der alternden mêr sach man in kinde haben ûzer- Babenbergerin, in dem 6. von seiner halp der $\hat{e}^{\ll}$. In diesem Exkurs über neuen Ehe mit Kunigunde von Halï̌, die Familie Ottokars sieht der Heraus- Enkelin K. Bélas IV. (im J. 1261 ) und geber einen Anklang an die Kgs. Chr., schließt: „Ex hac domina rex OttakiKap. 6, Seite 46.

rus duas filias et tres filios habuit, quorum duobus mox in infantia defunctis, iunior ... in regno verus heres successit".

1) Wir müssen beide Möglichkeiten vor Augen halten, obwohl ich geneigt wäre, nach dem heutigen Stand der Forschung, welche durch die Namen: Huber, Busson und Seemüller gegeben ist, diese Eigenschaft eher der Vorlage zuznsehreiben.

2) Das Heer Rudolfs kommt mit Raub und Plünderung nach Böhmen. Wir dürfen keine moderne Empfindung hineintragen und nicht glauben, da $O$. damit etwas Ungünstiges über Rudolf erzähle. Im Gegenteil, das waren Begleiterscheinungen, die zu jedem siegreichen Zuge in ein fremdes Land gehörten (der Gewinn war auch ein Ziel des Krieges) und die den Ruhm vermehrten; $O$. hebt sie ausdrücklich hervor und - - iibertreibt sie.

3) Rudolf will Rache an Wenzel nehmen. Man darf' wieder nicht glauben: dalf diese Auffassung Rudolf ungünstig ist; nein, die Rache des Reiches ist gerecht und der Zorn Rudolfs ist berechtigt, meint 0 . Er will damit betonen, welche schwere Folgen der Ungehorsam gegen das Reich mit sich bringt, daß der Ungehorsame der Strafe nicht entgeht. Es ist derselbe Standpunkt, welcher auch in den Annales Ottocariani (F. R. B. 2, 331) zu Tage tritt, wenn der Verfasser den Köuig Ottokar wegen soiner Kühnheit tadelt und von der , magnitudo bracchii 
Diese zwei Nachrichten - jede in anderem Zusammenhange stimmen sachlich überein. Aber noch eine größere Übereinstimmung, schon in der chronologischen Koïnzidenz, findet man in den Annalen Heinrichs von Heimburg. Ähnlich wie O. bringt auch Heinrich die Nachricht zur Mitte des Jahres 1278 und sagt: Regnavit (Ottokar) annis 27 et reliquit filium unum nomine Wenceslaum et duas filias (F. R. B. 3, 317). Wären wir nicht berechtigt, eher an die Benutzung der Annalen Heinrichs zu denken als an die der Kgs. Chr.?

Aber wir können bestimmt sagen, daß 0 . sicher an dieser Stelle weder die Kgs. Chr., noch die Annalen Heinrichs von Heimburg verwendet hat: denn er zeigt, daß er auch ïber die illegitimen Kinder König Ottokars informiert ist. Hingegen nennt sie der Kgs. Abt ${ }^{1}$ ) so wie auch Heinrich ${ }^{2}$ ) nur gelegentlich. Es ist kaum zu erwarten, daß 0 . die zerstreuten Belege fleilig gesammelt und hier verwendet hat (dann miißßte er das ganze erste Buch der Kgs. Chr. und keine Exzerpte in der Hand gehabt haben). Er schöpfte seine Nachricht auch nicht aus den übrigen böhmischen oder deutschen Quellen; sie bieten darüber nämlich keine Mitteilung. Der steierische Dichter mußte hier eine (heute) umbekannte Quelle beniitzt haben, oder beruht seine Kenntnis auf der mündlichen Überlieferung? ${ }^{3}$ ). Unsere Schlußfolgerung wird noch durch einen andern Umstand bestätigt: Vers $17733 \mathrm{ff}$. läßt sich 0 . breit über die ehelichen Kinder König Ottokars aus, breiter, als uns je die Kgs. Chr. und die übrigen Quellen erzählt haben. Damit ist wohl gezeigt, daß er eine andere und gut unterrichtete Quelle gehabt hat und daß er bei 17496 - nicht zur Kgs. Chr. greifen mußte.

Kunigunde, die erste Tochter Ottokars; Vers $17733 \mathrm{ff}$. (Seite 235). 0. erzählt: Der Sohn Ottokars hieß Wenzel (fruotic was er unde balt). Eine der zwei Töchter (Kunigunde)4), hat das jungfrüuliche Leben in dem Kloster des heiligen Franziscus in Prag vor-

electi Romanorum " spricht, die eine Panik in dem böhmischen Heere hervorgerufen hat.

1) Seite 80 „frater Wenceslai dux Nicolans" (Kap. 25); Seite 200 „Elizabeth (Gysela), que et ipsa erat regis Ottakari flia" (Kap. 83).

2) F. R. B. 3, 321 : anno 1296 obiit frater regis [Wenceslai II.] Jessko prepositus Wyssegradensis.

3) Die zwei vorher angeführten Belege, sowie auch der spätere Franz von Frag (F. R. B. 4, 351) bestätigen, daß die Nachricht 0.'s glaubwürdig ist.

4) 0 . sagt „ze guoter mâze kleine". Kunigunde war das erste Kind Ottokars mit der Königin Kunigunde (geb. im J. 1265). Das zweite Kind (Agnes) folgte nach vier Jahren (1269). Wenzel ist das jüngste (geb. im J. 1271). Vgl. To mek: Dèje mèsta Prahy 12, 195. 
gezogen. Vers 17746: „ich hôrte aber sît, daz ir der orden waer unmaere, wand [weil] ir wart ze tragen swaere des magetumes [jungfräulichkeit] burde ... man sol datz Prâge drumbe frâgen, dâ weiz man wol ir leben". Sie hat dann nach Polen den Herzog Bolezlâ (Boleslav II. von Mazovien) geheiratet' ${ }^{1}$.

An diesen Exkars 0.'s über Kunigunde hat S. in der Einleitung einige Bemerkungen angeknüpft; er will der Gefahr einer möglichen Annahme - wir werden sie später kennen lemen - entgehen: nach meiner Meinung vergeblich. Genauere Daten ${ }^{2}$ ), wie z. B. die, welche in der Edition Emlers enthalten sind, hätten ihn der Mühe überhoben. Deshalb verdient die Stelle eine nähere Untersuchung; sie zeigt auch, wie gut 0 . über Kunigunde informiert war ${ }^{3}$ ).

Kunigunde, das erste Kind König Ottokars und der Kunigunde ist Anfang 1265 geboren ${ }^{4}$ ). Im J. 1277 hat sie der Vater in das St. Clarenkloster bei dem heiligen Franz in Prag gebracht5); sie war da-

1) S. erklärt das Wort falsch als Wladislaus (S. 235, Anm. 4). Die Bezeichnung der Rchr. ist richtig. Boleslav II. war ein Sohn Ziemovits I. und der Bruder Konrads II. Er war zweimal verheiratet. Seine erste Frau hieß Sophie; sie starb im J. 1288 und hinterließ zwei Söhne und eine Tochter. Boleslav heiratete dann die böhmische Prinzessin Kunigunde. Vgl. Osw. Balzer: Genealogia Piastów, Kraków (1895) S. $421 \mathrm{ff}$.

2) als die, welche er verwendet hat, vgl. Einl. S. 8.2 und im Texte S. 235 Anm. 3 ("Von 1305 ab ist Kunigunde als Äbtissin des Georgsklosters zu belegen und stirbt 1312"). Ein unrichtiges Todesdatum finden wir auch in der III. genealogischen Tafel der „Österreichischen Geschichte" von Krones-Uhlirz (Sammlung Göschen): Kunigunde +1311.

s) Der ersten Tochter Ottokars hat der bedeutende polnische Jurist und Historiker $O \mathrm{sw}$. Balzer in seinem großen Werk: Genealogia Piastów S. 424-8 eine ausführliche und gute Studie gewidmet. Mit großer Gründlichkeit sammelte er alle Belegstellen und fixierte die Hauptdaten ihres Lebens; die Erzählung 0.'s ist ihm jedoch entgangen.

4) Annales Pragenses pars I. (F. R. B. 2, 299); sie geben jedoch bloß die Zeit der Taufe an: 1265 rex celebravit convivium pro baptismo filiae suae primogenitae, et hoc in festo b. Mariae purificationis (Febr. 2). Es ist deshalb nicht ausgeschlossen, daß sie 1264 geboren wurde. Diese Nachricht wird fast wörtlich von Neplach (F. R. B. 3, 475) und von Marignola (F. R. B. 3, 572) übernommen. Die Prager Annalen führen keinen Namen an - auch Neplach und Marignola haben keinen Namen angeführt; $O$. ebenfalls. Balzer hat bewiesen, daB es Kunigunde war (l. c.).

5) obzwar sie schon einem Sohn König Rudolfs verlobt war. Vgl. An nales Ottocariani (F. R. B. 2, 329) und Chronicon Colmariense (M. G. H. SS. 17, 249). Beide Chroniken stimmen in der Sache überein. Den Bericht der Annales Ottocariani hat Franz von Prag kopiert (F. R. B. 4, 353), aber die Spitze gegen den König (Ottokar) brach er ab. Aus denselben Annalen schöptte wahrscheinlich auch Neplach (F. R. B. 3, 477), dann Marignola (F. R.B.3, 573) 
mals 12 Jahre alt — ,ze guoter mâze kleine“ sagt 0 . Ihr Aufenthalt in dem Kloster läßt sich in den Urkunden verfolgen: die erste mir bekannte Urkunde ist am 3. August 1283 datiert, vgl. Emler, R. B. 4, 738, Nr. 1854 (Chunegundis, filia olim d. Ottocari, regis Bohemorum, monialis); vgl. weiter ibid. 2, 595, Urk. Nr. 1386 vom 20. Juni 1286 =-= Novák, Formulár biskupa Tobiáše z Bechyně, S. 116. Das letzte Dokument rührt vom 8. Oktober 1288 her, Emler, R. B. 2, 1190, Nr. 2726. Von diesem Jahre an hören alle Urkunden, welche die Chunegundis monialis oder nur bloß Chunegundis anführen, auf, um wieder durch die erzählenden Quellen ersetzt zu werden. Neplach erzählt: amuo domini 1290 Kunegundis, filia regis Przyemysl, de ordine s. Francisci exivit1). Die chronologische Unordnung Neplachs macht das Datum ein wenig zweifelhaft; Balzer korrigiert es auf 1291. Aus welchem Grunde Kunigunde das Kloster verlassen hat, sagt uns die Reimchronik, Franz von $\mathrm{Prag}^{2}$ ) und zwei polnische Quellen ${ }^{3}$ ). Man darf vielleicht der Nachricht einen tieferen Sinn geben: Im Jahre 1291 beginuen die Praetensionen Wenzels auf Krakau, er sucht Verbindungen mit Polen anzuknüpfen; dazu dient auch die Heirat seiner Schwester Kumigunde mit dem Herzog Boleslav II. von Mazovien -wir vermuten es wenigstens. (Franz von Prag sagt prägnant: Que excepta fuit per regem W. et [per eum] tradita duci Mazouie.) Als "ducissa Mazouie wird Kunigunde in einer polnisehen Urkunde, welche von ihr ausgestellt ist, erwähnt (,illustris femina, filia regis Bohemie, domina C., ducissa Mazouie $\left.{ }^{4}\right)^{4}$ ). Ein Dezennium lang blieb sie

und Pulkava (F. R. B. 5, 163). Da in den Prager Annalen der Name Kunigundens fehlte, füllte Marignola äie Lücke selbst aus - mit dem Namen der zweiten Tochter Ottokars, Agnes. Der steierische Chronist erzählt auch von ihrem Eintritt in das Kloster, aber er motiviert ihn durch ihre Vorliebe für das Klosterleben. - Balzer meint, daß Kunigunde zweimal in das St. Clarenkloster eingetreten sei (1276 und 1277). Diese Meinung unterstützt er durch eine zu wörtliche Interpretation der Chronik des Franz von Prag. Sein Verfahren ist aber methodisch verfehlt, weil der Bericht Francisci pragensis nicht originell, sondern den Annales Ottocariani entlelınt, und unrichtig modifiziert ist. Als Ausgangspunkt der Untersuchung muß doch immer die originale Quelle genommen werden. Was Franz nachher (selbständig) von Kunigunde erzählt, ist ungenau und unrichtig; deshalb dürfen wir auch das, was vorangeht, nicht zur Grundlage der Interpretation nehmen.

1) F. R. B. 3, 477 .

2) F. R. B. 4, 353 Que excepta fuit de monasterio per regem Wencezlaum, fratrem sum, et tradita fuit in matrimonium duci Mazouie.

3) Rocznik franciskański Krakówski, Monumenta Poloniae historica 3, 47. Lwów 1878 und Dlugosz: Hist. Polon., siehe l. c. bei Balzer.

4) Kętrzyński, Dokum. Płoc. nr. 16. Die (undatierte) Urkunde fällt in die Jahre 1291-8. Siehe l. c. bei Balzer. 
bei dem Gatten, im J. 1302 sehen wir sie wieder in Prag ${ }^{1}$ ). Wann sie nach der Heimat zurückgekehrt, ist unsicher ${ }^{2}$ ). Im Jahre 1302 trat sie in das Georgskloster auf der Prager Burg, das vornehme Damenstift ein, wie Pulkava erzählt: ,1302, Juli 22 Cunegundis, soror regis W', religionem assumpsit aput sanctum Georgium in castro pragensi". (F. R. B. 5, 181). Das Datum ist glaubwürdig. Es wird von einer Handschrift der Prager Universitätsbibliothek (sign. XIII A. 2) bestätigt: „abbatissu Gunegundis, que recepit habitum monasticum anno 1302 die Marie Magdalene $=$ Juli 22 ${ }^{3}$ ). Kurz nachdem sie in das Kloster eingetreten war, ist sie Äbtissin geworden. Kin striktes Datum bringt ein Kodex des Klosters Si. Joannis sub Rupe, den Dobner: Mon. hist. Boemiae 6, 373 zitiert: „Anno 1302, Juli 22 Gunigundis religionem suscepit, quattuor succedentibus temporibus abbatissa facta ...4). Dieser Quatember fiel damals auf den 19. Sep-

1) Lo serth J. Dr., „Das St. Pauler Formular" (Prag 1896) S. 39, Nr. 22 fülırt ein Dokument an, welches in den J. 1291-96 von Kunigunde, Äbtissin zu St. Georg, ausgestellt sein soll. Das Datum ist gut berechnet, der Name der Äbtissin aber ist falsch. In der Handschrift sind die Namen ausgelassen, Loserth hat ihn aus einer Urkunde vom J. 1305 ergänzt. Im J. 1305 war Kunigunde ohne Zweifel Äbtissin zu St. Georg, sie bekleidete aber diese Würde erst vom J. 1302. Ihre Vorgängerin hieß Sophie. Sie wird im „Fragmentum Praebendarum ecclesiae s. Georgii", einer Hdschr. des 14. Jdts. aus dem Georgskloster in Prag, erwähnt - Sophia abbatissa, que fuit ante Gunegundem, D o b n e r, Mon. hist. Boem. 6, 347 und ebenso in einer Urkunde v. J. 1300 (Emler, R. B. 4, 757, Nr. 1926): Sophia, abbatissa. s. Georgii facit commutationem bonorum cum sorore sua Margaretha. Ob Soplie anch in den Jahren 1291 bis 1296 Äbtissin war, können wir nicht angeben es liegt auch jenseits unserer Aufgabe. Im J. 1285 ist als Äbtissin Dobromira belegt. (Emler, R. B. 2, 579, Nr. 1343).

2) Franz von Prag teilt mit (F. R. B. 4, 353): tradita fuit duci Mazonie, cum quo plures pueros generavit. Ipso defuncto fuit abbatissa ad sanctum Georgium in castro pragensi. . . Diese Erzählung ist durchwegs unrichtig. Ihr Gatte ist erst 1313 gestorben - sie war damals längst Äbtissin von St. Georg; aus der Ehe ist cine Tochter und ein Sohn entsprossen. "Domina Perchta; dominae abbatissae, filiae regis gnata d dürfte vielleicht ihr uneheliches Kind sein (angef. in einem Kodex der Prager Univ.-Bibl., hrg. von D o bn er: Mon. histor. Boemiae, 6, 330). Dobner und Balzer 1. c. halten sie für die Tochter Boleslavs, obwohl diese in einer polnischen Quelle Eufrosca genannt wird. Vgl. weiter.

s) Hrg. von Dobner: Mon. hist. Boemiae 6, 334 und angetührt ljei Truhlář: Catalogus codicum manuscriptorum latinorum ces. reg. bibl. Prag Nr. 2245 .

4) Pulkava sagt l. c. „facta est succedentibus temporibus abbatissa ". Er hat hier das Wort "quattuor (succedentibus temporibus) ausgelassen, welches erst dem Satze deu richtigen Sinn gibt. Seine Nachricht ist dann mit der des Codex Si. Joannis sub Rupe wörtlich übereinstimmend: 
tember. Die Verläßlichkeit des Datunss ist auch durch die Notizen der religiösen Bücher (haupts. Breviere) nachgewiesen, welche Kunigunde zur Zeit ihrer Verwaltung schreiben ließ und welche sich jetzt in der Prager Universitätsbibliothek befinden. Die Notizen haben gewöhnlich die folgende Form: a. d. 1319 Chunegundis, abbatissa monasterii s. Georgii in castro Pragensi, Ottacari II. filia, istum librum .... fecit scribi et contulit ecclesine s. Georgii benediccionis sue anno decimo octavo". Die Anwendung des Titels ,abbatissa“ in Verbindung mit ,benediccio“ beweist, daß es sich nicht um die Benediktion bei der ,mutatio habitus", sondern um die bei der , constitutio abbatis" handelt. Solche Schreibernotizen finden wir in den Handschriften - bei Truhlár: Catologus cod. lat. Prager Univ. bibl. - Nr. 2156, 2157, 2335, 2521, 2544, und sämtliche führen als ,annus benediccionis* das Jahr 1302 an. Urkunden, welche Kunigunde als Äbtissin der Benediktinerimnen von St. Georg kemnen, sind erst vom Jahre 1305 vorhanden ${ }^{1}$ ) und reichen bis 1321 Nov. 19. An diesem Tage hat die sterbende Königstochter ihre letztwillige Verfügung gemacht (Emler, R. B. 3, S. 299 Nr. 736). Der Kgs. Chr. nach ist sie am 27. November verschieden ${ }^{2}$ ); an diesem Tage, lant der schon zitierten Hdsft. .Fragmentum praebendarum*, beging auch der Nonnenkonvent von St. Georg die gottesdienstliclue Feier zu ihrem Andenken ${ }^{3}$ ). Das Datum der Kgs. Chr. erweist sich dadurch als richtig. - Die Nachricht der Kgs. Chr. wiederholt Franz von Prag (F. R. B. 4, 394) und mit einer gewissen Modifikation Beneš Krabice (F. R. B. 4, 477).

Codex Synchronus m. s. bibl. Pulkava (F. R. B. 5, 181 - die s. Joannis subRupe (apud Dobner, böhm. Übersetzung Seite 314):

Mon. hist. Boemiae, 6, 373, Anm. t.):

Anno M. CCC II, XI kal. augusti Gunigundis, soror regis Wenceslai II., reiigionem suscepit apud s. Georgium in castro pragensi, quattuor succedentibus temporibus abbatissa lacta, monasterio multa bona contulit.

Anno domini M CCC II ${ }^{0}$, XI0 kal. augusti, Cunegundis, soror regis Wenceslai secundi, religionem assumpsit aput sanctum Georgium in castro pragensi et facta succedentibus temporibus abbatissa, monasterio multas obtinuit libertates.

Wir können vermuten, daß Pulkava seine Nachricht diesem Kodex entlehnte, ein Moment, das für die Kritik seiner Überlieferung nicht belanglos ist.

1) Emler: R. B. 2, 890, Nr. 2064; ibid. 2, 893, Nr. 2069; ibid. 2, 907, Nr. 2102 ; ibid. 3, 127, Nr. 316; ibid. 3, 270, Nr. 639.

2) Seite 415, 2. Buch, Kap. 10. „Anno 1321 generosa, deo devota domina, quondam regis $O$. filia, dicta Chunigundis, Vo kal. dez. moritur et in suo monasterio, ubi multis annis utiliter abbatizaverat, sepelitur". kal. dez.œ.

3) Dobner: Mon. historica Boemine 6, 353 , et in sno anniversario $V$. 
Die Kenntnis 0.'s reicht nicht so weit, er führt den Lebenslauf Kunigundens nur bis zu ihrer Heirat mit dem Herzog Boleslav II. im J. 1290 oder 1291 und sagt: lassen wir sie da bleiben und gehen weiter! Warum sagt er das? Die erste mögliche Antwort ist, daß er von der Rückkehr Kunigundens und von ihrer neuen geistlichen Würde nichts gewußt hat, weil er vor 1302 schrieb. S. bekämpft diese Schlußfolgerung: „man soll die Möglichkeit offen lassen, sagt er, daß 0. zwar von den späteren Schicksalen Kunigundens gewußt, aber absichtlich an jener "Stelle nichts davon gesagt habe" (Einl. 82).

Diese Schlußfolgerung ist abor kaum richtig, oder wenigstens in der zu großen Vorsicht nicht. Sie ist doch ein wenig gezwungen. Wir vermuten, was S. dazu führte: die Kenntnis des ganzen Materials und die aus der Gesamtheit des Eirzählten geschöpfte Überzeugung. S. lagen zuch nur ungenaue Daten vor (Kunigunde 1305 Äbtissin, stirbt 1312); die Operation mit ihnen mußte zu Fehlschlüssen führen; und drittens sind die Worte "nû lâz wir si belîben dâ" anders zu deuten, als es S. getan hat. Sie sind eine bloße Übergangsformel zur Charakteristik der jüngeren Tochter Ottokars, mit welcher sich der Dichter befassen will: nû lâz wir si belîben dâ und sagen von der andern magt ... Eine ähnliche Übergangsformel findet man z. B. in der Rehr. Vers 18414, S. 244: „wie lang er [Záviš von Falkenstein] des kunigs [Wenzels II. von Böhmen] phlac, daz lâz wir ieze under wegen und grîfen her wider, wie die Osterrîche sider fuoren heim "; von den böhmischen geht 0 . zu den österreichischen Angelegenheiten über.

S.'s Vorsicht scheint mir nicht berechtigt zu sein; ich halte die von ihm bezweifelte Annahme für richtig: weil 0 . von dem Lebenslauf Kunigundens nach ihrer Heirat mit Boleslav II. von Mazovien nichts wußte, geht er zu ihrer Schwester über; er hat nichts gewußt, weil die Nichricht vor 1302 abgefaßt wurde - oder sollte auf einmal sein Gedächtnis aufgehört haben? Möglich, aber doch nicht wahrscheinlich. Wenn er schon dabei ist, in einem Exkurs ihr ganzes Leben zu schildern und in Einzelheiten einzugehen - Einzelheiten, welche wirklich unbedeutend sind -, hätte er sich da nicht ihrer Rückkehr und ihrer neuen Würde erinnert? Bei der Genauigkeit seiner Informationen, bei dem nicht uninteressanten Plus seiner Erzählung ${ }^{1}$ ) und bei szinem guten

1) 0 . spielt auf den, für eine Nonne nicht gerade makellosen Lebenswandel Kunigundens an (ohne dabei ein Moralist zu sein). Vgl. oben. Dadurch bekommen zwei bisher dunkle Stellen anderer Autoren eine bessere Beleuchtung. Der pol$n$ ische Franziskanermönch hat sie, weniger geschmackvoll als $O$. als spessima bezeichnet, ohne einen Grund anzuführen. (Mon. Pol. Hist. 3, 47 : Boleslaus 
Willen, die ganze Familie Ottokars und ihre Schicksale vorzuführen, wäre es unlogisch vorauszusetzen, daß er den zweiten Teil des Berichtes verschwiegen, oder daß er davon nichts gewußt hätte. Die Nachricht entspricht nach meiner Meinung den Verhältnissen vor dem J. 1302, und zwar hat der Dichter hier eine ältere (heute sonst unbekannte) Aufzeichnung in sein Werk übernommen. Diese Annahme entspricht gut dem heutigen Stand der Forschung, welche die Nachrichten der Rchr. eher auf die schriftlichen Quellen, als auf die persönliche Erfahrung zurïckführen will. Wie konnte auch der Dichter, ein Steirer, der, wie ihn S. schildert, ein ganz bescheidener Mann und dessen soziale Stellung nicht hoch war (Einl. $91 \mathrm{ff}$.), über die Verhältnisse der böhmischen Königsfamilie so genau unterrichtot sein? Wie konnta es geschehen, wenn 0. diese Partie um 1308 schrieb (S.: die ersten 20000 Verse sind vor 1308 entstanden. Vgl. oben), daß er die ältere und auch belanglose Geschichte Kunigundens vollständig angeführt hat und die neue, ihm zeitlich nahe, völlig vergab? Man kann auch sehr bezweifeln, daß ein Bericht von Mund zu Mund alle die Einzelheiten bewahrt hätte, welche 0 . da bringt: wie das Kloster heißt, wo es liegt, welcher Orden, wen sie geheiratet hat. Solche Details pflegt die mündliche Überlieferung, besonders wenn es sich um eine fremdeNation und eine fremde Herrscherfamilie handelt, kaum festzuhalten. Auch die Worte „ich hôrte aber sît“ (Vers 17 746) sind nicht beweisend. Wir müssen sie nicht auf persönliche Erfahrung beziehen; sie werden als eine geläufige Formel angewendet, auch dort, wo sicherlich eine schriftliche Aufzeichnung vorliegt (S. Linl. 64). Aus diesen Gründen wäre ich nicht abgeneigt, eher eine unbekannte Vorlage anzunehmen, welche vor $1302 \mathrm{zu}$ setzen wäre ${ }^{1}$ ).

.. de sorore regis Bohemie [Wenceslai] pessima, moniale professa, genuit Wankonem et Eufroscam). Ich glaube, dab auch $\mathrm{Neplach}$ eine ähnliche Nachricht vorlag, denn er schreibt: 1290 Kunegundis, timore dei abiecto, de ordine sancti Francisci exivit. (F. R. B. 3, 477).

1) S. macht auf die Erzählung der gleichzeitigen Annales Ot tocariani als Vorlage O's aufmerksam (S. 235, Anm. 2): Anno domini 1277 Otakarus, immemor spon. sionis suae, filiam suam, quam desponsaverat N. filio Rudolfi, electi Romanorum, reclusit eam in monasterium sancti Francisci, subiiciens eam regulae et religioni, quae vocatur religio pauperum dominarum. Intraverunt et aliae cum ipsa decem virgines ... Huius puellae assumptio monasticae vitae ... reputabatur initium fuisse totius mali (des neuen Krieges zwischen Ottokar und Rudolf und der Niederlage des ersteren. F. R. B. 2, 329). Diese Nachricht hat meines Erachtens mit der 0.'s nichts gemeinsam; sie ist sachlich, sowie auch in der Auffassung verschieden, außerdem weisen beide ein gegenseitig verschiedenes Plus aut. Zusammenhängend wie $O$. bringt den Lebenslauf Kunigundens Franciscus Pragensis (F. R. B. 4, 353), aber an eine gemeinsame Ableitung ist nicht zu denken. 
Die Resultate der kritischen Untersuchungen S.'s über den Verfasser der St. Rchr. und seine Lebensverhältnisse sind jedoch nicht definitiv - S. sagt es selbst (Einl. $58 \mathrm{ff}$.). Wir müssen deshalb uns immer noch die Möglichkeit, die Nachricht rühre von 0. selbst her, vor Augen halten. In diesein Moment kompliziert sich aber unsere Aufgabe. Bisher haben wir die Parenthesis über die Kinder Ottokars, welche in der Rchr. vor den Schiedspruch der Vertranensmänner über die Friedensbedingungen zwischen Böhmen und Rudolf gesetzt ist, kompositionell als einheitlich aufgefaßt. In dem Moment aber, in dem wir sie für eine persönliche Erfahrung des Dichters erklären, dürfen wir kaum die Wor'e ,ich hôrte aber sît* als eine bloße Formel betrachten. Sie können da eine gute Bedeutung haben: Was vor 17746 liegt, ist um das Jahr 1278 entstandeu, der ursprüngliche Kern des Berichtes. Nach 1290 (nnd vor 1302) wurde ihm ein Nachtrag hinzugefügt, in dem 0 . den Lesern mitteilte, daß Kunigunde nach Polen geheiratet hat. Demnach wäre der Bericht über Kunigunde zeitlich als zweistufig zu betrachten. Es gibt aber noch andere Lösungen; zwischen ihnen zu entscheiden ist vorderhand - vielleicht auch in der Zukunft - unmöglich.

Die jüngere Tochter K. Ottokars. Die zweite Tochter Ottokars, Agnes, wird mit großam Lob bedacht - im Gegensatz zu ihrer Schwestrr und auch darum, weil sie die Gemahlin des Sohnes Rudolts werden sollte. Sie ist die kiusche und diu schoene, die saeldenbaere. (18056 = Glück bringende).

Vers 17760 tugend und klârheit ir die jâhen, darzuo kiuseh und zuht

lac an ir mit genuht.

Diese Verse sind nicht die einzige Stelle, wo 0. von ihr spricht 1 ). Sie kehrt, das nächstfolgende, wo über die Iglauer Hochzeit referiert wird, nicht eingerechnet, noch dreimal in der Erzählung wieder, (Vers 20186 , S. 267 ; 22815 ff. S. $301 ; 93863$, S. 1218), aber nicht in derselben Weise.

In der Schlußpartie der Rchr. ist der Dichter mit seiner Darstellung zur Ermordung K. Albrechts gelangt. Den Mord hat Johann, Agnes' und Herzog Rudolfs Sohn, verübt. O. hat niclit genug abschreckende Worte und Beispiele (vom Brudermord Kains angefangen), un die Tat zu charakterisieren. Er leitet seine Erzählung mit einer

1) Kunigunde tritt in der Rchr. nur in der genannten Partie 17739 auf. 
Versammlung der Teufel ein (S. 1217): auf Gebot des höchsten Luzifer gelobt Satan Johann zur Ermordung seines Oheims aufzustacheln, er nistet sich in sein Herz V. 93860, „ob er darinne iht funde bêheimischer tucke, die in nâch ungelucke von sîner muoter erbten an und von dem ungetriwen man, sînem enen [Großvater], kunig Ottackern..." Wenn 0. die Verse 17760 nach der Ermordung Albrechts (nach dem Jahre 1308) geschrieben hätte, würde er sicher über Agnes einen nicht so schmeichelhaften Ton angeschlagen und an der Heirat Agnes' mit Herzog Rudolf keinen so sichtlichen Gefallen gefunden haben. Wir können deshalb im allgemeinen dem Herausgeber zustimmen, daß diese Partie (S.: bis 20000) vor 1308 abgefaßt wurde ${ }^{1}$ ).

Wir haben dem Kgs. Abt mit der Behauptung, daß er die theverlöbnisse der Kinder Ottokars und Rudolfs in ihrer definitiven Form nicht kennt, ein wenig Unrecht getan. Er kennt sie, aber er setzt sie um zwei Jahre früher in seiner Erzählung an (Kap. 7, S. 48): „a. d. 1276 [Rudolf und Ottokar] fedus pacis per heredum suorum contractum matrimonii duraturum iugiter firmaverunt; Rudolfus duxit Agnetem, Gutaque nupsit Wenceslao (und fügt das Geburtsjahr Wenzels und Gutas hinzu)". Die Form des Ehevertrages ist die des Jahres 1278; zwei Jahre vorher war er anders und nicht so bestimmt formuliert (BöhmerRedlich Reg. 623). Dem Kgs. Abt ist folglich der definitive Ehevertrag vom Jahre 1278 nicht entgangen; aber die Einreihung und die Motivierung, sowie auch die Form der Bedingungen (im Vergleich mit der Rchr.) zeigen, daß der Kgs. Bericht von dem 0.'s völlig verschieden ist.

\section{Záviš von Falkenstein.}

Eine Individualität, die längst das Interesse der Historiker ${ }^{2}$ ), wie auch der schönen Literatur ${ }^{3}$ ) erweckt hat. Von Palacký rührt der erste

1) Wir haben in der I. Partie drei Daten gefunden, welche zur Bestimmung der Abfassungszeit der Rchr. nützlich sein können. Nach 1289, vor 1308 und vor 1302; das letzte Datum ist jedoch sehr schwer zu benützen und mit den anderen in Einklang zu bringen.

2) Das vollständige Verzeichnis der historischen Arbeiten über Z. siehe bei Zíbrt, Bibliografie ceské historie 1, S. 343, Nr. 9048. Der erste Teil ist im J. 1900 erschienen. Als kritische Fortsetzung dieses breit angelegten Werkes kann die Bibliographie der böhmischen Historie, die seit dem Jahre 1905 in der Beilage des Ceský casopis historický erscheint, betrachtet werden.

s) Und zwar der deutschen sowohl als auch der böhmischen. Über die böhmischen Themas in der deutschen Literatur handelt das hübsche Werk von Arnošt 
wissenschaftliche Aufsatz übar ihn her ${ }^{1}$ ). Wenn seine Abhandlung noch ein apologetisches Gepräge trägt (eine Abwehr gegen die Beschuldigungen zweier Mönche: von Fürstenfeld und von Königsaal), so sind die neueren Arbeiten weit über diesen Standpunkt hinausgelangt.

Wir verzeichnen - von den eng genealogischen Arbeiten abgesehen - zwei Biographien. Die erste hat M. Pangerl in den Mitt. des Ver. für Gesch. der Deutschen in Böhmen (10. Jahrg. 145ff.) im J. 1872 veröffentlicht. Eine Arbeit, die den Menschen noch nach den guten und schlechten Eigenschaften werten wollte - das Urteil war ungünstig für Záviš ausgefallen. Sie bedeutete hauptsächlich in den genealogischen Ausführungen einen Fortschritt, sonst ist sie - manchmal naiv und schon veraltet. Die zweite Monographie erchien im Jahre 1895 in Česky časopis historický, 1. Jahrg. (S. 69 ff.). Der Verfasser J. Susta hat in der Darstellung der sozial-wirtschaftlichen Zustände des böhmischen Adels am Ausgange des 13. Jhdts. die Basis geschaffen (damals war der Gedanke ganz neu), aus welcher sein Z. emporwächst. Er hat auch die Urkunden vollständiger herangezogen und versucht, durch ihre Kombination mit den erzïhlenden Quellen, die Wege und Ziele der ehrgeizigen Politik Z.'s zu ermitteln.

Dan Biographen steht die zweite Gruppe von Arbeiten zur Seite, welche von der allgemeinen politischen Geschichte Böhmens ausgehend zur Charakteristik der Persönlichkeit Z.'s gelangt sind. Die Reihe von Forschern eröffnet wieder F. Palacký (ich benütze die sechste Ausgabe: D. N. Č., $2^{6}$, Seite 115) und ihm folgt B. Dudík: M. A. G. 7, Seite $75 \mathrm{ff}$. Sie sind noch nicht zu einer vollen Wertung der Person Z.'s gekommen; seine Regentschaft stellt ihnen eher eine kurze Episode der böhmischen (innerpolitischen) Geschichte dar, die vielleicht menschlich interessant, historisch eine untergeordnete Rolle spielt. Erst Redlich, durch einen neuen Fund geführt, hat Z. eine größere Bedeutung beigemessan und seine Politik mit dem Streben nach der Wiedererrichtung der Großmachtstellung Böhmens in Zusammenhang gebracht (Mitt. d. Inst. Ergbd.

Kraus: Stará historie česká v nèmecké literatuře, Prag 1902, welches zeitlich bis 1278 geht. Der achte Abschnitt ist Přemysl Ot Il., Kunigunde und Záviš gewidmet. Kraus führt uns von dem Drama des schwäbischen Dichters Werthes aus dem 18. Jahrhundert und über Grillparzer und Horn bis zum Romane von A. Sperl: Die Söhne des Herrn Budiwoj, 1897. Als das letzte Glied in der Reihe der böhmischen Literatur ist das dramatische Werk von Jar. Hilbert: Falknštejn (Prag, 1901) neu in der Auffassung, jung und frisch in der Behandlung zu nennen. Der Stoff wurde schon im 1ó. Jdt. literarisch behandelt, vgl. das Reimwerk über Záviš in F. R. B. 3, S. 240 .

1) In Čas. čes. Musea 1831 „O panu Závišovi z Rosenberka"; nen in Palackýs ¿Spisy drobné« 2, S. 40 gedruckt. 
4, 1893: Zur Geschichte der österreichischen Frage unter König Rudolf I., S. 150 ff.). Ihm schloß $\left.\operatorname{sich}^{1}\right)$ Bach mann (G. B. 1, 1899, S. 672) und Graebner an ${ }^{2}$. Hauptsächlich Graebner verdanken wir die prägnante Deutung einzelner urkundlicher Nachrichten und ihre Verbindung zu einem wirksamen Bild der Politik Böhmens seit Premysl Ottokars Tod; er geht jedoch manchmal zu weit und ist geneigt, zu starke Farben anfzutragen. Seine Resultate wurden von J. B. Novák in einer sehr soliden Arbeit und unter Heranziehung eines neuen Quellenmateriales der Nachpriifung unterzogen und in vieler Hinsicht korrigiert und ergänzt $\left.{ }^{3}\right)$.

Graebner hat versucht, auch von einer anderen Seite auf die Geschichte Böhmens nach 1283 ein nenes Licht zu werfen (M. V. G. D. in B. $42,168 \mathrm{ff}$.). Er will in die Filiation der erzählenden Quellen eine neue Ordnung bringen; für einen Teil der Kgs. Chr. (vom J. 1283 bis 1308) hat er eine verloren gegangene annalistische Aufzeichnung supponiert, die von Pulkava, möglicherweise auch von Beneś Krabice benutzt wurde. Er stellte diese Hypothese auf; zu ihrer Lösung hat er nicht viel beigetragen, auf Grund nur flüchtiger Erhebungen ist er zu weit gegangent). Weniger ist die nichtböhmische Überlieferung von ihm beachtet worden; die Rchr. ist bloß zitiert.

Dieser Weg ist nicht neu und nicht von ihm als ersten betreten; wir begegnen da wieder den Namen Palacky's und Dudík's (l. c.), welche beide eine umfassende Quellenkenntnis hatten und Quellenkritik übten. Zu einer klaren Erkenntnis der ursprünglichen und der abgeleiteten Quellen sind sie jedoch nicht gelangt. Vor Graebner hat sich noch Bachman $n^{5}$ ) mit den Quellen zur Geschichte Z.'s beschäftigt. Er zeigte, daß Otto von Thüringen, dex Verfasser der ersten 51 Kapitel der Kgs. Chr., auch die österreichischen Annalen benützt hat ${ }^{6}$ ); aber

1) Zuerst ¿̌́usta in dem schon genannten Aufsatze im Ces. čas. hist. 1, 296 an.

2) Graebner F., Böhmische Politik vom Tode Ottokars II. bis zum Aussterben der Přemysliden. Mitt. ^. Vereins f. Gesch. der Deutschen in Böhmen, Band 41, $42(1902-4)$.

3) J. B. Novák, $\mathrm{K}$ nové literatuře a nově nalezeným pramenům o Václavovi II. Ceský časopis histor. 12, $196 \mathrm{ff}$. Die Inaugural-Dissertationen von W. P f e f f e r, Die böhmische Politik unter K. Wenzel II., Halle 1901 und ron G. Ry ll, Die böhmische Politik bei der Königewahl Adolfs ron Nassau, Marburg 1909 - sind wertlos.

4) Vgl. Novotn ý, l, c. Einl. 47.

5) Die Editoren Kopke, Enler, Jirccek, Loserth u. a. nicht eingerechnet.

a) Vgl. was Novotný, Einl. 38 darüber sagt.

Blitteilungen XXXIIII. 
seine Quellenübersicht zur Historie Z.'s (die übrigens nicht vollständig war) führte zu keinem Ergebnis 1 ).

Die Überlieferung über die ersten Regierungsjahre Wenzels II. ist reichhaltig genug. Die Geschichte Z.'s ist nicht auf die böhmischen Chroniken beschränkt geblieben; sie hat in die österreichischen, bayerischen und polnischen Aufzichnungen Aufnahme gefunden; sogar eine Straßburger Quelle führt einige Motive von ihr an. Eine ausführliche Schilderung hat ihm der steierische Chronist gewidmet. Diese mittelalterlichen Geschichtswerke sind die Grundlage der spüteren Aufzeichnungen geworden, welche mannigfaltig verschönert und erweitert sich bis in die neueste Zeit (bis zur kritischen Auftretung Palackýs, in der Belletristik noch länger) erhalten haben. Auf diese neuere Überlieferung werde ich nicht eingehen; sie ist im Großen und Ganzen für unsere Untersuchung von keiner Bedeutung.

A. Die böhmischen Quellen. Die Überlieferung der böhmischen Quellen ist nicht einheitlich. Auf einer Seite stehen die mit der Kgs. C'hr. verwandten Erzählungen (Gruppe A). In der chronologischen Ordnung folgt der Kgs. Chr. Franz von Prag (um 1350) ${ }^{2}$ ); er hat größtenteils die Kgs. Erzählung fast wörtlich übernommen (vgl. J. Loserth: Archiv f. öster. Gesch. 51, S. 451) und hie und da etwas ergänzt. Hierïber sind die Meinungen ungeteilt. Auch über Beneš Krabice ${ }^{3}$ ) (vor 1375) und Pulkava ${ }^{4}$ ) (um 1374) sind die Forscher bisher einig gewesen. Man hat Loserth beigestimmt, der meint, daß Beneš die Nachrichten der Kgs. Chr. erst mittelbar durch Franz von Prag kennen gelernt hat5). Pulkava soll hingegen sowohl die Kgs. Chr., als auch das

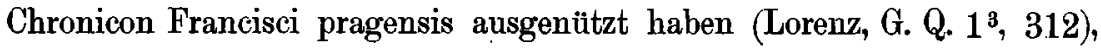
nach Emler auch die Chronik des Domherrn Beneš Krabice (Emler F. R. B. 5, Einl. 5). Graebner stellte, wie ich schon erwähnt habe, eine neue Filiation auf.

1) Beiträge zur Kunde böhmischer Geschichtsquellen des 14. Jhdts. III. Die Kgs. Chr. und Záviš von Falkenstein. M. V. G. D. in B. 36, 277 ff. - Bachmann hat sich nicht ejnmal die Mühe genommen, zu den einzelnen Berichten Stellung zu nehmen.

2) Die Chronik ist in F.R. B. 4, 347 von Emler vollständig ediert worden. Loserth hat in seiner Edition alles, was Franz aus der Kgs. Chr. ausgeschrieben hat, hinweggelassen. (F. R. A. Scriptores 8.)

s) Ediert in F. R. B. 4, 4.59 .

4) In F. R. B. 5, $170 \mathrm{ff}$.

5) J. Loserth, „Die Chronik des Beneš Krabice von Weitmühl». A. Ö. G. 53, 315. Vgl. Lorenz: G. Q. 13, 309 und Emler: F. R. B. 4, Einl. 26. 
Auf die Ermittelung des Verhältnisses dieser vier Quallen untereinunder kann ich an dieser Stelle nicht eingehen; ich habe es in den vorbereitenden Studien getan, so weit ich es für meine Arbeit branchte, aber die Untersuchung hat zu keinem sicheren Resultate geführt. Es hat sich gezeigt, daß alle vier Quellen sehr eng zusammenhängen: man kamn nicht nur auf einzelne Motive, sonderm auch auf identische, sich wiederholende Redewendungen und Phrasen hinweisen. In welcher Weise jedoch die vier Schilderungen von einander abhängig sind, ist unsicher. Es scheint, als ob Beneš und Pulkava einander näher stünden und die betreffende Partie der Kgs. Chr. (in ihrer heute bekannten Fassung) nicht unmittelbar benutzt hätten, sondern, daß sie vielleicht gemeinsam einen Auszug von ihr verwendeten. (Vgl. auch Novotný 47, Anm. 47.)

Die Kompilation Pulkava's ist stark in Gebrauch gekommen; sie wurde mehrmals abgeschrieben und sowohl in das Böhmische als auch das Deutsche übertragen ${ }^{1}$ ). Die fehlerhafte böhmische Übersetzung der Rezension A. Pulkava's war eine der Quellen des Gedichtes über Z., diss in einer Handschrift des Vyšehrader Kapitels eingetragen erscheint ${ }^{2}$ ) and die Kennzeichen des 15. Jdts. an sich trägt. Die anderen Motive dieses Gedichtes führen uns zur Gruppe B., aber auch über die Grenzen Böhmens hinaus.

Eine zweite Gruppe (B) ist nicht einheitlich, sondern nur eine $\mathrm{Zu}-$ sammenfassung verschiedener Erzählungen. Den ersten Platz, was die Bedeutung anbelangt, nimmt die böhmische Reimchronik, der sogenannte Dalimil (um d. J. 1314 verfaßt) ein; man muß jedoch noch zwischen deu Handschriften unterscheiden (F. R. B. 3, Seite 193, 196, 200). Den Begebenheiten steht auch Heinrich von Heimburg nahe (F. R. B. 3, Seite 317, 320); später (Mitte des 14. Jdts.) ist Neplach (F. R. B. 3, Seite 477). In diese Gruppe können wir zum Teil auch das schon erwähnte Reimwerk über Z. einbeziehen, welches als seine zweite

1) Ihre Erzählung ist auch in das Geschichtswerk des Krakauer Domherrn, Dlugosz $(\dagger 1480)$ übergegangen: Histor. Pol. 2. Teil, Seite 497 ed. Alex. Przezdziecki, curavit Ignatius Žegota Pauli.

2) Hrg. in F. R. B. 3, 240 als ein Nachtrag zur Chronik Dalimils. Leider hat der Herausgeber das Gedicht bloß aus dem Drucke übernommen und ist auf keine Kritik eingegangen. Über dieses Gedicht besitzen wir eine kritische Studie von J. Šusta, Píseñ o králi Přemyslu Otakarovi a Záviši. Ceský časopis historický 2, 206-209. Sie bringt zwar keine definitiven Resultate - auch Šusta hât die Handschrift nicht in den Händen gehabt - aber sie gibt eine Belehrung über die Heimat und die Hauptquellen des Gedichtes, ich snge nicht über alle. Das - dem Z. günstige Gedicht - soll nach 1420 und in Südböhmen, wahrscheinlich am. Hofe dex Herren von Rosenberg (?) entstanden sein. 
Quelle den Dalimil gründlich benutzt hat'1), und endlich die eigentümliche Erzählung der Rez. B Pulkavas, die von der Rez. $A^{2}$ ) absticht und einige individuelle Nachrichten ausgenützt zu haben scheint (F. R. B. $5,170 \mathrm{ff}$.$) .$

B. Die nicht böhmischen Quellen. Von den nicht böhmischen Darstellungen soll zuerst die bay e rische Überlieferung ,Cronica de gestis principum " erwähnt werden (Boehmer, F. R. G. 1, 8 ff.), welche sich ausführlich mit der Person Z.'s beschäftigt. Loserth behauptete, daß sie ,aus der Kgs. Chr. einen förmlichen Auszug bringt“3). Ich möchte dieser Behauptung (der Beweis fehlte) nicht beipflichten, insoweit ich von meinem engeren Arbeitsgebiete dazu berechtigt bin. Die Erzählung des Fürstenfelder Mönches über Z. (ein einziges Motiv und die Tendenz ausgenommen) schließt jede direkte Abhängigkeit aus.

Andere (deutsche) Chroniken bringen nur kurze Notizen über Z. und Kunigunde: so die Continuatio Vindobonensis (SS. 9, 713, 716), Hermanni Altahensis continuatio (SS. 17, 411); dessen Nachrichten hat Eberhardus Ratisponensis ïbernommen und erweitert (SS. 17, 593). Auch in eine entferntere Quelle hat die Historie Z.'s Aufnahme gefunden: in die Chronik des Mathias von Neuenburg4) (1273-1350; vgl. über ihn neuestens Jansen: „Historiographie und Quellen der deutschen Geschichte bis $1500^{\text {* }}$ in Meisters Grundriß 1, $524 \mathrm{ff}$.). Es ist zu bedauern, daß er die Schicksale Z.'s nur streift - wegen der Hypothese, welche $K$. Rieger ${ }^{5}$ ) und mit ihm eine Reihe von Forschern, auch S.6), an seime Chronik angeknïpft haben ${ }^{7}$ ). l. c. 206 .

1) In wie weit das Gedicht von Dalimil beeinflußt wurde, siehe bei Šusta,

2) Ich wende da die Bezeichnung Emlers als die des Herausgebers an, obwohl das zeitliche Verhältnis der Texte umgekehrt ist (Vgl. F. R. B. 5, Einl. 19).

s) F. R. A. 1. Abt., 8, 1875, Seite 10. Emler (in F. R. B. 4, Einl. 14) und š u ta sind nicht abgeneigt ihm zu folgen (Šusta in Ceský časop. historický 1, 290).

4) Hrg. von Boehmer, F. R. G. 4, 159.

5) Im A. O. G. 48 , S. 305. Er meinte, Mathias habe eine hente verschollene Geschichte des Hauses Habsburg verwendet, deren Spuren auch bei anderen Autoren des 13., 14. und 15. Jahrhunderts (z. B. bei dem Fürstenfelder Mönch, bei O.) zu finden sind. Sie rühre aus der Feder Bischof Heinrichs I. von Konstanz (12931306) aus dem Hause Klingenberg her, der seiner Zeit Kanzler des Königs Rudolf war.

6) Einl. 59: „aus den Übereinstimmungen der Rchr. mit Mathias von Neuenburg habe ich eine neue Bestätigung für die Riegersche Hypothese geschöpft, daß es eine verlorene Geschichte des Hauses Habsburg gegeben habe müsse ...*

7) und mit welcher sich $\nabla$ ictor Thiel in einem vorzüglichen Aufsatze in M. I. Ö. G. 20, S. 567 ft. unter dem Titel „Die Habsburger Chronik Heinrichs von 
C. Die letzte Gruppe bildet die steierische Rchr. und die von ihr abhängigen Erzählungen ${ }^{1}$ ): die österreichische Chronik von den 95 Herrschaften (M. G. Deutsche Chroniken 6, 1909, S. 137, 140; früher Hagen gen.) und - der Meinung des Herausgebers nach - auch der Abt von Viktring (SS. rer. Germ. 1909, I, S. 280). Im zweiten Teile dürfte die Notiz des Chronisten eher mit der Chronik „De gestis principum * verwandt sein, oder stellt sie eine verdorbene Überlieferung der Rehr. dar?

Palacky hat noch die Rchr. prinzipiell der Kgs. Chr. gegenüberübergestellt't); S. ist zu einem anderen Schlusse gelangt: 0 . habe die Person Z.'s durch die Kgs. Chr. kennen gelernt.

In der Rchr. tritt zum erstenmale die Person Z.'s Vers 17062 (S. 226) hervor — und zwar gleich in Verbindung mit der Königin Kunigunde.

,Die Schlacht am Marchfelde (1278) ist für König Rudolf ausgefallen, Ottokar tot. Der steirische Dichter hält ihm einen Nachruf. Ottokar war Diener ,der Welt' und rang nach weltlichem Ruhm. Die ,Welt' hat ihn auch belohnt - er vergoß Menschenblut, die ,Welt' ließ ihn im eigenen Blut ertrinken'...

17032 „er was mit unkiusche sô gar gehôrsam der uppigen lazheit, daz si vertreip ûz sines herzen sinne die tugentlichen minne." Die Untreu hat er gebüßt. 17057: sin wip, die kuniginne..mit fremder minne unstaetikeit bî im phlac; unde dô er tôt gelac, den hôhen

Klingenberg “ beschäftigt und sie als vollkommen unzulänglich bezeichnet hat: ,die Berührungen einer Reihe von Geschichtsschreibern setzen keineswegs das Vorhanclensein einer gemeinsamen Vorlage voraus; Rieger ließ die Fortpflanzung durch die mündliche Überlieferung außer Acht, welche bei dem Charakter der in Frage kommenden Parallelstellen unbedingt berücksichtigt werden muß, und die Kritik der historischen Zeugnisse, welche von einem Geschichtswerk des Bischof Heinrich ron Konstanz über die Habsburger Kunde geben, zeigt, daß dieselbe niemals existierte, und da $\mathrm{B}$ die betreffende Notiz Manlius's in Chronicon episcopatus Constantiensis auf Irrtum beruht:. - Thiel macht auf das Moment aufmerksam, daß die von Rieger besprochenen Berührungen fast durchwegs eine Anekdote ans dem Leben Rudolfs zum Inhalte haben und daß deshalb nicht ansgeschlossen sei, daß die genannten Autoren eine Anekdotensammlung über König Rudolf verwendeten.

1) Ich habe diese Gruppe von den übrigen Chroniken abgetrennt, weil wir erst ihre Stellung und ihr Verhältnis zu denselben kennen lernen wollen.

2) Vgl. D. N. C. 6, Seite 160, Anm. 294. Palacký hat gegen die Rchr. - als einen historischen Roman - ein großes Mißtranen gehegt $\left(2^{8}, 82\right)$; dennoch hatte er von ihr in seiner Erzählung reichlich Gebrauch gemacht und ganze Partien ins Böhmische übertragen. (2a, Seite 27 und 124). 
kunic, sô man sagt, mit dem Zaewisch si verklagt'1). — Das war der Lohn der Welt" 2 ).

Die bayerische Fürstenchronik bemerkt zun Tode König Ottokars: folgendes :

„Lugebat nimirum etiam regina cum duobus liberis suis scilicet cum filio et filia; sed utrum seriose fleverit, deus, quem nullum latet secretum, ipse novit. Causam vero erroris inter regem Bobemie et uxorem suam promisi superius suo in loco explanandam. Hic ergo breviter declaretur. Hic convenit explanari, quod superius intermisi ${ }^{3}$... und gleich wird die Gesckichte Z.'s angeknüpft: fuit enim in regno Bohemie quidem supanus dictus Zawisch ....(F. R. G. 1, 8).

Dieses Motiv und seine Einkleidung weisen einige, mit der Rchr. ïbereinstimmende Merkmale auf: 1. Die Struktur des Berichtes über die Zustände Böhmens nach 1278 ist in beiden Chroniken fast die gleiche: beide gehen über die Regentschaft Ottos in Böhmen mit Stillschweigen hinweg; der Krieg zwischen König Ottokar und Rudolf wird durch die Verlobung der Kinder beigelegt; der Roman Kunigundens wird an den Bericht über den Tod des Königs Ottokar angeknüpft.

2. Das Motiv bewegt sich in beiden Werken in demselben Gedankenkreis: In beiden wird darauf angespielt, daß die Königin ihren Gatten schon bei seinen Lebzeiten betrog (aber nur angespielt!); die Königin trug Trauer zur Schau, die jedoch nicht aufrichtig war (lugebat - den kunic verklagt); es wird auch gleich gesagt, warum: man sagt, daß sie ihn ,mit Zaewisch verklagt' hat. ... fuit in regno Bohemie quidam supanus dictus Zawisch. ...

Es gibt jedoch hier nicht nur Übereinstimmungen, sonderu auch Divergenzen. Der moralistisch zugespitzte Abschluß, mit welchen 0 . den Leser traktiert, die ausführliche Schilderung des Zuges Rudolfs ïber Mähren und der Iglauer Hochzeit fehlen in der bayerischen Fïrstenchronik; man findet auch keine wörtliche Ähnlichkeit etc. Das alles dïrfte meines Erachtens hauptsächlich wider die direkte, weniger aber wider die Möglichkeit einer indirekten Verwandtschaft zeugen; die oberwähnten Übereinstimmungen und außerdem noch ein anderes Moment scheinen mir diese Vermutung zu bestätigen.

1) Damit deutet 0 . an, daß er die Sache später zur Sprache bringt. S. meint, daß durch solche Verweisungen anf Früheres oder Späteres die Zusammengehörigkeit aller Teile der Rchr. bewiesen wird; sie ruhren ron e in e m Verfasser her (Einl. 47). - In vielen Fällen mag das Urteil zutreffen.

2) Vgl. die Deutung der Stelle bei S., Einl. $54 \mathrm{ff}$.

s) Dieser Satz bildet - nach Boehmer - eine Art von Randnotiz. Eine moderne Ausgabe von dieser Chronik käme der Forschung sehr gelegen. 
In der Fürstenfelder Chronik ist der Gedanke ,lugebat... regina, sed utrum seriose fleverit... u. s. w.", so wie auch die ganze Erzählung vom Tode König Ottokars durch die Vorgeschichte des Jahres 1276 bedingt, auf welche die Worte „hic convenit explanari, quod superius intermisi * deutlich zurückweisen (F. R. G. 1, 3). Eine Parallelerzählung findet man auch in der R.chr. (Vers 14761, S. 195).

„Das Jahr 1276. Nach dem mißglückten Feldzug kehrt König Ottokar heim und wird von seiner Gemahlin zornig bewillkommt: er habe so viele Länder verloren und den Rest als Leben empfangen müssen ...

14769 got si ez gekleit, si regina, inimica pacis - sagt der [die Königin] sprach, daz man iuch Mönch von Fürstenfeld - regem ie gesach bî sô vil wirdigkeit und obsecrat dicens: fore indecens et êren sit ir genomen habt ze herren inhonestum tam potentem et grâf Ruodolfen, den Habspurgatre... famosum regem se subicere unius comitis servituti.

Durch ihre Worte getrieben läßt sich Ottokar in einen nenen Krieg mit Rudolf ein - und findet den Tod"1).

1) Dieses Motiv ist verbreitet. Es gibt mehrere Chroniken, die der Königin die Rolle zuschreiben, den König zur Wiederaufnahme des Kampfes bewogen zu haben. Sie verzeichnet Buss on, Der Krieg vom J. 1278, A. Ö. G. 62, S. 14 Anm. 2; einen Nachtrag siehe bei S., S. 195 Anm. 5. Von ihnen steht die Chronik des St. Petersklosters zu Erfurt der Rchr. und der Fürstenfelder Chronik sehr nahe; sie faßt sich folgendermaßen: rex Boemorum domum revertitur torvoque vultu a regina suscipitur, dicente ipsum nullius esse valoris, qui se simplici comiti tam leviter subiugas set... Busson und S. nahmen an, daß O. die Erturter Chronik gekannt hat: ihr Heransgeber (Holder-Egger) bemerkt in der Einleitung, daß diese Annahme falsch ist (S. 354). - Auch Johannis Vitodurani Chronicon (hrg. durch Georg von Wyss, Zürich 1856 in dem 11. Bande des Archivs f. schweiz. Gesch.) berührt diese Geschichte (S. 24): „Fertur quod rex B., dictus Ottaker, ob persuasionem coniugis sue nimis elate et de fastigio regalis honoris sui supra modum inflate, contempsit regi Rom. Ruodolfo parere. - Endlich gelobte er ihm doch die Treue und empfing von ihm seine Länder als Lehen.... Quod dum evenisset et rex B. remeasset et consorti hec... enarasset, plus quam dici possit igne furoris accensa regem conviciis affecit... dicens: Quare a tali tibi dissimili...., cum sis longe prestantior eo diviciis, gloria et honore, regnum tuum titulo feodi petere... presumpsisti? Hiis verbis ipsum ... provocavit...".

Wenn mann die Annales Ottocariani aufmerksam liest, findet man, daß sie ähnliches berichten; sie wagen jedoch nicht - der Grund ist naheliegend - den Namen auszusprechen. Sie schreiben: "Anno 1277 rex Ottocarus filiam suam, quam desponsaverat N., filio Rudolfi, ... reclusit in monasterium. Huius puellae assumptio monasticae vitae... reputabatur initium fuisse totius mali et ruina regni Bohemiae. Cuius instinctu seu consilio rex Otakarus allectus ista fecerit, vel facienti consenserit, quia inter sublimes personas versatur factum, ad enarrandum difficile manet...*. (F. R. B. 2,329 ). 
Die Verwandtschaft der Erzählungen ist hier unverkennbar: der Gedanke ist derselbe, er wird an der gleichen Stelle eingereiht - und ist in ähnlichen Worten gehalten. An ihn knüpft der Fürstenfelder Geschichtsschreiber die Anspielung auf das Liebesverhältnis zwischen Z. und Kunigunde an: sie liebte heimlich Z. und deshalb hetzte sie den König in den Tod;... lugebat etian regina, sed utrum seriose fleverit, deus, quem nullum latet secretum, ipse novit. Auch 0 . scheint die Vermutung nicht fremd zu sein, daß Kunigunde dem königlichen Gatten nicht treu und daß Z. die Ursache war - wenn er sagt: sîn wîp die kuniginne mit fremder minne unstaetigkeit bî im phlac; unde dô er tôt gelac, deu hôhen kunic, sô man sagt, mit dem Zaewisch si verklagt". Doch darüber, ob man es so auffassen darf, werden wir nicht streiten ${ }^{1}$ ). Ich wollte nur zeigen, daß die Verse 14769 zu den Versen 17057 in einer gewissen Beziehung stehen, die in der "Cronica de gestis principun" eime bestimmte Gestalt annimmt und zu einem Schema wird.

Es wäre jetzt - hauptsächlich in Bezug auf die Verse 14769 und auf die Schilderung der Begebenheiten nach Premysl Ottokars Tod (Geschichte Z.'s) - zu untersuchen, wie diese Ähnlichkeit zwischen beideu Chrouiken entstanden ist. Nach Lorenz, D. GQ. 13, 203 hat der Fürstenfelder Mönch in J. 1328-1329 die Ausarbeitung seines Buches begonnen (andere setzen die Entstehung zu 1326 an). Es wäre folglich sehr gut möglich, daß er noch die Reimchronik (resp. ihre erste Partie) benutzt hat, besonders, wenn die ältere Meinung von Lorenz (betreffs der Entstehungszeit der Rchr.) wieder zu Ansehen gebracht wäre. Die

Die historische Wissenschaft läßt zwar die persönlichen Momente der Rache, des Ehrgeizes etc. nicht umberiicksichtigt; aber es ginge doch zu weit - und der ganze Sachverhalt ist zu bekannt -, um einer solchen Fabel Glauben zu schenken. Desto mehr interessiert uns die Frage, wie es gekommen ist, daß eine so stattliche Zahl von Quellen anf' diesen Gedanken verfällt. Die Erklärung B u s on s (cherchez la femme) ist ungenügend; es ist wenig wahrscheinlich, daß alle die Chronisten selbständig auf den Gedanken gekommen wären (und sich dabei auch ähnlicher Worte bedient hätten). Wir müssen eben damit rechnen, daß wir es mit einer Gruppe von Quellen zu tun haben, welche ein und dasselbe Motiv (Anekdote?) verwendeten. (Dieses Motiv findet man zum Teil auch in der Translatio s. Delicianae. S. B. der Wiener Akad., Hist. Cl. 159, 2. Abt., S. 14.). Das Motiv ist ein dauerhaftes Eigentum der Historie geworden. Wir begegnen ihm bei A eneas Sylvi us (die bohhm. Ausg. von J. Vičar, Prag. ohne Datum, S. 62) und es kehrt noch in Grillparzers Drama (Ottokars Glück und Ende) wieder. (Vgl. Joachimsen I'a I, Geschichtsauffassung und Geschichtsschreibung in Deutschland unter dem Linflusse des Humanismus. Leipzig 1910, Seite 29.)

1) Als $O$. das Thema über $Z$. - cinige Hundert Verse weiter - aufinimmt, sxtat er den Roman Kunigundens erst mit ihrem Witwentum an! 
Divergenzen, auf welche ich früher hingewiesen habe, scheinen mir jedoch dafür zu sprechen, daß die Verwandtschaft beider Quellen durch die Vermittlung einer dritten Erzählung entstanden ist. Diese Möglichkeit ist für die Rchr.von besonderer Wichtigkeit; wir hätten da mit einer verloren gegangenen schriftlichen ${ }^{1}$ ) Überlieferung über ( $K$. Rudolf? nnd) die Geschichte Böhmens um das Jahr 1278 zu tun, welche, anch was die formale Gliederung anbelangt, in die Rchr. übernommen wurde $\left.{ }^{2}\right)$.

Vers 18128-18424. Der Roman Kunigundens. Nach der Ansicht Seemüllers stellt diese Partie von 300 Verson einen, in der Reihenfolge der Erzählung, vollständig fremden Körper dar; sie wurde etwa um April 1317 in das schon im J. 1308 fertige Werk eingeschoben, um die etwas weiter folgende (Vers 20217, S. 269) ausführliche Bəhandlung der Geschichte Z.'s vorzubereiten (Siehe S., Einl. 84). Ieh kann dieser Vermutnng schon von dem formalen Gesichtspunkte nicht beistimmen.

1) Keine mündliche Überlieferung; das zeigt die wörtliche Übereinstimmung der Verse $14769 \mathrm{ff}$. mit der Fürstenfelder Chronik.

2) Es ist noch notwendig zu ergänzen, daß neben der Rchr. und der Fürstenfelder Chronik auch das mehr erwähnte böhmische Reimwerk über Z. den Gedanken ausspricht, Z. habe schon zur Lebenszeit des Königs mit der Königin heimliche Bekanntschaft unterhalten: „Také jej [das heißt Z.] král proto vyhnal bíśe, że u králové na freji biše". (F. R. B. 3, 241). Wie dieses späte Gedicht zu dieser Behauptung kam, ist mir vollkommen unklar.. (Einfluß der ausländischen Überlieferung oder eine verlorene einheimische Erzählung?) - Von den modernen Forschern hat $\mathrm{Pangerl}$ der Kombination der Fürstenfelder Chronik Raum gegeben. Hu ber (G. Ö. 2, 31, Anm. 2) sagt dazu: „Wenn Pangerl den Z. schon vor Ottokars Il. Falle mit dessen Gemahlin unerlaubte Beziehungen unterhalten läßt, ja vermutet, daß diese die nächste Veranlassung des 1276 erfolgten Bruches beider [König Rudolfs und Ottokars] gewesen seien; so hat er den Klatschereien, die in das Geschichtswerk des Fürstenfelder Mönches Aufnahme gefunden haben, zu viel Gewicht beigelegt«. Wir stimmen mit Huber überein. Da jedoch die Überlieferung des Fürstenfelder Mönches im Böhmischen (aber auch im Deutschen) ein Pendant besitzt, bedarf ihr Ursprung einer anderen und auch einer näheren Erklärung (mit dem Worte ,Klatscherei' ist zu wenig gesagt). Die Geschichte hat im J. 1900 Jos ef Salaba in einem Feuilleton der ,Národní Listy‘ Nr. 336 wieder aufgewärmt. Der Verfasser hat sich zwar eine hohe kritische Aufgabe gestellt und will ernst genommen werden; der Aufsatz ist jedoch konfus und verdient nicht in der B. C: H. von Zíbrt l. c. zitiert zu werden. Salaba kommt auch zur Überzeugung, Kunigunde und Z. hätten zur Lebenszeit Ottokars ein Verhältnis gehabt. - Die Fabel dürfte f r ühestens in den Anfangsjahren der Regierung Wenzels II. entstanden sein : ein Geschichtenerzähler hat, als das Liebesverhältnis zwischen $Z$. und der. Königin bekannt ward und Z. als Regent des Landes fast an die Stelle des Königs trat, die späteren Begebenheiten in die Jahre 1276/7 zurückversetzt. 
Dem Roman Kunigundens geht die Schilderung der feierlichen Doppelhochzeit zu Iglau (vgl. Böhmer-Redlich: Reg. 1027 a, November 1278) voran. An der Hochzeit nimmt auch die Königin-Witwe teil (S. 238). Sie unterhält sich während des Festes mit König Rudolf und erscheint als ,eine schöne, kokette Witwe, die sich bald verlieben und den ihr unebenbürtigen Záviš heiraten wird". (Vers 17942 ff.; vgl. S., Einl. 96). Als die Hochzeitsgäste sich verabschieden, fährt auch sie nach Hause 1 ). 18128: ez gestuont unlanc darnâch daz si des witibentums verdrôz. Sie wünscht das Trauerkleid abzulegen und einen Gatten zu finden. In diesem Momente erscheint Záviš $\left.(18167)^{2}\right)$.

Schon darin, daß O. die Königin an der Iglauer Hochzeit teilnehmen läßt, erblicke ich die Absicht, gleich nachher zur Geschichte Kunigundens überzugehen. Es ist ein technisches Auskunftsmittel O.'s, wenn er zu einem anderen Thema gelangen will, die Hauptperson bereits in dem vorangehenden Ereignisse auf die Szene zu bringen, gleichviel, ob sie an ihm beteiligt war oder nicht - um von ihr aus dann die Darstellung fortzusetzen. Als solche Anknüpfungsgelegenheiten eignen sich besonders Feste, Reichstage, Kriegszüge u. s. w., wo man die Person unbeschadet der Glaubwürdigkeit des Geschilderten einbeziehen kann. Wir werden später ein prägnantes Beispiel kennen lernen: Der Schilderung 0 . gemäß nahm der Sohn K. Ottokars, Wenzel, am Reichstage zu Augsburg als Kurfïrst teil (im J. 1282) ${ }^{3}$ ), obgleich Wenzel damals - ein unmündiges Kind - in der Gewalt (und fast in der Gefangenschaft) des Narkgrafen von Brandenburg sich befand und kein Kurfürst war. 0 . hat ihn trotzdem als anwesend angaführt, um die böhmische Geschichte (vom J. 1287 aufwärts) anznknüpfen4). Etwas ähnliches dürfte auch in unserem Beispiele vorliegen, um so mehr, als auch der charakteristische Zug in der Natur Kunigundens erfaßt und damit die folgende Erzählung vorbereitet erscheint. Sollte es so sein, dann hat 0 . die Luebesgeschichte Kunigundens schon zur Zeit, als er

1) Es wird nicht gesagt, wo sie hinfährt . . 18126 „dô fuorten die von Bêheim ir frouwen an irn gemach«. Die Ursache liegt darin, daß 0 . die Regierungszeit Ottos von Brandenburg stillschweigend übergeht und gleich mit dem Jahre 1283 (oder mit einem noch späteren Datum - die Datierung ist da ungenau) beginnt. $O$. hat sich hier - gemäß seiner früheren Auffassung - einen Sprung von 5 Jahren erlaubt und setzt die Schilderung fort, als ob Wenzel (oder besser gesagt seine Mutter) die Regierung gleich nach dem Tode Ottokars übernommen hätte.

2) Auf eine Disharmonie, die zwischen Vers 18167 und 17057 obwaltet, habe jch bereits Seite 264 Anm. 1 hingewiesen.

8) Seite 261, Vers $19712 \mathrm{ff}$.

4) Seite 264, Vers $19931 \mathrm{ff}$; Seite 267, Vers 20163. 
die Anfangsteile seines Reimwerkes verfaßte, gekannt, und hat er sie gekannt. und $17942 \mathrm{ff}$. Kunigunde absichtlich auf die Bühne gebracht, dann ist die Partie $18128 \mathrm{ff}$. gleichzeitig mit der vorangehenden entstanden und ist als logische und ununterbrochene Fortsetzung der Schilderung des Hochzeitsfestes zu Iglau anzusehen. Aber 0. könnte doch - so wird man einwenden -, als er den Anfang der Geschichte Z.'s um das Jahr 1317 hinter 18127 einschob, die Vorgeschichte der Iglauer Hochzeit entsprechend modifiziert haben? Ja, aber er mïßte dann noch die Verse 17057 , welche 18128 vorbereiten, vorschieben, die wieder in einer Beziehung zn 14769 stehen und ein festes Glied und eine bewußte Zuspitzung des Nachrufes nach Ottokar bilden. Der tektonische Bau dieses Nachrufes, den S. in der Finleitung S. 54 einer literarischen Analyse unterzog, hätte daher nach 1317 erweitert oder gar das ganze Stück erst zusanmengereimt und nachträglich in die Erzählung eingeschoben werden müssen. - Gar nicht gerechnet, daß diese Kombination inmer neue und weitgreifendere Konsequenzen hätte nach sich ziehen müssen, erscheint der Vorgang zu kompliziert, künstlich und daher unwahrscheinlich.

S. ist zu seiner Auffassung nicht aus dem Werke selbst (etwa aus der Beobachtung der Komposition) gekommen: die Erzählung macht stets den Eindruck einer logischen und zusammenhängenden Gedankenreihe, auch dort, wo sie einen sachlichen und chronologischen Lapsus (z. B. die Auslassung der Jahre 1278-83) begeht. Der Quellenvergleich hat S. auf die Idee gebracht, daß die böhmische Geschichte bei 0 , eine Nachbildung der Kgs. Chr. sei und daß 0 . auch die Person Z.'s durch die Kgs: Chr. kennen gelernt habe. Im Sinne dieser Feststellung muß S. die formale Gliederung des Werkes zu erklären versuchen: Da 0. die betreffende Partie der Kgs. Chr. frühestens April 1317 in die Hand bekommen hat und dieser Teil der Rchr. schon 1308 abgeschlossen wurde, bleibt keine andere Schlulffolgerung übrig, als daß die Verse $18128 \mathrm{ff}$., $17057 \mathrm{ff}$. und andere später eingeschoben und daß der erste Teil der Rehr. in vieler Hinsicht umgeändert wurde. Der Vorgang schien uns der formalen Seite nach unwahrscheinlich. Diese Beobachtung genügt aber nicht; wenn man den Beweis liefern will, muß man in den Quellenvergleich selbst eingehen.

Die Königin war der Trauer satt, sie suchte wieder die Gesellschaft aut - und hoffte die Liebe eines Mannes zu finden. Die Zeit verstrich und weil keiner kam, der ihr ebenbürtig war, hat sie - iren suppan'11) - Záviš [von Falkenstein] liebgewonnen (18167). Wie ist

1) Suppan: Der Herausgeber gibt in dem Glossar an, daB das Wort den böhnnischen Adeligen ,im Allgemeinen' bezeichnet. Ich möchte - den Belegen 
das geschehen? Darauf erwidert 0 . in dem 177. und 178. Kapitel im Dialog des Dichters und der Frau Minne ${ }^{1}$ ), der im Sinne der höfischen Poesie geführt ist. Frau Minne sucht den Dichter zu überführen, daß ihrer süßen Macht niemand widerstehen kann: der weise Salomon, der starke Samson, sowie auch die Königin Dido ... alle sind ihr unterlegen. 18278 , wie möhte danne widerstreben mîner kraft, sprach diu Minne, von Bêheim diu kuniginne?*2) Diese Erklärung ist viel glaubwürdiger, natürlicher - und menschlicher, als wenn die zwei Mönche von der ,ars magica' und ,nigromantia' des Mannes sprechen, dessen Gattin die Königin geworden ist ${ }^{3}$ ). Ich glaube nicht, daß sie beide unabhängig und selbständig auf diese Art der Erklärung geraten sind; sie ist weder einfach noch naheliegend. Loserth hat angenommen, daß der Fürstenfelder Mönch die Kgs. Chr. gekannt und benutzt habe; dadurch würde man wohl die Übereinstimmung erklären können. Ich habe jedoch schon früher gesagt, daß ich der Meinung Loserths nicht beipflichte und den Grund dafür angeführt. Das gleiche Motiv wird eher durch die übereinstimmende mündliche oder schriftliche Überlieferung in beide

nach, welche S. in der Rchr. gesammelt hat - die Definition insoweit beschränken, daß das Wort hauptsächlich den hohen Adel bezeichnet, der die Ämter besaß und sich um die Person des Königs gruppierte - den Hofadel. (Vgl. Vers 14682, S. 194: dâ saz ouch an der wîle an des kuniges rât der brobst von Wischerat [Vyšehrad; der böhm. Kanzler] und manic bêheimischer suppan). - Es sei noch bemerkt, daß der T'erminus den böhmischen Quellen (Chroniken und Urkunden) sehr wenig geläufig ist. Er kommt zuerst am Anfang des 13. Jdts. in zwei päpstlichen Briefen vor und wird selten genug angewendet; im 14. Jdt. bedeutet er einen beneficiarius niederen Ranges. Die čechischen Texte kennen das Wort durchaus nicht, obwohl das Dorf "Županovice" (bei Kanýk n. V.) bezeugt, daß das Wort der böhmischen Sprache nicht unbekannt war. Vgl. J. Peka ̌́, O správním rozdèlení země ceské do 13. stol. in ,Gollův Sborník', Seite 98. - In der Kgs. Chr. wird Záviš ,baro' tituliert (S. 64), oder bloß Z, genannt. Da limil nennt ihn ,výborný rytieř (F. R. B. 3, 193), die deutsche Übersetzung Dalimils ,Herr Zewisz: (F. R. B. 3, 196). Aus den böhmischen Quellen hat O. das Wort nicht übernommen. Warum hat die steierische Quelle den böhmischen Hofadel als ,suppaner bezeichnet? (gegenüber dem nichtböhmischen Adel ?).

Wenn O. sagt, daß die Königin , ir en suppan' liebgewonnen hat, ist er dazu vollkommen berechtigt. Záviš trat in ihren Dienst, als sie in Mähren weilte, und ist Burggraf auf ihrer Burg Grätz bei Troppau (Hradec u Opavy) geworden. Vgl. Em le r: Reg. Boh. 2, 1228 Nr. 2802, die Urk. vom 11· Febr. 1281.

1) Bekannter Dialog, in welchem die Frau Minne den Dichter als Ottokar anredet 18186.

2) Die Schilderung O.'s ist für die Königin sehr schmeichelhaft; man darf jedoch nicht vergessen, daß sie damals eine nahezu vierzigjährige Frau war. Vgl. Dudík, M. A. G. 7, 68.

3) Die Kgs. Chr., Kap. 16, S. 64; Cronica de gestis principum, bei Boehmer, F. R. G. 1, 9. 
Werke Fingang gefunden haben. Warum nur in diese zwei Werke? -- Vielleicht war es nur ein Zufall, oder darum, weil sie beide ungünstig und tendenziös gegen $Z$. schreiben wollten und auch geschrieben haben? Oder war es den beiden Mönchen unerhört und ohne, ars magica unbegreiflich, daß ein Sprosse eines Königshauses und die Witwe des einst mächtigsten Herrschers von Mitteleuropa, sich mit einem einfachen Adeligen, obwohl von mächtigem Geschlechte und der besten ritterlichen Tugenden, in ein Verhältnis einließ und ihn zum Manne wünschte?

Über die Anknüpfung des Verhältnisses zwischen Z. und Kunigunde bringt die Kgs. Chr. folgendes vor: Als die Hungersnot in Böhmen ausbrach, begab sich die Königin, durch die Not gezwungen, nach Mähren ${ }^{1}$ ). In dieser Zeit tritt $Z$. (quem culpis suis exigentibus rex Ottacarus proscriptionis sententia mulctandum duxerat) in ihra Dienste; er hoffte, daß er durch die Beziehungen zur Königin seine von Ottokar eingezogenen Güter zurückerlangen werde. Durch seine dämonische Macht und ,nigromantia' habe er ihre Liebe erreicht; sie gebar ihm — stando. secum in Moravia - einen Sohn (Kap. 16).

So weit der Königsaaler Mönch - der über das ,unerlaubte Verhältnis' moralisch sehr empört ist. 0 . berichtet nichts derartiges; er kennt nicht das Vorleben Z.'s und sein Verhältnis zum König Ottokar, er weiß nichts über den mährischen Aufenthalt der Königin, über die Hungersnot in Böhmen, er ist nicht moralisch entrüstet, im Gegenteil, er findet an dor Sache ein sichtliches Gefallen. Wenn er von der Kgs. Chr. abhängig wäre, hätte er kaum die angeführten Momente unberücksichtigt gelassen und sich von der, nigromantia' und dem ungünstigen Ton dor Erzählung Ottos emanzipieren können, obwohl ich nicht bestreite, daß er, ein Nachfolger und Nachahmer von dem großen Minnesänger Wolfram von Eschenbach, gleich von Anfang an die Liebe und das Liebesverhältnis Z.'s mit anderen Augen gesehen hat, als der fromme Zisterziensermönch von Königsaal.

Vers 18306-18328²). Ottokar fährt fort: „Die Königin hat Z. geheiratet $^{3}$ ) (18309 êlich nam); damit ist er zur Macht gekommen. Er

1) Novotny, S. 35, Anm. 1 sagt „Kunigunde hat sich nach Mähren im J. 1279, folglich noch v or der Hungersnot in Böhmen begeben ".

2) Zum Verse $18325 \mathrm{ff}$. siehe die Anm, S.'s S. 243.

3) O. schreibt 18306, „der unwille was grôz gegen der kunigin: umbe daz wâren si ir gehaz, daz si den Z. êlich nam ". Ein schroffer Unwille tritt uns auch bei der Lekturre der Kgs. Chr. entgegen; aber zwischen beiden Autoren ist eine prinzipielle Meinungsverschiedenheit: Der steierische Dichter referiert bloß; fụ̣r seine 
zog die königlichen Burgen (18310ff.) und das königliche Gut (18321) an sich; auch König Wenzel war vollkommen in seiner und der Königin Macht (18328). Er wufte seine Stellung zu sichern, indem er die Burgen mit seinen (Bluts-) Verwandten besetzte (18316 verchmâgen) und sein Geschlecht förderte (18 326). *

Der Grundgedanke der Schilderung 0.'s ist nicht neu: Z. soll seine Machtstellung im Lande durch die Heirat mit der Königin erreicht haben und durch ihn auch die Wittigonen zur Regierung gelangt sein. Den Gedanken kennen wir schon aus der Kgs. (hr. ${ }^{1}$ ); er ist dann von der Gruppe A. übernommen worden. Wir begegnen ihm auch in deu Annalen Hermanns von Altaich: Z. hat die Königin geheiratet; er kam dadurch zur leitenden Stellung im Lande. Sed filius regis... regnare incipiens, Zebischum occidit (SS. 17, 411). Die historische Literatur war bis auf Graebner in dieser Anschaunng einhellig. Graebner versuchte hauptsächlich auf Grund der urkundlichen Nachrichten über die Parteikämpfe in Böhmen sie zu stürzen und eine andere, glücklichere Lösung aufzustellen. Scharf formuliert lautet sie, wie folgt: nicht Z. hat seine Sippe, sondern dieselbe und ihr Sieg üher die bisher regierende Partei hat ihn ans Ruder gebracht (M. V. G. D. in B. 41, S. 584). Novák hat mit Recht diese Formulierung unter Hinweis auf einige nicht beachtete Quellenbelege gemildert: Der Sieg der Partei Z.'s ist nicht ohne seine Beihilfe gewonnen worden; im entscheidenden Momente steht er sogar an der Spitze der Aktion²) (Čes. čas. histor. 12, 57). Mit dieser Schlußfolgerung hat sich Novák der älteren Meinung und auch beiden

eigene Person findet er an dem Liebesverhältnisse Gefallen. Der Kgs. Abt referiert nicht; er ist Partei; er ist moralisch entrüstet (illicitae nuptiae, res nefaria, reatus; diabolus malorum concepcionum intentator war der Urheber dieses Unglïckes). Das Verhältnis war nach Otto v. Thüringen so lange sündig, bis die beiden in die rechtmäßige, von der Kirche gesegnete Ehe eintraten. Erst dann ist das Mönchsgewissen ruhig. Kap. 18: rex (Venceslaus) errorem revocans utriusque priorem, Zewischio munde de consensu Chunigunde desponsat matrem.... rex matrem pro consorte legitima publice Z. desponsavit, ut qui ad actum illiciti connubii prius consenserant, nupciis celebratis a modo licite commanerent. o. fapt die Sache so auf, als ob nur der Adel unzufrieden gewesen wäre und den Grund hiezu erst die Tranung (resp. die Ehe) gegeben hätte. Nach dem, was vorangeht und was folgt, vermuten wir, das die Unzufriedenheit melr politiochen Inhalts und von der politischen Eifersucht diktiert war.

1) Kap. 17 , Sewischius regie familiaritatis adeptus graciam regina annuente curam sibi curie assumpsit ... familiares suos eisdem in officiis singulis subrogavit, statum curie pro sua voluntate disposuit.

2) Bei den Verhandlungen zwischen den Gegnern - noch vor dem vollen Siege seiner Partei - erscheint Z. als besonderer Bevollmächtigter des Königs. Novák, Formuláŕ biskupa Tobiáše Nr. 96. 
Chronisten genühert; es frägt sich nur, ob der Gedanke, den der Kgs. Abt und 0 . ausdrückt, auch derselbe ist.

Die Kgs. Chr., Kap. 17, S. 65 erzählt:

Zur Zeit, als der junge Wenzel aus seinem Exil zurückkehrte, weilte die Mutter in Mähren. Ihrer Schuld (reatus) bewußt, quod pernitiose degenerans servo suo in re tam nefaria conquievit, wagte sie nicht $z u$ kommen. Sie knüpfte mit Wenzel eine Korrespondenz an, die dazu führte, daß er sie herzlich zu sich lud, indem er ihr verzieh. Das war auch der Wendepunkt im Leben Z.'s. Kunigunde ebnete ihm den Weg, so daß ihm Wenzel den Frevel gegen das Land (resp. gegen den König Ottokar) vergab und ihn an seinen Hof aufnahm (Kap. 18). In kurzer Zeit erwarb Z. durch seine Persönlichkeit die volle Gunst des Königs und gelangte am Hofe zu einer dominierenden Stellung. Die Verleihung von Ämtern, wie auch die Leitung der Regierungsgeschäfte riß er an sich. Er war fast der Herrscher. Auf seinen Wunsch hat ihm Wenzel seine Mutter in legitime Ehe gegeben (Seite 68).

Diese Schilderung hat Graebner mit Recht angezweifelt: es ist verfehlt einer Person in Wenzels Alter ${ }^{1}$ ) und mit seinem Charakter eine solche Entschlußfähigkeit zuzuschreiben. (M. V. G. D. in B. 41, S. 580.) Wir wissen auch, welchem Umstande wir diese Schilderung zu verdanken haben: zum Teil entspricht sie der mittelalterlichen Anffassung über den Ursprung der Macht; außerdem tritt bei dem Verfasser offenkundig das Bemühen hervor, Wenzel als Mittelpunkt der Ereignisse darzustellen ${ }^{2}$ ); er leitet alles ein, er dirigiert, er entscheidet alles nach seinem eigenen Ermessen. Er soll auch als Gegenpol zu Z. erscheinen, dem bösen Z., der W. nach dem Leben trachtet, Wenzel, welcher sich ihm und Kunigunde so nachsichtig erwiesen hat. Durch diese Auffassung ist der Verlauf der Ereignisse verdunkelt und einseitig wiedergegeben: der Widerhall der Parteikämpfe dringt nur hie und da hindurch.

Ebenso schwierig gestaltet sich die kritische Analyse des Berichtes 0 .'s. Er bleibt treu seiner Darstellung des Jahres 1278: Er weiß nicht, daß zwischen dem Tode Ottokars und dem Regierungsantritt Wenzels eine fünfjährige Pause verstrich, welche die Regentschaft Ottos von Brandenburg ausfüllte. Nach seiner Ansicht geht im J. 1278 die Regierungsgewalt an die Königin über; sie hat sich in $\mathrm{Z}$. verliebt und ihn zuletzt geheiratet - die Zeitbestimmung geht 0 . völlig ab. Durch die Heirat ist Z. mächtig geworden; er hielt alles in seiner Gewalt; die königlichen Burgen, das königliche Gut - und den jungen König

1) Im August 1283 war Wenzel erst 12 Jahre alt ,und gar nicht der Vormundschaft ledig'.

2) Vgl. Novotný, Einl. 35. 
selbst. 0. gelangt zu demselben Gedanken wie der Kgs. Abt; aber der Weg, den er geht, und die Umstände, unter welchen er es geschehen läßt, sind von denen der Kgs. (hr. gänzlich verschieden....

Der steierische Dichter hat in seiner Darstellung den jungen König sehr wenig berïcksichtigt. Er ist nicht handlungsfähig, noch unselbstständig, in Gewalt seiner Mutter und des Stiefvaters (18327). Das ist einer der wichtigen Gegensätze, welche die Schilderung Ottokars gegenüber der Auffassung Ottos (von Thüringen) aufweist. Eine mit der Kgs. Chr. verwandte Erzählung könnte sich kaum so völlig von ihr emanzipieren. Das zeigen Franz von Prag (F. R. B. 4, 355) und Beneš Krabice (F. R. B. 4, 460) deutlich.

Vers 18310-18325. Z. hat besonders zu drei Iningen seise Machtstellung verwertet: er zog die königlichen Burgen und Festen an sich (gegen Recht); er besetzte sie mit seinen Verwandten (-18316 und hiez im selben dâmit swern $=$ huldigen) und hat das königliche Gut und Vermögen (guot und hab) als sein Eigen angesehen.

Ähnliche Nachrichten bieten anch die Kgs. Chr, die Continuatio Hermanni Altahensis und die Urkunden, immerhin aber anders als 0. Was 0. in einem Zuge sagt, ist in den Berichten - hauptsächlich der Kgs. Chr. - an verschiedenen Stellen zersplittert und in einen anderen Zusammenhang gebracht.

1. Die Kgs. Chr. erzählt: Kap. 25, Seite 80: .. municiones regni, quas Z. in sua potestate habuerat...; Kap. 18, Seite 67: Z. sibi familiares in ipsius regni non tam officiis quam beneficiis exaltabat. Hunc quidem camerarium, illum purcravium ... ordinavit. Kap. 24, Seite 78. Z. non solum uxorem, verum eciam thesaurum universumque apparatum regis Ottakari olim defuncti sibi vendicaverat regalibus sibi assumptis insigniis in Ungariam proficisci disposuit.

2. S. meint, daß 0 . Vers 18320 vielleicht der Continuatio Hermanni Altahensis nachgebildet hat. Aber diese berichtet bloß: Z., qui per reginam, quam duxerat, thasauros habere ceperat. (SS. 17, 411). Diese Mitteilung ist zu beschränkt, als daß sie die Quelle 0.'s gebildet haben könnte. Sie spricht nur von den ,thesauri, über welche auch die Kgs. Chr. (Kap. 24, S. 78) einige Worte verliert, welche daher mit demselben Rechte als die Vorlage 0 .'s betrachtet werden konnte; hingegen erzählt 0 . nie von dem königlichen Schatze, den' $Z$. sich angeeignet habe, sondern nur allgemein von dem Gute, bezw. der Habe, und das Hauptgewicht legt er auf den Besitz der königlichen Burgen und Festen. 
3. Die Urkunden. Laut der Urkunde bei Emler: Reg. Boh. 2, S. 569 Nr. 1316 rom 24. Mai 1284 und anderen sind die Witigonen Anfang 1284 in den Besitz der Landesämter und zur Verwaltung von einigen Burgen gelangt, - 0 . erwähnt die Landesämter nie. In der Urkunde Emler 2, 586 Nr. 13508 vom 23. Okt. 1285 schenkt König Wenzel einige Güter (Polička, Lanšperk und Lanškroun) dem Z. und seinem Solnne; es ist die einzige Urkunde, nach welcher $Z$. als possessor iure hereditario ac perpetuo de donatione des königlichen Gutes erscheint. Als er in die Gefangenschaft des Königs geriet, wurden ihm diese auf immerwïhrende Zeiten geschenkten Güter wieder abgenommen.

Zwischen dissen Nachrichten und der Rchr. ist wenig Übereinstimmung. Sie decken sich nur, was das Endurteil anbelangt, welches wir uns erst auf Grund des ganzen Materiales bilden; sie sind in den genannten Chroniken in verschiedenen Zusammenhang gebracht, durch verschiedene Umstände motiviert und betonen inhaltlich ein ganz anderes Moment. Es ist nicht denkbar, daß 0 . seine Schilderung aus solch unbedeutenden Chronikensplittern, welche in der Erzählung, in der sie auftreten, völlig verschwinden, zusammengesetzt und im Gegenteil die Momente, welche Otto von Thüringen ausführlich behandelt und betont, völlig unbeachtet gelassen hätte. Das bezieht sich vornehmlich auf das 18. Kap. der Kgs. Chr.: Z., gracie regis restitutus, dirigierte den ganzen Hof. . . Curam sibi curie assumpsit, statum curie pro sua voluntate disposuit... ommia ordinat, omnibus imperat, totam curiam pro libitu suo vertit et invertit ... cuncta regni negocia iuxta sue voluntatis arbitrium ordinavit etc. Die Stellung Z.'s am Hofe ist der eigentliche Gegenstand der Schilderung und auch der Angriffe Ottos. 0 . behandelt die Stellung Z.'s von einer anderen Seite; er erzählt, daß Z. die königlichen Burgen besetzte und das königliche Gut sich aneignete. Die verschiedene Auffassung der Machtstellung Z.'s seitens der beiden Autoren scheint mir hinlänglich zu beweisen, daß der Bericht 0.'s von dem der Kgs. Chr. nicht abgeleitet ist; darauf weist anch der Umstand, daß die steierische Chronik mehr weil, als die Kgs. Chr.: sie teilt nämlich später mit, wie Z. zu dem (königlichen) Vermögen gekommen ist (Vers 20599 ff., S. 272).

Hroznata von Husic. Dietrich Spatzmann. Vers $18323 / 4$ erzählt 0., daß die Schwestern Z.'s an die Herren Hroznata (von Husic) und Dietrich Spatzmann verheiratet waren. Über die Zeit, wann das gesehehen ist, äußert er sich nicht. Es wäre falsch - der Einreihung der Nachricht nach - zu glauben, daß die Heirat zwischen den Jahren 1278-85 zustande kam. Die Stilisierung gibt zu dieser Vermutung 
den geringsten Anlaß. 0. koustatiert die Sache bloß. Man darf auch nicht so ohneweiters annehmen, daß die beiden Genannten zu jenen Personen aus der Verwandtschaft Z.'s gehörten, welche er in Ämter beförderte - weil gleich darnach erzählt wird, wie Z. sein Geschlecht hob. 0. sagt bloß, daß sie die Schwestern Z.'s zur Frau nahmen und auf solche Weise mit $Z$. verschwägert wurden.

Als seimer Zeit Pangerl die Abhandlung über die Witigonen schrieb, hat er die Angabe 0.'s, wie sie da steht, übernommen, ohne sie durch andere Quellen bestätigen zu können (A. Ö. G. 51, S. 548). Seit dieser Zeit sind unsere Quellenkenntnisse erheblich vermehrt worden, besonders was die Urkunden anbelangt, und auch das genealogische Studium ist fortgeschritten; die Nachricht 0 .'s ist jedoch bis jetzt vereinzelt geblieben, so daß man ihre Verläßlichkeit nur auf indirektem Wege prüfen kann ${ }^{1}$ ).

Hroznata von $\mathrm{Husic}^{2}$ ) wird zum erstenmale im J. 1284 erwähnt - das Jahr, welches den Witigonen den Sieg über die bisher regierende Partei brachte. Sie besetzen jetzt die Landesämter und die besiegte Partei gelobt ihnen, Frieden zu halten (Emler, Reg. Boh. 2, Seite 569, Nr. 1316 und Nr. 1317) ${ }^{3}$ ). Unter den neuen Würdenträgern, in einer rein witigonischen Umgebung, erscheint auch Herr Hroznata4). Zdislav (von Löwenberg = Lemberg), Mitglied der Gegenpartei, hat ihm Platz gemacht5) und er ist Prager Burggraf geworden. Diese Stellung behauptete er vier Jahre ${ }^{6}$ ); als $Z$. stïrzte, fiel er mit ihm. Das ereignete

1) Pangerl hat sie ohne Skrupel verwendet (1. c. vgl. anch M. V. G. D. in B. 10, S. $149 \mathrm{ff}$.). Š Susta war schon mißtrauischer. Direkt hat er sich nur über Hroznata ausgesprochen (Čes. čas. histor. 1, 291, Anm. 2), aber die Nachricht über Spatzmann verwendete er ebenfalls (S. 388). Graebner beachtete beide als verläBlich (M. V. G. D. in B. 41, 323; 42, 12).

2) Die Repertorien des böhmischen Adels von Král, Der Adel Böhmens, Mährens und Schlesiens, Prag 1904 und von Zíbrt in Bibliografie české historie 1, Nr. 5044 geben im Sinne der grundlegenden Forschung Palack $y^{\prime}$ s $1^{\text {a }}, 500$ von dem Geschlechte „z Husic" an, daß es ein Zweig der „Kounici“ war und im roten Felde zwei silberne Seeblätter führte.

s) Vgl. Graebner, 1. c. 41,583 .

4) Thm geht Hogerius von Lomnic voran, Záviš und sein Bruder Vítek folgen.

5) Emler, Reg. Boh. 2, 560 Nr. 1298 (vom 28. Aug. 1283): Sdislaus [de Löwenberg], burggravius pragensis. Emler, Reg. Boh. 4, Suppl., S. 738 Nr. 1855 (vom 24. Okt. 1283): Zdislaus, burchravius pragensis.

6) Vgl. Em ler, Reg. Boh. 2. 586, Nr. 1358 (vom J. 1285); S. 589 Nr. 1368 (v. J. 1286); Nr. 2296 (v. J. 1287 und nicht, wie Emler angibt, v. J. 1284-5: vgl. Graebner, 1. c. 41, 597). Dann besitzen wir noch zwei Belege in den Formelbüchern: in dem Formelbuch des Bischofs Tobiáš von Bechyně, hrg. von J. B. Novák, Formulár biskupa Tobiáăe z Bechyně, Nr. 28 (siehe anch bei Emler, 
sich wahrscheinlich in der zweiten Hälfte des Jahres 1288. Am 10. Jünner 1289 hat schon Herr Zdislav von Sternberg das Prager Burggrafenamt inne (Emler, Reg. Boh. 2, S. 630 Nr. 1466). Hroznata knïpfte sein Schicksal an das Glücksgestirn Z.'s; er fiel als sein eifriger Parteigänger. Herr Hroznata ist jedoch noch weiter gegangen; er griff mit den anderen Witigonen zu den Waffen und spielte in dem südböhmischen Adelsaufstand eine nicht geringe Rolle ${ }^{1}$ ). Nachdem der König Herr desselben geworden, wurde er (und seine Söhne) mit anderen Witigonen vor Gericht gestellt, seine (und seiner Söhne) Güter konfisziert und dem Bisch of Tobias, der in dem Kriege den meisten Schaden erlitt, zugesprochen (Emler, Reg. Boh. 2, 1195, Nr. 2734, die königliche Bestätigung vom 17. Juni 1291). Dann verschwindet Herr ,Roznat' aus der Geschichte. Die Mitteilung 0.'s paßt in die Reihe der Urkmudenzeugnisse; sie erklärt, warum sich sein Lebenslauf so gestaltet hat 2 ).

Dietrich Spatzmann ${ }^{3}$ ) tritt in der Rehr. schon an einer früheren Stelle hervor, in der Schlacht am Marchfelde 1260. Bela IV., König von Ungarn, sieht vom linken Ufer dem Kampfe zu und läßt sich von einem Österreicher, Heinrich Preussel, die einzelnen feindlichen $\mathrm{Ab}$ -

Reg. Boh. 2, Nr. 1993). Die Formel ist von Novák ,bald nach d. 14. Jänner 1288 gesetzt. Das Formelbuch Zdenkos von Třebíč - die einzelnen Formeln sind in Emlers Reg. Boh. 2 ediert - enthält eine datierte Urkunde vom 11. Juli 1288 (Nr. 2323), in welcher ,Hrosnata, purchravius pragensis' als ,arbiter auftritt. Aber die Angaben dieses Formelbuches sind wegen absichtlicher Entstellung vorläufig niclit verwendbar.

1) Die heftigste Feindiseligkeit richtete sich gegen das Oberhaupt der Gegenpartei, den Prager Bischof Tobias. Das in der bischöflichen Kanzlei entstandene Formelbuch enthält mehrere Briefe, in welchen sich Tobias in wehklagendem Tone über die Plündernng und Verwüstung der bischöflichen Besitzungen beim Könige beschwert (No. 89, 189, 193, 200). Den Brief Nr. 193 hat Novák in das Jahr 1289 gesetzt. In ihm beklagt sich der Bischof über die Gewalttaten seitens Budivoj, des Sohns Hroznatas (filius purgravii Pragensis). Da jedoch am 10. Jänner 1289 Herr Zdislav von Sternberg das Burggrafenamt von Prag besitzt, ist die Formel eher in das Jahr 1288 zu setzen und der Kampf gegen Tobias somit schon damals ausgebrochen. Sollte wahr sein, was Novák in der Anmerkung zur Formel Nr. 193 annimmt, daß der Bürgerkrieg durch die Gefangennahme Z.'s hervorgerufen wurde, so wurde Z. schon im J. 1288 (und nicht, wie Graebner behauptet hat, im J. 1289, 1. c. 42, S. 7) gefangen genommen.

2) Da die Söhne Hroznatas eifrig am Kampfe teilnehmen und mit ihren Gütern den Frevel büßen, kann man gut annehmen, daß sie seine Söhne von der Schwester Falkensteins waren. Die Heirat müßte dann in die Jahre 1260-70 fallen.

3) In den Urkunden wird er Theodericus, Dytricus (dictus) Spazman oder nur Theodoricus, Dytricus genannt. Palack'́ D. N. C. $22^{\circ}, 35$ und Tomek, 
teilungen und deren Führer bezeichnen. Vers 7259, S. 96: hern Dietrich Spatzmanen sach man die banier leiten: in einem rôten samit breiten was geworht ein lewe wîz (die böhmische Abteilung). Wir haben keine Ursache, dieser Mitteilung nicht zu glauben, umsoweniger, als sie gut mit den Urkunden zusammenstimmt. Dietrich verkehrt am Hofe König Ottokars und erscheint als Zeuge in verschiedenen Königsurkunden; seiner Nennung in der Zeugenreihe nach zu urteilen, bekleidet er am Anfange seines Dienstes noch kein bestimmtes Aut (Emler, R. B. 2, 164, Nr. 426, die Urk. v. 2. Juli 1263. Eine unsichere Urkunde enthält der Kodex Zdenkos von Trebíč, Emler, R. B. 2, 1033 Nr. 2388 vom Jahre 1267). Um das Jahr 1269 wurde er mit. dem Burggrafenamt zu Brüx (Most) betraut (Emler, R. B. 2, 251 Nr. 644; im Jahre 1267 ist noch ein Heinko als ,burchravius de Ponte' genannt, siehe Eimler, R, B. 2, 214 Nr. 556). Sein Bruder Albert ist zu gleicher Zeit als Kastellan in Pürglitz (Krrivoklát) angeführt (Emler, R. B. 2, 252 Nr. 647: Albertus, frater suus, eastellanus in Purgelino). Neben diesem Dienste wurde Dietrich anch das Unterkämmereramt übertragen. Im Jahre 1271 tritt er das erstemal in dieser Funktion hervor und behält sie bis zum Tode Ottokars ${ }^{1}$ ). Dann hören (auf 2 Jahre) die Belege auf. Bis zu diesem Zeitpunkte ist die Parteistellung Dietrichs durch sein Dienstverhältnis und durch die Umgebung, in welcher er lebte 2 ), bestimmt. Er gehörte damals sicher micht zu den Witigonen ${ }^{3}$ ), welche vom J. 1269 an den Hof mieden und schließlich in einen Krieg mit dem Könige geraten sind ${ }^{4}$ ).

Dèjepis mèsta Prahy 12, 607 nennen ihn „Dètř ich špaček z Kostelce». Das. erwähnte Adelsrepertorium von $\mathrm{K}$ rál behauptet, daß er von den "Buzici " abstammte; Palack $\dot{y}$ gibt jedoch $1^{6}, 490$ an, daß die Herren von Kostelec ein Zweig des Geschlechtes „Hronovci“ waren.

1) ,Dytricus, subcamerarius Boemieb. (Em.ler, R. B. 2, 299, Nr. 753.) In den Urkunden bei Emle r, R. B. 2, Nr. 980, 1005 wird er mit dem ganzen Namen angefïhrt, Theodericus Spathmannus, subcamerarius. Das Unterkämmereramt verwaltet Dietrich frühestens vom J. 1271 an, da im Oktober 1270 noch ein Hablo [Havel von Löwenberg] als Unterkämmerer genannt ist (Emle r, R. B. 2, Nr. 708, 721 ), und behält es ununterbrochen bis 1278 , wie die folgenden Urkunden in den Regesten Emlers, 2. Teil, bezeugen: Nr. 753 , 765, 771, 787, 813, 821, 980, 1005, 1092 (vom J. 1277) und 1111 v. J. 1278). Nebstbei versah er das Burggrafenamt zu Brüx. Vgl. die Urkunden Nr. 670 vom J. 1269 und Nr. 1089, S. 459 vom. J. 1277.

2) Diese Umgebung ist besonders durch die Namen Purkarts von Janovic und Zbyslavs von Třebuñ, welche später die führende Rolle in der Gegenpartei Z.'s. spielten, charakterisiert.

3) Besser gesagt: zu der Witigonenpartei. Seine politische Stellung schließt doch die Möglichkeit nicht aus, daß er schon damals mit der Schwester Z.'s verheiratet war.

4) Vgl. Šusta, I. c. $248 \mathrm{ff}$. 
Aus der Zeit des Interregnums (1278-1283) besitzen wir von ihm zwei Nachrichten. Am 20. Februar 1280 bezeugte „Thitricus Spasmannus, camerarius regni Bohemiae, in Gemeinsehaft mit den vornehmeren Brüxer Bürgern, dominum Wobolinum, civem pragensen, hospitalensibus Pragae cum stella in pede pontis contulisse villam Nemilkowe (Nemilkov), quae iacet circa civitatem Brüx"1). Die Urkunde ist, wie ich glaube, sicher echt ${ }^{2}$ ). Es erscheint folglich sicher, daß Spatzmann noch in J. 1280 den Titel ,camerarius regni Boemiae führte und daß er wahrscheinlich auch das Burggrafenamt zu Brüx besaß, wie man aus dem Umstande sshließen darf, daß er eine Brïxer Urkunde (an erster Stelle) unterfertigt.

Graebner schloß aus dem Titel Dietrichs, daß er noch im J. 1280 zur alten Partei König Ottokars, welche in die Partei Ottos von Brandenburg überging, zu zählen sei ${ }^{3}$ ). Diese Vermutung, bei Graebner ist es eine Behauptung, ist aber keineswegs sicher. Ich glaube, daß Graebner hier in den Fehler der Schematisierung verfallen ist. Die Regierungspartei vom J. 1278 darf man nicht so ohneweiters mit der Partei des Markgrafen identifizieren ${ }^{4}$ - und wenn das auch zuträfe, ist es durchaus unwahrscheinlich, daß dies auch für Dietrich gilt. Er ist nie vor noch nach 1280 unter den Männern angeführt (leider bəsitzen wir aus der Zeit 1278-83 nur ein spärliches urkundliches Material), mit welchen er vor 1278 am königlichen Hofe in regem Verkehr stand und welche hie und da in der Umgebung Ottos zu sehen sind ${ }^{5}$ ).

1) Emler, R. B. 2, 1185, Nr. 2710.

2) Sie ist nicht im Originale erhalten, sondern in einem Kopialbuch des Kreuzherrenarchives in Prag aufbewahrt, aus welchem Emler mehrere Urkunden ans der zweiten Hälfte des 13. und dem Anfang des 14. Jahrhunderts in sein Werk übernahm (Nr. 2786, 2661, 63, 66, 96, 2700, 07, 10, 13, 19, 26, 2728 u. s. w.; sie scheinen verläßlich zu sein). Soweit man aus dem Regest sehen kann, wurde das Rechtsgeschäft folgendermaßen in Brüx (Most) vorgenommen: Die Parteien sind am 20. Februar 1280 (Mittwoch vor Exsurge) vor den iudices civitatis Pontensis zusammengetreten und dort wurde das Rechtsgeschäft verlautbart; darauf ist die Urkunde ausgestellt worden (actum et datum die) und die testes bezeugten die Verlautbarung (deshalb wird inf. perf. angew.: contul isse).

3) 1. c. 41, S. 323 .

4) Novák sagt richtig l. c., S. 53, daß die Untensuchungen Graebners, wiewohl sie definitiv sein wollten, kein definitives Resultat brachten, und daß es durchaus sehr schwer sei sicherzustellen, welche Adelspartei sich dem Markgrafen anschloß.

5) Vgl. die Urk. Em ler, R. B. 4, Suppl,, S. 737, Nr. 1850 vom Nov. 1281. - Es ist wahrscheinlich. daß Dietrich an der Erneuerung der Regierung (im Jänner 1282 nach Graebner) nicht partizipierte. 
Die andere Nachricht bringen die ,Prager Aufzeichnungen iiber die fünf unglücklichen Jahre nach dem Tode K. Ottokars' (Annules Pragenses II; F. R. B. 2, S. 343) und zwar in folgendem Zusammenhange: Der Prager Chorherr spricht von dem Regengusse am 23. Juli anni praeteriti (die Jahreszehl ist nicht angegeben), welcher viel Schaden auf der Burg Prag und in der Stadt anrichtete. Dann setzt er ,de impetu ventorum vom 3. Dezember fort und sagt "Sub decursu temporis impacati, quid boni sive mali fecerint in stationibus suis sub monte Petrzin (Petrino) Spakmaunus (Spatzmannus, Spacimanus), Syberk et Sazema cum suis comitatibus, stylo explantri non est necesse, quia sufficienter notata creduntur apud illos, qui molestias diversarum passionum et iacturam rerum pertulerunt. Molendinum in Strahov ventosum vi ventorum corruit et eodem anmo reaedificatum est “. Die Erklärung dieser Nachricht bereitet nicht geringe Schwierigkeiten ${ }^{1}$ ). Die Edition Köpkes in M. G. SS. 9, 194, welche wuch für die F. R. B. 2 mafgebend war, hat den ursprünglichen Zusammelhang zerrissen; deshalb hat Graebner zur älteren Edition Pelzels und Dobrovskỳ's (SS. rer. Boh. 1) zurückgegriffen (l. c. 41, 336 Anm. 8). Der Text der Prager Jahrbücher ist aber schon in originali nicht einheitlich, undatiert und durch Zusätze in eine chronologische und sachliche Unordnung geraten. Diese zwei Momente haben verursacht, dal3 ihre Angaben fast von jedem Forscher in verschiedene Jahre gesetzt werden $\left.{ }^{2}\right)$.

Tomek erklärte die Nachricht auf die Weise, daß sie eine Phase des Kampfes gegen Otto von Brandenburg darstelle. Dietrich Spatzmann greift in Gemeinschaft mit einem Witigonen Sezema (von Laudstein alias von Stráz) und mit (Albert) von Seeberg die Hauptstation Ottos auf der Burg Prag (und die Kleinseite) an. Die Kämpfe gegen Otto in der Umgebung von Prag werden auch im Dalimil geschildert (F. R. B. 3, 197), er führte jedoch andere Namen an. Sie fallen in das Jahr 1280 (Tomek, D. M. P. 12, 206).

Graebner läßt die Begebenheiten der Jahre 1278-82 in einer von Tomek verschiedenen chronologischen Ordnung folgen und verbindet sie auch anders. Der Kampf Dietrichs und Genossen richtete sich zwar auch nach seiner Meinung gegen Otto; er war vom König Rudolf angestiftet und hieng mit dessen Angriff auf Böhmen (resp. gegen 0tto) im Spätsommer 1280 zusammen; er spielte sich jedoch in

1) Abgesehen noch von dem Namen, der mit großer Wahrscheinlichkeit auf Dietrich Spatzmann gedentet wird.

9) Die Vergleichstabelle siehe bei Novák, l. c. S. 52 . 
Nordböhmen $a b^{1}$ ). (Die Kämpfe in der Umgebung von Prag, von welchen Dalimil berichtet, setzt er erst »u 1282 an).

Die Untersuchung Graebners über die Annales Pragenses bedeutet einen Fortschritt; eine definitive Lösung brachte sie nicht. Man müßte in die Handschriften eingehen, ihr Verhältnis zu einander so wie auch ihren Inhalt und die Stellung des Verfassers zu den kämpfenden Parteien einer sorgfältigen Prüfung unterziehen. Dann würde es sich herausstellen, ob die Datierung der Nachricht zu 1280, die heute am nächsten liegt, verläßlich ist und ob die Deutung der Nachrisht, daß es sich um den Kampf gegen den Markgrafen handelt, der Wahrheit entspricht. Es wäre auch notwendig, die politische Stellung der beiden commilitones Dietrichs, der Herren Sezima (von Landstein) ${ }^{2}$ ) und (Albert) von Seeberg vor und nach 1280 genau kennen zu lernen. Dazu haben wir weder Zeit noch Raum. Auf Grund nur flüchtiger Erhebung und nur über den letzten Punkt läßt sich siogen, daß Sezima ein entschiedener Witigone war; er stammte aus diesem Geschlechte und nahm stets eine solehe Parteistellung ein, wie sie die Interessen des Geschlechtes forderten (vgl. Emler, R. B. 2, Nr. 1271, 1293, 1316, 1623). Auch den Herrn Albert von Seeberg erblicken wir in dem Jahre 1284, das den Witigonen den Sieg brachte, unter den Vordermännern

1) Graebner ist hier ein unangenehmer Fehler unterlaufen. Er hat die Ortsbezeichnung (des Kampfiplatzes) - sub monte Petrzin - als Personenname ,Peter $=$ Poto von Mšeno ? aufgefaßt und den Kampfplatz in einer weitreichenden Kombination nach Nordböhmen verlegt (l. c. 41, 322). Er sagt: „Seit Sommer 1280 drohte der Angriff Rudolfs von Habsburg, des Beschützer's der Witigonen schon gegen Ottokar. Sein Eingreifen mußte die inneren Wirren wieder aufleben lassen ... Rudolfs Angriff mißlang, aber der Same der inneren Zwietracht ging auf; bis in Ottos Anhang hinein hatte der König seine Intriguen gesponnen und Abfall erweckt. Die Ruhestörer sind: Peter, Dietrich Spatzmann, Albert v. Seeberg und Segema v. Landenstein ... Albert von Seeberg weilt am 1. Jänner 1281 in Komotau, nahe seinen Gütern, in Gesellschaft seiner Brüder und zahlreicher Edler ... Da auch Dietrich wohl bei Brüx ansäßig war, sehen wir hier eine ganze L a nds ch aft in UnbotmäBigkeit, eine Landschaft, deren Feindseligkeit bei Rudolfs Angriff Otto im Rücken beunrnhigen mußte. Anscheinend brach der Aufstand nicht rechtzeitig aus, um dem deutschen Könige den beabsichtigten Dienst zu leisten; aber dic PlanmäBigkeit der Anlage deutet doch a uf einen engen Zusammenhang der Bewegungen". - - Die Prager Annalen II beschränken sich hauptsächlich anf die Prager Ereignisse; schon daraus erhellt, daß es sich um eine Prager Bégebenheit handelt. „Sub monte Petrzin“ bedeutet ,unter dem Berge Petřn', der am linken Moldaunfer südlich von Hradschin liegt und jetzt in das Prager Stadtgebiet einbezogen ist. Damit fällt die Lokalisierung der Kämpfe auf Nordböhmen weg und die ganze kühne Konstruktion stürzt zusammen.

2) Zu gleicher Zeit tritt noch ein zweiter Sezima auf, namens von Krašovic. Dieser gehört der Gegenpartei Z.'s an. Vgl. Emler, R. B. 2, Nr. 1298, 1316. 
der Partei Z.'s (Emler, R. B. 2, 569 Nr.1316). Man darf folglich annehmen, daß Dietrich zwischen den Jahren 1278 bis 1282 von der ehemaligen Regierungspartei König Ottokars zu der Opposition, welche von den Witigonen geführt wurde, übergegangen ist. Er tritt auch der bisherigen Anschauung uach - im J. 1283 und später als Anhänger Z.'s auf der politischen Bühne auf (Emler, R. B. 2, S. 562 Nr. 1304, die Urk. vom 27. Dez. 1283; siehe die Deutung Graebners 1. c. 41, 582. Dann die Urk. vom 27. Jan. 1288, Emler, R. B. 2, 617 Nr. 1430). Wenn wir auch glauben, daß vielleicht die politischen Momente und neue Gruppierung des Adels wach 1278 bei dem Übergange Dietrichs die größte Rolle spielten, konnte nicht seine Verwandtschaft mit Z. wenigstens den Weg ebnen helfen?

Im J. 1284 besetzten die Anhänger Z.'s die Änter; den Namen Dietrichs finden wir jedoch micht unter den neuen W ürdenträgern $\left.{ }^{1}\right)$; er fehlt auch in der Liste der Vordermünner der Partei Z.'s (Emler, R. B. 2, 569 Nr. 1316). Eine Funktion erlangte er m. E. erst in J. 1287 oder 1288; wir schließen es aus dem Umstande, daß. er am 27. Jänner 1288 am Hofe weilt und zwischen den Würdenträgern angeführt wird. Er verwaltet wahrscheinlich das Burggrafenamt in Frimberg (Přimda); sicher hat er es erst vom 10. Jänner 1289 inne (vor ihm ist im J. 1286, Febr. 28, ,Beneda de Trebl' als ,purchravius in Phreymperch genannt. Emler, R. B. 2, 591, Nr. 1373). Mit den Staatsstreiche, der um 1288/89 den allmächtigen Z. zum Sturze brachte, hat Dietrich seine Karriere nicht geschlossen. Er hat wieder seine Partei gewechselt (u. zw. nicht allein) und sich seinen frïheren Genossen aus der Zeit Ottokars angeschlossen. Seine Dienstfertigkeit der neuen Regierung gegenüber wurde auch belohnt: er hat sein Amt behalten (so wie auch andere Herren), möglich, daß er es ersi jetzt bekam. Laut der Urkunde vom 10. Jänner 1289 ist er als Burggraf in Frimberg bestellt (Emler, R. B. 2, 630 Nr. 1466) und auch bei Hofe tritt er öfters auf: beim

1) In Emler, R. B. 2, 617 Nr. 1430 (vom 27. Jänner 1288) und in dem Formelbuche des Bischofs Tobias Nr. 28 (die Urk. ist von Novák zu 1288 datiert! tritt zwar ein „Theodericus subcamerarius« auf. Man könnte vermuten, daß Spatzmann seine alte Würde aus der Zeit Ottokars wieder erlangt habe. Dennoch ist rieser Schluß nicht richtig; in der Urkunde bei Emler werden als testes zwei Theoderici hintereinander genannt: Theodericus subcamerarius regni Boh., Ditricus Spazmanus etc. (die Interpunktion Emlers halte ich für unrichtig!). Daraus ist ersichtlich, dab es sich um zwei Personen des gleichen Vornamens handelt und dab es nicht Spatzmann war, der das Unterkämmereramt bekleidete. Der Theodericus subcamerarius verschwindet mit dem Sturze Z.'s rom Hofe; am 10. Jänner 1289 rimut seine Würde Beneš von Wartenberg ein (Emler, R. B. 2, S. 630). Spatzinann verbleibt dagegen ain Hofe. 
Gerichte, welches Hermann, den Sohn Hroznatas (seines Schwagers) ,propter excessus ${ }^{6}$ zum Verluste der Güter verurteilte ${ }^{1}$ ), war er sogar Beisitzer (Emler, R. B. 2, 727). Im 0ktober 1291 ist er noch als Burggraf der Grenzburg in der Angelegenheit der böhmisch-bayerischen Grenzräubereien zum Schiedsrichter erwählt worden (Emler, R. B. 2, 667 Nr. 1554). Seit dieser Zeit verschwindet er aus den Urkunden; zum letztenmale wird seiner nach vier Jahren gedacht. Die Schenkungsurkunde Wenzels II. an den Prager Bischof Tobias vom 11. Aug. 1295 erwähnt ihn als den ehemaligen Beisitzer des hohen Gerichtes über Hermann [ron Husic] Theodoricus, dictus Spaczmannus, in Frimperch tun c purcravius (Emler, R. B. 2, 727). Aus dem Wortlante geht hervor, daß er damals noch lebte, aber das Burggrafenamt in Frimberg verwaltete längst ein anderer $^{2}$ ). Das ist die letate Spur von $\mathrm{ihm}^{3}$ ).

Noch eine Frage ist zu beantworten: wie stellt sich der steierische Dichter zu dem Schicksale Dietrichs (und Hroznatas) nach 1287/8? Er berichtet: Wenzel habe, um den Sturz Z.'s einzuleiten, für seine Absicht die Gegner Z.'s, aber auch seine Freunde und Verwandten gewonnen. (Vers 20417.) Unter den Herren, welchen es zur Aufgabe gemacht wurde, sich der Person Z.'s zu versichern, waren sogar drei seine Schwäger (20519). Diese Schilderung muß nicht bis auf die letzte Silbe richtig sein, aber auf Dietrich Spatzmann, sowie auch auf andere Freunde Z.'s paßt sie vollkommen.

Das Resultat, welches wir durch die schwierige und umständliche Untersuchnng des ganzen Materials für die Rchr. gewonnen haben, läßt sich kurz wie folgt formulieren: Die Angabe 0.'s betreffs Hroznatas von Husic ist glaubwürdig und kann in den historischen Darstellungen ohne Vorbehalt verwendet werden. Was Dietrich Spatzmann anbelangt, wissen wir wenigstens das bestimmt, daß keine der heute bekannten Quellen

1) ,Excessus 6 bedentet den südböhmischen Adelsaufstand, der im J. 1288 wegen der Gefangennahme Z.'s ausgebrochen ist.

2) „Tunc (d.h. im J.1290/91) purcravius «. - Als Beisitzer wird z. B. auch Thobias, in Bechin tunc purcravius genannt, welcher seit 1292 den Titel: Thobias de Bechin, burcgravius de V roburg führt (Emler, R. B. 2, S. 679, 1198). Einige Beisitzer sind mit ,quondam bezeichnet; diese dürften im J.1295 schon tot sein (Purchardus de Winterberch und Sdezlaus de Sternberch). Denn nach 1290 verschwinden sie vollkommen aus den Urkunden.

3) In dem Formelbuche Zdenkos von Třebíc befindet sich eine Urkunde, durch welche König Wenzel II. Albert, Oberstkämmerer in Böhmen, villam Kralowitz, quam olim Theodricus Spatzmannus possedit, zu Eigen schenkt (Emler, R. B. 2, $1025 \mathrm{Nr}$. 2360). Sie ist leider schwer verwendbar, da sie undatiert ist und die Personennamen des Formelbuches vollkommen unverläßlich sind (vgl. Novák, Formuláŕ biskupa Tobiáše z Bechynè, Einl. 31). 
der Rchr. widerspricht. Die Angabe 0.'s dürfte sicher noch in dem Verhalten und in der politischen Stellung Dietrichs während der Jahre 1278-88 eine gute Stütze finden, falls unsere Untersuchung, welche, wie wir gut wissen, keine endgiltige Lösung gebracht hat, durch weitere Spezialforschungen bestätigt würde.

Die Nachricht 0.'s steht in der Geschichtsschreibung vereinzelt da. Wo stammt sie her? Hat 0. von den genannten Herren erzählen gehört, oder hat er eine heute unbekannte schriftliche Aufzeichnung verwendet? Die erste Möglichkeit scheint mir - vom Standpunkte der bisherigen Forschung - durchaus unwahrscheinlich. Ein steierischer Ritter, von dem wir nicht einmal sicher wissen, ob er das Land Böhmen je besucht hat, und mit den Böhmen in Verkehr gekommen ist, dürfte kaum die Familienbeziehungen Z.'s kennen und uns zwei bestimmte Namen überliefern, welche selbst der einheimischen Geschichtsschreibung völlig entgangen sind, zumal in der Zeit, als er die Chronik schrieb und die verschiedensten Geschichten in Verse zu bringen bemüht war (vor 1308), die Person Z.'s in den Hintergrund getreten ist. Wir finden die Witigonen wieder am Hofe und in den Ämtern ${ }^{1}$ ). Eine neue Generation ist inzwischen erwachsen, neue Leute aufgekommen. Wenn nicht Herr Hroznata, der doch eine bedeutende Rolle spielte und dann hart bestraft wurde, so war Dietrich schon längst vergessen und wahrscheinlich tot. Nach meiner Ansicht trifft eher die Vermutung zu, daß 0. eine schriftliche Aufzeichnung rorlag, die den Ereignissen zeitlich und örtlich näher (als 0 .) stand.

Vers 18329-18339. „Die anderen Suppane, die sich durch Z. beschädigt fühlten, habeu beim König Rudolf Zuflucht gesucht und ihn gebeten, Z. zu beseitigen ${ }^{2}$ ). Für Rudolf ist jedoch noch nicht der ent-

1) Die Königsurkunde vom 6. Januar 1301: Henricus de Rosenberc, fidelis: noster, nunc camerarius regni nostri. Emler, R. B. 2, 805 Nr. 1872 ; ibidem 823, Nr. 1914, die Urk. vom 8. April 1302.

2) Z. wird der Titel ,meizoge erteilt. S. gibt im Glossar an, daß das Wort ,den Erzieher ${ }^{\star}$ bedeutet. Die Stellung Z.'s am Hofe hatte sicher eine gewisse Ähnlichkeit mit dem Berufe eines Erziehers, Z. war doch der Stiefvater des Königss und die Kgs. Chr. berichtet, er habe Wenzel Ritterspiele gelehrt (Kap. 18), und Wenzel wird als sein ,alumpnus، (Kap. 21) bezeichnet. Aber Z. war unvergleichlich mehr, obwohl er kein bestimmtes Amt bekleidet hat (vgl. Šusta, l. c. 293 - ,nezastávaje úřadu, vládl všemi‘). Das böhmische Gedicht (Král Přemysl Otakar a Záviše) nennt ihn - das Wort und der Begriff gehören dem 15. Jahrh. an - Landeshauptminn (F: R. B. 3, Seite 242). Von Palacký rührt die Bezeichnung Obersthofmeister her; Pangerl sagt dazu: er war in der Tat ein solcher und z; ar in viel weiterem Sinne, als welchen wir heute dieser Würde beimessen. I. c. 171. 
scheidenle Moment gekommen. ,Ez geschach aber sît, dô sîn stat was" ".

Die Kgs. Chr. berichtet: „Zewischius ... barones Bohemie, qui prius negociis regni prefuerant, clam palamque non fuit veritus persequendo turbare; ... cunctos officiales, quos in curia reperit, de suis amministracionibus removens, familiares suos eisdem in officiis subrogavit (Kap. 18). Quidam de curia regem [Wenceslaum] adierunt et non tantum destruccionem regui, verum eciam cororruptam erga eum intencionem Zewischii sibi nanrraverunt (Kap. 22). Sie beschuldigten Z., daß er dem Leben Wenzels nachstelle.

Von dem Eingreifen König Rudolfs in die böhmischen Verhältnisse ist dem Kgs. Mönch nichts bekannt. Auch den übrigen Quellen ist dies fremd geblieben, mit Ausnahne der Urkunden. Sie bestätigen, daß die Gegenpartei Z.'s bei Rudolf Zuflucht suchte und daß Rudolf ihr seinen Schutz micht versagts. Sie sagen noch mehr als 0.: In Böhmen ist ein wirklicher Bürgerkrieg ausgebrochen, in welchem die Partei Z.'s die Oberhand gewonnen hat. In diesem Moment erschien König Rudolf auf dem Kampfplatze: Er zwang Wenzel und die Witigonen zur Einstellung des Kampfes; Wenzel versprach für sie und für sich: „treugas servare secundum statuit eas dominus Rudolphus, rex Romanorum “ (Emler, R. B. 2, 565 Nr. 1311; April 1284). Rudolfs schützende Hand greift noch weiter ein. Wenzel wird dazu vermocht ,correccioni Rudolphi Rominorum regis" sich zu fügen, "wenn er einen der bisherigen Gegner ungerecht behandelte-1). Rudolf hat sich in Böhmen eine Art von Klientel geschaffen (die Tendenz war gegen $Z$. gerichtet), an deren Spitze Bischof Tobias und Herzog Nikolaus von Troppau standen²). Die Frïchte dieser Verbindung sind jedoch erst nach vier Jahren reif geworden. 0 . hat angedeutet (ez geschach aber sît etc....), daß er auf Rudolf und diese Geschichte noch zurückkonmen wird. An dieser Stelle werden wir auch auf die Darstellung näher eingehen.

1) Emler, R. B. 2, 980, Nr. 2256. „omne ociium adversus barones et nobiles nostros, Purchardum [de Winterberg] et ceteros amicos ipsorum ... abolentes, restituimus eos nostre gracie, promittentes eis, quod ipsos universaliter et singulariter in sinu nostri favoris fovebimus et curabimus gubernare ... quod si forte predicta non observabimus, tune correccioni domini et patris nostri d. Rndolphi Rom. regis volumus subiacere ". Der Name Burchards beweist, daß unter den Gegnern Wenzels, welche jetzt unter dem Schutze Rudolfs stehen, die Gegenpartei Z.'s zu verstehen ist. Die Urkunde ist dem Formelbuch des Heinricus Italicus, das von Voigł. herausgegeben wurde, entnommen. Das Formelbuch bringt verläBliche Stücke.

2) Vgl. Graebner, l. c. 41, Seite 580 ff. 
Vers 18340-18357. Charakter Wenzels. „Wenzel, obwohl jung, war klug und weise. Ihm war, wie er später gezeigt hat (18352) zuwider, daß seine Mutter und Z. ,mit sînem guote wurben nach irem muoté. Äußerlich trug er eine gleichgiltige Miene zur Schau, innerlich hegte er aber Ingrimm ${ }^{1}$ )..."

Der Herausgeber weist auf die Kgs. Erzählung (Kap. 17, 21, 22) als die Quelle 0.'s hin (S. 243, Anm. 2). Der Hinweis ist insoweit richtig, als die Kgs. Chr. wirklich die Natur Wenzels ähnlich charakterisiert, aber in der Auffassung und Motivierung zeigt sich eine unüberbrückbare Divergenz, welche eine direkte Abhängigkeit ausschließt. Zum Vergleiche sollen die betreffenden Partien der Kgs. Chr. angeführt werden:

Kap. 17, (3. 66), die Schlußverse: hoc rogo, scire velitis, quod iuvenes dudum servant in pectore ludum, quem tune luserunt, pueriles quando fuerunt -- (allgemein gehalten).

Kap̣. 21, (Seite 72): Záviš war ein Heuchler; er stellte sich Wenzel gegenüber als ein wohlwollender Pflegevater und im Geheimen trachtete er nach seinem Leben.

Kap. 22: Das Verhalten Wenzels war bloß eine Gegenwehr. Lir war über die Pläne Z.'s durch einige Hofleute unterrichtet, jedoch war er unentschierlen — adhuc puer et tenellus —, wie er sich ihm gegenüber verhalten soll. 0 puerilium annorum hand facile evadenda anxietas! 0 iuvenilis cordis absque dubio dampnosa perplexitas! - ruft emphatisch der Kgs. Mönch. Endlich ist Wenzel auf den Gedanken gekommen eine Maske zu gebrauchen: äußerlich freundlich und liebenswürdig, innerlich bereitet er Z. das Verderben.... So haben beide zusammen den mährischen Feldzug (der näher in dem Kap. 22 beschrieben wird) mitgemacht.

Diese Schilderung sticht von der O.'s in folgender Weise ab:

\section{Ottokar.}

Kunigunde lebt und wird auch auf die Szene gebracht.

\section{Die Kgs. Chr.}

Die Königinmutter wird in der Kgs. Chr. nicht mehr erwähnt. Sie ist im J. 1285 gestorben — ihr Tod und

1) Die Österreichische Chronik vonden 95 Herrschaften, früher Hagen (hrg. in M. G. Deutsche Chroniken 6, 1909 von Seemüller), welche aus der Rchr. einen Auszug gibt, schreibt wie folgt: „Chünig Wenczla, der jung von Pehaim weisleich verdekchet allen sein unmit, den er het gen seiner mutter, umb das, daz si het genomen den Z. und daz sy umb gieng mit seiner hab, wie .sei gelustet«. Die Chronik von den 95 Herrschaften sagt mehr, als die Rchr. enthält. Dieses Plus darf man nicht als ein Mißverständnis der Vorlage erklären, denu ähnliches berichtet auch Dalimil (F. R. B. 3, 200. Do slug er (Wenzel) Zawissio ab durch der mutter willin sin houbt). Lag vielleicht dem Verfasser eine andere Handschrift der Rchr. vor? Als ein Mißverständnis dürfte wohl bezeichnet werden, woranf' S. in der Chronik von 95 Herrschaften, S. 137, Note 294 aufmerksam inachte. 
Begräbnis werden in einem der vorangehenden Kapitel (Kap. 19) geschildert.

Wenzel zürnte, daß Z. und sie sich daß königliche Gut anmaßten.

O. weiß gar nichts von dem Feld-

Die Pläne Z.'s gegen das Leben des jungen Königs und dessen Furcht waren die Ursache, daß er sich verstellte. Gemäß der Kgs. Chr. (nicht der Rehr.) ist er noch ein Knabe, kindlich unfertig und ängstlich. zuge Z.'s und Wenzels nach Mähren.

Beide Berichte, bis auf die eime Beobachtung, was den Charakter Wenzels anbelangt, weisen nichts Gemeinsames auf. Die Nebenumstände, die Bedingungen, welche die gleiche Wirkung hervorrufen, so wie die Einzelheiten, mit welchen die Erzählung ausgestattet wird, sind verschieden - in einem Falle stehen sie sich auch schroff gegenüber (das Leben und der Tod Kunigundens). Es ist nicht denkbar, daß 0. sich von der Kgs. Schilderung so völlig emanzipiert und nur das psychologische Moment erfaßt hätte. Beide Berichte sind von einander unabhängig; dennoch will ich nicht bestreiten, daß sie ein gemeins ames Motiv selbständig bearbeitet haben. Es wäre ein zu großer Zufall, wenn beide aus einem so verschiedenen Materiale auf denselben Gedanken gekommen wären. Auf welchem Wege er ihnen zugekommen ist (durch mündliche oder schriftliche Überlieferung?), läßt sich schwer entscheiden. Ich möchte eher der zweiten Möglichkeit beipflichten: außer dem gleichen Inhalte zeigt das Motiv auch dieselbe kompositionelle Verwendung: Es ist vorausgenommen, um den Fall Z.'s vorzubereiten. Seinem zeitlichen Ursprunge nach sollte es erst nach der Erzälllungr von der Gefangennahme Z.'s, resp. von seiner Hinrichtung (im J. 1290) eingereiht werden. Denn erst damals konnte die Welt sehen, daß die Liebenswürdigkeit Wenzels nur eine Naske war, hinter welcher er seine Befürchtungen und seine Pläne verbarg; erst von diesem Angenblicke an war ein Beobachter im Stande, das Verhalten des jungen Königs als Verstellung zu charakterisieren und deshalb ist die Erzählung vom Charakter Wenzels frühestens im J. 1290 entstanden. Wenn die beiden Chronisten sie zu diesem Jahre gebracht hätten, wäre es logisch und kaum auffällig. Aber sie haben dieselbe gemeinsam in die Jahre 1284 bis 1287 vorgeschoben. Sind beide selbständig auf die Idee geraten, den causalen und chronologischen Nexus der Schilderung aufzulösen und einen Teil davon vorzuschieben, um eine erzählerische Wirkung zu erzielen? Nein; ich glaube vielmehr, daß sie beide ein gemeinsames 
Schema, welches schon auf eine literirische Behandlung des Stoffes schließen läßt, übernommen haben.

\section{Verse $18358-18419$. (Vgl. auch Verse 18292-18305).}

„Die Königin gebar Z. einen Sohn, namens Johann. Der Vater hegte den Wunsch, ihn als Markgrafen von Mähren zu bestellen. Die Königin, welche Wenzel nicht sehr geneigt war, wollte sich seiner durch Vergiftung entledigen 18371 , daz si sicherlich mit dem kunicrich den Z. möbte gemieten'. (Der Gedanke kommt sehon $18292 \mathrm{ff}$. vor.) Die Pläne Z.'s gingen nicht so weit; warum, ist schon 18300 gesagt: swie gerne si [die Königin] bet daz getân, dô [doch] enmoht sîn niht geschehen, wand man muos in Bêheim sehen manigen hôhen herren, fler an guote und an êren wol was sîn [Z.'s] ebeu genôz. - Z. wehrt sich gegen den Vorschlag: daz sol iu got verbieten! - sagt er der Königin. Ich weiß, daß alles, was ich jetzt besitze und was ich bin, nur meiner Stellung als Stiefvater zu verdanken habe (18376 - daz geschiht wan von sinen wegen). Wenn Wenzel sterben sollte, ,daz lantvole zehant wurbe daz wir [er und die Königin] wurden verstôzen von disen êren grôzen die wir haben von im'. Kunigunde erwidert 18336 , Z. werde, wenn Wenzel groß geworden sei, seine jetzige Schwäche bitter bereuen, denn Wenzel sei zwar liebenswürdig, aber das sei nur Verstellung. 18392 kumt er immer darzuo [irgend einmall, er erzeiget uns haz. Z. tröstet sie mit Hinweis wuf seine große Macht, die ihn gegen jeden Unfall schütze. Mit Laien wie mit Geistlichen habe er vorteilhafte Bündnisse geschlossen, die Burgen seien in seiner Gewalt, so diß er ,vor allen gesten vertribens sicher sei $^{‘} 1840$ 2. Da die meisten Großen des Landes ihm wohl gesinnt sind, brauche er sich nicht ausschlieflich auf seine Sippe zu stützen ${ }^{1}$ ). 18409 ,darumbe sî dir unmaere, ob er hiut gekrônet waere, er müeste mich für guot haben.

Guoten trôst si an einander gâben,

mit hûse wâren si ze Prag.

Dann geht $0 . \mathrm{zu}$ den österreichischen Angelegenheiten über (Übergangsformel $18414-24)$.

Diese lange Schilderung lüßt sich in einige Motive auflösen:

Die Erzählung über den Sohn Z.'s und Kunigundens. 0. kommt noch auf ihn und sein Schicksal zurück; bei dieser Gelegenheit werden wir zusammenfassend über ihm handeln und das Verhältnis 0.'s zur Kgs. Chr. prüfen.

Es wird gesagt, daß Z. seinen Sohn Johann zum Markgrafen von Mähren zu erheben wünschte (18362ff.). Eine recht merkwürdige Erzählung, aber sie ist nicht aus der Luft gegriffen. Wir können eine Nachricht ähnlicher Gattung nachweisen, welche auch in den Urkunden eine teilweise Bestätigung findet. Die erste Druck-

1) Z. sagt stolz 18404 ,Ouch gaeb ich niht ein kicher umb mîne hûsgenôzen, wand swaz man siht der grôzen, di sint mir almeiste holt'. 
ansgabe der Chronik Dalimils vom J. 16201), welcher eine jetzt unbekannte Handschrift zu Grunde lag, so wie auch die Ausgabe (der deutschen Übersetzung Dalinnils) von Pez nach der Handschrift Christof Hoffmimns2), enthalten folgenden Passus:

Tehdy králová za Záviši jsúci snide, Dieselben czeyt starb die kungynne, ¿ Závišr tak vysoko vznide, že poje die den Z. genommen hatte. Und sestru krále uherského $\mathrm{i}$ pisášse sě darnach steigt der Z. also hoch auff, knízem knožstra moravského. das er nam des kunges von Ungern Proto Záviši knirz hlıvu spudi. (F.R. B. 3, Seite 200.) fur einen fursten von Merhern. Und darumb lis yn der kunig kopfen. (F. R. B. 3, Seite 293.)

Was bedeuten die Anspielungen 0.'s und Dalimils anf die Herrschaft Z.'s in Mähren?

Als König Ottokar fiel und Otto von Brandenburg gemäß der Einigung zu Sedlec im Oktober 1278 Böhmen verwaltete, hat die verwitwete Königin in Troppau Zuflucht genommen (im J. 1279) ${ }^{3}$ ). Sie hatte an Troppau gewisse Besitzrechte gehabt, die sie dort schon zu Lebzeiten ihres Gatten genoß)4, vielleicht wurden sie ihr erst durch die Verabredungen in Sedlec zugestanden ${ }^{5}$ ). In Grätz bei Troppau hielt sie Hof und als - domina terrae Oppaviae - sammelte sie den Adel um sich and hat das Land verwaltet ${ }^{6}$ ). Aber sie war nicht die alloinige Herrin des Landes. Neben ihr genoß dort gewisse Rechte Nikolaus, der illegitime Sohn Ottokars (Palacky 26, 116, Dudík 7, 22). In der Schlacht bei Dürnkrut wurde er gefangen genommen und in Ungarn zurïckgehalten. Im J. 1280 oder 81 kehrte er heim und setzte sich in Troppau fest (Graebner, 1. c. 41, 330; Novák l. c. 54). Das Troppauer Ländchen hatte jetzt zwei Herren, die um ihre Besitz- und Hoheitsrechte in einen heftigen Streit gerieten. Die Situation mußte sich verschärfen, als Kunigunde den Sohn Johann gebar, welcher als Erbe ihres Rechtes gelten konnte. (Die Ehe ist durch die offizielle Eheschließung im Jahre 1285

1) Jireček in F. R. B. 3, Einl. S. 15.

2) Pez, Scriptores rerum Austriacarum 2, 1045 ff. (vom J. 1725); neu in F. R. B. 3, $257 \mathrm{ff}$. Die pehemische Cronica dewcz.

3) Graebuer 1. c. 41, 317; Novotný l. c. 35, Anm. 1.

4) Palacký 20, 116.

5) Boehmer-Redlich: Reg. 1022; Emler, R. B. 2, 496, Nr. 1154. Die Urkunde ist nur als Formel in Codex Treverensis (hrg. von Bodmann) erhalten, der aus dem Anfange des 14. Jahrhunderts stammt und zur ersten Redaktion der Formelbticher aus der Zeit Rudolf́s gehört. Vgl. Kretzsch mar: Die Formularbücher atis der Kanzlei Rudolfs von Habsburg S. 9.

8) Graebner, l. c. 41 , S. 317 ; Novák, l. c. 49. 
— vgl. Novotný, l. c. 39 Anm. 3 - rechtskräftig geworden. Z. drïngte sicher darauf, wie wir es zwischen den Zeilen der Kgs. Chr. Kap. 18 lesen können.) Im Jahre 1285 wurde der Zwist provisorisch beigelegt und dem Herzog Nikolaus auf drei Jahre der ruhige Besitz der Provinz verbürgt (Graebner, l. c. 41,585 ; Novák, l. c. 149, vor 23. April 1285). Nicht lange danach ist die Königin gestorben (1285, Sept. 9; vgl. Novotný, l. c. 42 Anm. 4). Damit ist die Sache noch komplizierter geworden: neben der Frage des Anrechtes Kunigundens an Troppau ist eine neue hinzugetreten, ob ihre Besitzrechte auf ihren Sohn Ješek und mit ihm auch auf Z. übergangen sind 1 ). Das war wenigstens die Meimung Z.'s; denn, als die dreijährige Friedensfrist verfloß, hat ex sich am ungarischen Hofe, als er um die ungarische Prinzessin warb, ,dux de Opavia tituliert $^{2}$ ) und damit kund gegeben, daß er auf seine Rechte nicht verzichten wolle. Tatsächlich verblieb Nikolaus im Besitze des Landes und hat ihn innerlich wie äußerlich zu festigen gesucht: er zog den Landesadel an $\operatorname{sich}^{3}$ ) und gewann die Unterstützung Rudolfs, indem er seine Verwandte zur Frau nahm4). Wie sich die rechtliche Frage weiter entwickelt hätte, ist schwer zu sagen, denn bald danach vereitelte das Schicksal Z. alle seine Pläne; er wurde gefangen und auf den Richtplatz geführt. Sein Sohn ist dann der Stiefmutter abgenommen und wie berichtet wird, in die Fremde geschickt worden.

Das Land Troppau war im 13. Jahrhundert ein fester Bestandteil der Markgratschaft Mähren; zu einem Herzogtum hat es Kaiser Karl IV. (durch die Privilegien vom 7. April 1348 und vom 26. Dez. 1349) erhoben. Er hat das Verhältnis des Landes zu Mähren und Böhmen formuliert. Von da an bildet es auch juristisch ein Ganzes - aber stets in den Grenzen Mährens ${ }^{5}$ ).

1) Die zitierte Formel bei Emler, R. B. 2, Nr. 1154, durch welche der Kunigunde die Einkünfte aus Troppau in der Höhe von 300 Mark Silber zugewiesen wurden, enthält keine näheren Bestimmungen. Damals hat man jedoch nicht gedacht, daß sie noch heiraten und einen Sohn haben werde.

2) und sich auch titulieren lassen vgl. Mon. Hung. His tor., Diplomata 17, S. 471. Die Urk. vom 5. Juni 1280: "Nos Ladizlaus rex Hungariae . . ad peticionem et instanciam domini Zawissii, ducis de Opauia, karissimi generis nostri te donine Elizabeth, consortis eiusdem, sororis nostre ... possessiones dominarum de Insula (confirmamns)“. Hierher gehört chronologisch auch die Nachricht Dalimils.

s) Grabner, l. c. 41 , S. 332 .

4) Boehmer-Redlich, Reg. Nr. 1882: Graebner, l.c. 41, 584 .

5) Die Daten sind dem Werke Kalouseks, Ceské státní právo, S. 78 eutnommen. - In späteren Zeiten hat sich Troppau vollständig seinem Mutterlande entfremdet und wurde in die Verwaltung Schlesiens einbezogen. Im J. 1567 wurde es provisorisch, 1613 und 1622 definitiv und für immerwährende Zeiten Schlesien 
Wenn sich also Z. im Dalimil den Titel Herr von Mähren aneignet und nach der Rchr. seinen Sohn zum Markgrafen von Mähren erheben will, so liegt dem vielleicht ein Gerücht zu Grunde, zu welchen die Bemühungen Z.'s um Troppau (so wie auch sein Titel ,dux Opauie') den Stoff geboten haben ${ }^{1}$ ). Es ist jedoch auch möglich, daß Z. mit den Praetensionen auf Troppau wirklich eine ähnliche kühne Absicht verband - oder die Leute es wenigstens glaubten. Dann wäre auch seine Gefangennahme und sein Tod leichter erklärbar²).

Auf eine nähere Untersuchung der Sache kann ich nicht eingehen (Graebner ließ das Moment völlig unbeachtet). Ich wollte nur zeigen, daß die Nachricht 0.'s keineswegs aus der Luft gegriffen ist. Sie findet in einer Chronik eine Variante und in den Urkunden eine teilweise Bestätigung. Die Kgs. Chr. (und andere Quellen) bringen nichts derartiges, und die Nachricht Dalimils wird wieder anders eingeleitet. 0 . ist hier eine selbständige Überlieferung vorgelegen.

Die Königin wollte ihren Sohn vergiften. Z. hat ihr abgeraten. Das Motiv der Ermordung Wenzels spielt auch in der Kgs. Chr. eine und zwar große Rolle, aber auf eine andere Art und Weise. Die Königin ist hier schon tot, von Wenzel und von Závis gleich beweint $\left.{ }^{3}\right)$. Deshalb wird sie in die Erzählung nicht einbezogen. tuf den Gedanken Wenzel zu ermorden sei Z. selbst gekommen. Äußerlich heuchelte er väterliche Liebe, gleichzeitig suchte er aber den passenden Moment, W. aus dem Wege zu räumen ... occultus insidiator, qui hoste manifesto crudelior aestimandus est ${ }^{4}$ ). Weun 0. die Kgs. Chr. benützt hätte, würde er kaum deren weitläufige Darstellung in solcher Weise auf den Kopf gestellt haben: die tote Königin als lebend vorzuführen, von Z. auf sie die Schuld zuschieben und ihn, den bösen insidiator, der in der Kgs. Chr. mit wenig schmeichelhaften Namen bedacht ist, als den Retter Wenzels hinzustellen! Eine solche Verdrehung

einverleibt. Vgl. auch Prasek, Dějiny kraje Holasovského či Opavského. Vlastivèda slezská 3 , Abt. $1 \mathrm{~S} .65 \mathrm{ft}$.

1) Auf diesen Gedanken ist zuerst Palacký in der zitierten Abhandlung "O panu Zúvišovi z Rosenberka« gekommen (Spisy drobné 2, S. 51).

2) Dalimil sagt: Z. begunt sich czu schreiben fur. einen fursten von Merhern. Und darumb lis yn der kunig kopfen. - F. R. B. 3, 293, erste Spalte.

s) Die Kgs. Chr., Kap. 19.

4) Die Kgs. Chr. Kap. 21 „Ammirari nimirum ad plenum non sufficinus, dum Z. regi Wenceslao tam affabilium osculorum, tamque familiariun amplexuum blandiciis aplandere, sibique illudere apparenter cernimus, quem tamen sue vite occultas insidias demoliri, fama volante publica invenimus". 
der Vorlage halte ich für ausgeschlossen ${ }^{1}$ ). 0 . hatte auch keinen Grund hiezu ${ }^{2}$ ). Er ist ein fremder Beobachter, örtlich und zeitlich von den Begebenheiten entfernt. Er hatte kein Interesse, Z. oder die Königin in das Licht oder in den Sehatten zu stellen - und er ist es auch nicht allein, der in diesem Sinne spricht. Wir verweisen auf die bayerische Fürstenfelder Chronik, die 0 . viel näher steht als das Chronicon Aulae regiae. Sie erzählt (F. R. G. 1, Seite 9):

Sic regina [Kunigund] de morte regis [des Gatten] non contenta, tractat de parricidio, filio suo non parcens. Et ecce rex iunior subito incipit infirmari et divulgatur hec infirmitas in populo .... Vocantur medici ... nos vero scolares excurrimus et montem [Hradschin] conscendimus; intrantes aulam regiam vidimus ibidem regem suspensum per pedes et resupinum submisso capite, ut ab intimis visceribus efflueret, quod inbiberat vel gustaverat toxicatum. Seite 27 wird der Gedanke wiederholt: Wenzlaus ..., qui in adolescentia sua a matre fuerat intoxicatus, sed tunc salvatus a morte -

Die Erzählung des Fürstenfelder Mönches, hat durch die persönliche Färbung (die Erinnerungen aus der Studienzeit?) einen gewissen Grad der Glaubwürdigkeit bekommen; man wäre nicht abgeneigt ihm zu glauben, daß in Prag ein solches Gerücht von der Königin (aber nicht von Závišs) ${ }^{3}$ ) verbreitet war - dennoch ist diese Schlußfolgerung mit

1) Die Gruppe A. bietet ein lehrreiches Beispiel, wie die Schilderung O.'s ausgefallen wäre, wenn sie auch durch die Kgs. Chr. beeinflubt wäre.

2) 0 . findet zwar an Z. einen Gefallen, welches ihn jedoch nicht hindert, später ebenso unparteïsch vom Hochverrat Z.'s gegen Böhmen zu erzählen. Vers 20.265.

8) Otto von Thüringen leitet seine Erzählung mit den Worten ein, daß sie auf aller Lippe sei. Kap. 21: ... incomperte dolositatis quedam machinamenta comperio ... Hec namque formidine tactus nequaquam describendo proderem, si hec eadem lippis et tonsoribus iam cognita voce murmurantis populi non audirem ... etc. Diese Einleitung erinnert an Horatius, Sat. I., 7, 3 (Vgl. Norotny, l. c. 45, Anm. 1) und trägt nicht viel zur Glaubwürdigkeit des Erzählten bei. Es wirkt auch befremdend, daß keine von den zeitgenössischen Quellen von dem Plane Z.'s gegen das Leben Wenzels, ,der auf aller Lippen gewesen sein soll', unterrichtet ist. Die Kgs. Chr. und die von ihr abhängigen Erzählungen haben den ganzen Gang der Geschichtsschreibung (in einem für Z. ungünstigem Sinne) bis in das 19. Jahrhundert bestimmt. Erst Palacký (Würdigung 137 ; vgl. D. N. C. $6^{6}$, S. 160) und nach ihm andere, auch Loserth (A. Ö. G. 51, 466) haben mit der Überlieferung gebrochen und die Glaubwürdigkeit der Kgs. Chr. erschüttert. Man hat diesen Teil der Arbeit Ottos als den schwächsten bezeichnet..., er wußte sich nicht einmal von den lächerlichen Märchen frei zu halten (Bachmann, l. c. Band 36, 281.) Wenn jemand eine Veranlassung hatte, an der ursprünglichen Überlieferung etwas zu ändern, so war es der höfische Dichter, der Schreiber der Wenzelslegende - der Kgs. Chronist. Wir sind im Stande ein Beispiel vorzuführen. Bachmann nimmt an, daß der Kgs.-Erzähler die Wiener Kontinuation 
Vorsicht anzuwenden. Man darf nicht, der persönlichen Erfahrung' des Fürstenfelder Mönches so ohne weiters ganz Glauben schenken. Die Erzühlung von der Vergiftung Wenzels knüpft sichtlich an den Bericht von dem Tode Ottokars an. Die Königin befreite sich von dem Gatten und nun ist ihr auch der Sohn lästig. Der Fürstenfelder Mönch führt da den Gedanken weiter, der, wie wir vermuten, aus einer verlorenen Erzählung äbernommen ist und in einer gewissen Umbildung auch in der Rehr. eine Rolle spielt. Das Motiv von der Vergiftung Wenzels könute derselben Quelle entlehnt sein. Dasselbe gilt für die Rchr. Selbst wenn aber diese Annahme durch die weitere Forschung nicht bestätigt werden sollte, sind - wie oben angeführt - doch genug andere Gründe vorhanden um die Vermutung S.'s als vollständig gegenstandslos zu betrachten 1 ).

Vers $18297 \mathrm{ff}$., swie [obwohl] si [die Königin] doch was dâmit gehônt, sô hiet si gerne gekrônt für den sun den mań...

Vers 18400 sagt Z. zu Kunigunde: ,ouch hân ichz geschicket in dem land alsô mit vesten, daz ich vor allen gesten vertrîbens bin sicher etc.... darumbe sî dir unmaere, ob er hiut gekrônet waere, er müeste mich für guot haben'.

Der Sinn dieser Anspielungen liegt m. E. darin, daß Z. (oder die Königin) die Krönung Wenzels, welche bevorsteht, fürchtet. Sie soll das Ende des Regimes Z.'s bedeuten. Es droht ihm auch eine Gefahr von den ,gesten' (die junge Brant Wenzels, ihr Gefolge?); trotzdem betrachtet er seine Stellung als gesichert; der Landesadel ist ihm geneigt und die befestigten Plätze befinden sich in seiner Hand.

kannte und benützte (1. c., S. 273). In ihr hat er den bekannten Passus gefunden, da. die Königin den Gatten zum Kriege gereizt hatte; er hat ihm folgende Gestalt verliehen:

Cont. Vindob. ad a. 1277. (SS. 9, Die Kgs. Chr., Kap. 8, S.49. Otto708.) Rex Boh. Otocarus graviter ferens carus rex reversus in Boh. praedictas terin corde suo, regina quoque Boemie ras se resignare doluit et quorundam sua frequenter eum increpans, quod terras suorum animatus consiliis, ipsas predictas resignaverat etc. recuperare aut omnino perire decrevit.

Wenn sich die Annahme Bachmanns als richtig erweist, sind wir daraufhin zu der Annahme berechtigt, daß der Kgs. Abt auch bei anderen Gelegenheiten (im Falle Z.'s) die Überlieferung einer Umarbeitung unterzog.

1) Die Sache ist jedoch komplizierter, als dieser einfache Schluß erscheimen läßt. Obwohl ich behaupte, daß O. die Kgs.-Erzählung nicht gekannt hat und daß auch das ungekehrte Verhältnis kaum annehmbar ist, existiert doch zwischẹn beiden Erzählungen eine Übereinstimmung: in beiden Werken wird von der Verstellung Wenzels und von den Plänen zu seiner Ermordung - die beiden Motive stehen in einer sichtlichen Verbindung - in einem ähnlichen Zusammenhange erzählt. 
Die böhmischen Quellen berichten nichts von einer Krönung Wenzels, die noch vor dem Tode Z.'s (der äußerste terminus ad quem) stattfinden sollte - wie wir bereits wissen, wurde die Krönung Wenzels im J. 1297 vollzogen. Ebenso verhalten sich auch die reichsdeutschen und österreichischen Annalen - mit Ausnahme der Wiener Continuation 1). Wie wohl sie von der Krönung Wenzels im J. 1297 richtig und ausführlich referiert, bringt sie doch zu dem Jahre 1285 die folgende Nachricht: R[udolphus] rex in Egra sollempniter celebravit nuptias filie sue, quam tradidit filio domini Ottokari... quem eciam ibidem in rege em Boemie coronavit (SS. 9, 713). Es wird von mehreren Seiten belegt, daß in Eger in der Nacht vom 25. auf den 26. Jänner 1285 das feierliche Beilager König Wenzels mit Guta wiederholt wurde. Rudolf nahm aber seine Tochter wieder zurück (Redlich, Reg. 1877a). Von einer Krönung kann durchaus keine Rede sein; man kombiniert, daB Wenzel damals mit Böhmen belehnt wurde (Graebner, l. c. 41, 585), da er seither den bisherigen Titel (domiuus et heres regni Boemiae) in einen anderen (rex Boemiae et marchio Moraviae) umgeändert haben soll (vgl. Emler, F. R. B. 4, 25, Anm. 1). Diese Nachricht hat mit der Erzählung 0.'s nichts gemeinsames; 0 . ist von der Zusammenkunft in Eger, die den Inhalt der Nachricht ausmacht, nicht informiert und von Gutta spricht er ïberhaupt nicht.

J. Lo serth hat in A. Ö. G. (1878) Band 57, $463 \mathrm{ff}$. aus der Bibliothek des Prager Domkapitels ein Fragment eines Formelbuches veröffentlicht, das einige wertvolle Aktenstücke aus der deutschen Reichskanzlei enthält. Diesen Briefen entnehmen wir das interessante Faktum, daß die Krönung. Wenzels (und Guttas) schon für Pfingsten 1287 festgesetzt wurde (1. c. 471, 477-84; vgl. Redlich, Reg. 2089, 90, 91). Gutta sollte mit ihren Gefolge (familia) zu Pfingsten (am 25. Mai) in Prag eintreffen, um mit ihrem Gatten gekrönt zu werden und hinfort bei $\mathrm{ihm}$ zu verbleiben. Es waren schon Einladungen ergangen (Loserth, l. c. 477) - plötzlich scheiterte die Verhandlung. Guta ist erst zwei Monate nachher nach Prag gekommen und die Krönung erfolgte ein Dezenium später (Pfingsten 1297). Ich halte es für sehr wahrscheinlich, daß 0 . von diesen Märzverhandlungen zwischen Rudolf einerseits, Záviš und Wenzel andererseits unterrichtet war und daß er es Vers. $18297 \mathrm{ff}$. und $18400 \mathrm{ff}$. zum Ausdruck bringt. Auch die chronologische Einreihung spricht dafür. In der Fortsetzung der Geschichte Z.'s handelt 0 . gleich am Anhange von den Verhandlungen betreffs der Heimführung Gutas und von ihrer Ankunft in Prag (Juli 1287; vgl. Novotny, 1. c.

1) O. soll sie benützt haben. S. Einl. 59 . 
S. 43 Anm. 1.) Demnach wären die Anspielungen auf die Krönung Wenzels (18400ff.) vor März 1287 zu datieren. Der Umstand, daß die Königin Kunigunde noch als lebend dargestellt ist (obwohl sie schon im September 1285 gestorben war), spricht nicht dagegen. 0 . faßt die Sache so auf, als wenn sie erst kurz vor der Ankunft Gutas - in der ersten Hälfte 1287 - verschieden wäre ${ }^{1}$ ).

Z. fürchtete die, gesteb. Von der Ankunft Gutas und ihres Gefolges erwartete er etwas Ungünstiges für sich. In dem Formelbuche des Bischofs Tobias befindet sich ein Brief des Königs Wenzel an diesen, aus welchem hervorgeht, daß Wenzel das Gefolge Gutas von den Grenzeu Böhmens fernzuhalten wünschte (mandavimus de familia domine regine, consortis nostre, ut amoveretur ab ipsa) und erst später gestattete, daß es Guta nur bis nach Kaaden (Cadanum, am EgerfluB), begleite ${ }^{2}$ ). Wir werden kaum fehlgehen, wenn wir mit Novák (Anm. zur Formel 243) Z. als den Urheber dieser Verfügung bezeichnen und die Nachricht der Rchr. mit dem Briefe in Zusammenhang bringen.

Die Verhandlungen über die Krönung Wenzels im J. 1287 sind den anderen Chroniken durchaus unbekannt geblieben. Sie scheiterten und sind - am böhmischen wie am deutschen Hofe - in Vergessenheit geraten; das Publikum hat kaum von ihnen je gewußt. 0. erinnert sich ihrer. Sollen wir glauben, daß er am böhmischen oder deutschen Hofe lebte und in die Geheimnisse eingeweiht war, oder wenigstens, daß er im Verkehr mit dem Hofe war und in einem hochgestellten Manne einen Berichterstatter fand? Alles das, was S. aus dem Gesamtwerke über seine Persönlichkeit ermittelt hat, spricht gegen eine solche Annahme, und zudem war er zur Zeit der Abfassung von den Begebenheiten zeitlich genug entfernt; hätte er sich dieser unbedeutenden Geschichte erinnert? Ich nehme deshalb an, daß 0 . die Sache nicht aus eigener Erfahrung hatte (dann würde er auch nicht schreiben können, daß die Königin Kunigunde noch im Jahre 1287 lebte etc.), sondern

1) Vgl. Vers 19946. Die Königin ist erst ,niulichen tôt‘. - Verse $20225-$ 37. Wenzel und Z. beklagen den Tod Kunigundens; bei der Ankunft Gutas in Böhmen hält Z. noch Trauer.

2) Novák J. B., Formulár biskupa Tobiáše z Bechynè, S. 184, Nr. 243 „aclmittatur, ut eadem familia cum ipsa domina regina accedat ad nos et veniat in Cadanum «. Novák hat den Brief zu Ende Juni 1287 gesetzt; er glaubte, daß die Verhandlungen knapp vor der (wirklichen) Ankunft Gutas in Prag (am 4. Juli) geführt wurden. Man kann sie jedoch ebensogut in den März oder April 1287 verschieben, vor die für Mai proponierte Krönung Wenzels. Die Sache hat etwas für sich: dem Formelbuche nach müBte man glauben, daß Guta von Nordwest nach Böhmen gekommen ist; wir besitzen jedoch eine Nachricht, daß sie über Mähren (von Südost) nach Prag gelangte. 
daß sie erst durch Vermittlung einer dritten Quelle zu ihm gelangt ist. Die Korrespondenz schließe ich aus: seine ganze Schilderung müßte sonst etwas reeller ausgefallen sein. Wir nehmen an, daß er über eine erzählende Quelle verfügte und daß es dieselbe Aufzeichnung war, auf welche wir mehrmals gestoßen sind, und deren Spur wir auch anderwärts, in der Kgs. und der Fürstenfelder Chronik gefunden haben ${ }^{1}$ ). Ihr Verfasser zeigt sich als verhältnismäßig gut unterrichtet; vielleicht deshalb, weil er zeitlich und örtlich den Begebenheiten nahe stand. Er ist in die intimen Verhandlungen und Verhältnisse eingeweilht. Er kennt die Familienbeziehungen Z.'s, er ist über die Schritte der Gegenpartei Z.'s bei Rudolf unterrichtet usw. Eine Möglichkeit, glaube ich, dürfen wir fallen lassen, daß der Autor der Vorlage ein böhmischer Hofgeschichtsschreiber war. Ein solcher Annalist hätte nicht über die Mutter Wenzels ungünstige Fabeln verbreitet, die noch dazu, so viel wir wissen, völlig haltlos sind; ein Hofgeschichtsschreiber hätte nicht in seinem Panegyrikus erzählen dürfen, daß die Königin ihren Sohn vergiften wollte. Ähnlich wie der $\mathrm{Kgs.}$. Alot würde er die ungünstigen Nachrichten unterdrückt haben.

Zwischen zwei anderen Vermutungen ist schwer zu entscheiden; ob der Verfasser mit dem deutschen Hofe in Verbindung stand, wo wan die böhmischen Verhältnisse scharf verfolgte und gut kannte; oder ob er Z. und den Witigonen nahe stand und durch sie in die politischen Kämpfe Einsicht gewonnen hatte? Für jede Vermutung sind Gründe vorhanden; für die zweite Vers 18322,18361 , dagegen spricht $18310 \mathrm{ff}$. - arger liste was er [Z.] voll - 18320, u. a. die Z. ungünstig sind; für die erste spricht besonders 18332 .

Wann dürfte die supponierte Vorlage geschrieben sein? ${ }^{2}$ ). Schon mehrmals sind wir zum Jahre 1290 als der frühesten Zeitgrenze gekommen ${ }^{3}$ ). Und der Terminus ante quem? Die Unwichtigkeit des Erzählten scheint mir dafür zu zeugen, daß die Vorlage nicht sehr weit von den Ereignissen (1287-90) entfernt ist. Als die äußerste Grenze nehme ich das Jahr 1297 an, als die Krönung Wenzels und Gutas

1) Ich fasse die Vorlage als einheitlich auf. Wenn wir an der Hypothese S.'s festhalten wollten, müßten wir eine stattliche Zahl von verlorenen Quellen voraussetzen, was nicht gut denkbar ist. Übrigens weist auch die analoge Struktur der Fürstenfelder Chronik auf eine einheitliche Erzählung hin.

2) Aus den Versen $18386 \mathrm{ff}$. - vaticinium ex eventu - darf man nichts schließen. Sie können der Vorlage entlehnt sein, abcr ebensogut auf $O$. selbst zurtickgehen.

s) Da die Kornigin Kunigund noch im J. 1287 als lebend geschildert ist, liegt auf der Hand, daB die vormutliche Vorlage kaum gleichzeitig geschrieben worden konnte. 
wirklich vollzogen wurde. Wir dürfen vermuten, daß der Berichterstatter, wenn er nach 1297 geschrieben hätte, auf dieses spätere $\mathrm{Er}$ eignis aufmerksam gemacht, oder einen anderen Standpunkt eingenommen hätte. Denn die Verhältnisse lagen damals ganz anders.

0 . hat uns mit der letzten Nachricht bis in den März 1287 geführt. Er bricht da ab und kehrt zur Schilderung der "österreichischen, steierischen und salzburgischen Geschichte zurück (18419). Indem er Vers 19931 die böhmische Geschichte wieder aufnimmt, setzt er fort, wo er abgebrochen hat: im Jahre 1287 und bei den Verhandlungen um die Heimführung Gutas. 